\title{
CARACTERIZAÇÃO ARQUITETURAL DO SISTEMA RADICULAR DE SOJA
}

\author{
DIOGER ALEXANDRE TERUEL \\ Engenheiro Agrônomo
}

Orientador: Prof. Dr. DURVAL DOURADO NETO

Tese apresentada à Escola Superior de Agricultura "Luiz de Queiroz", Universidade de São Paulo, para obtenção do título de Doutor em Agronomia, Área de Concentração: Fitotecnia.

P I R A C I C A B A

Estado de São Paulo - Brasil

Setembro - 1999 


\section{ERRATA \& CORRIGENDA}

\begin{tabular}{|c|c|c|c|}
\hline p. & item & linha & onde se lê \\
\hline vii & LISTA DE FIGURAS & décima & Figura 16 \\
\hline & & $\begin{array}{l}\text { décima- } \\
\text { segunda }\end{array}$ & Figura 18 \\
\hline ix & RESUMO & terceira & Discute-se e emprega-se... \\
\hline & & $\begin{array}{l}\text { sexta e } \\
\text { sétima }\end{array}$ & ...modelagem numérica... \\
\hline & & décima & ...radicular $[\ldots]$, e discute-se... \\
\hline 24 & Figura 3 (legenda) & segunda & $\begin{array}{l}\text {...matéria seca total da planta. Ponto } \\
\text { representam valores medidos. }\end{array}$ \\
\hline 24 & 4.1 .1 & sexta & Robinson, 1994 \\
\hline 25 & Figura 4 (legenda) & segunda & ...de soja \\
\hline 26 & 4.2 & sexta & ...máximo igual a 3). \\
\hline 28 & Figura 5 (legenda) & segunda & Pontos representam valores medidos. \\
\hline 29 & 4.2 .3 & $\begin{array}{l}\text { décima- } \\
\text { terceira }\end{array}$ & ...e Fitter (1985). \\
\hline
\end{tabular}

31 Figura 7 (legenda)

$31 \quad 4.3$

32 4.3.1.1

33 Figura 8 (legenda)

35 Figura 9 (legenda)

37 Figura 10 (legenda) dias, ...

terceira ...para ambos os tratamentos.

$\begin{array}{ll}\text { oitava } & \text {...modelagem numérica... } \\ \text { décima } & \text {...modelagem numérica... } \\ \text { nona } & \quad \text {...modelo numérico... } \\ \text { quarta } & \text {...barras de desvio padrão. }\end{array}$
respectivas barras de desvio padrão.

segunda ...medidos experimentalmente.

\section{leia-se}

Figura 15

Figura 16

Discutem-se e empregam-se...

...modelagem mecanística...

...radiculares [...], e discutem-se...

...matéria seca total da planta, para três concentrações de $\mathrm{P}$ no solo. Pontos representam valores medidos e linhas representam curvas ajustadas.

Robinson, 1996a

...de soja (desenhada a partir de sistemas radiculares reais observados no experimento).

...máximo igual a 3)?

Pontos representam valores medidos e linhas representam curvas ajustadas.

...e Fitter (1985). Os valores experimentais de attitude para cada idade de planta amostrada foram calculados a partir da soma dos números médios de ramos de cada ordem, para cada profundidade de origem. A maior soma representa o caminho com o maior número de conexões, ou seja, a altitude do sistema naquela data.

décima- Os valores experimentais de $a$ foram Os valores experimentais de $a$ em intervalos quarta calculados através em intervalos de 5 de 5 dias,...

...para ambos os tratamentos. Pontos representam valores medidos e linhas representam curvas ajustadas.

...modelagem mecanística...

...modelagem mecanística...

...modelo mecanístico...

...barras de desvio padrão. Linhas representam curvas ajustadas. Os parâmetros de ajuste $a, b$, e c para cada curva são apresentados nas rotinas do modelo (Anexo G), como Av, Bv, e Cv.

primeira Curvas ajustadas de velocidade de a quarta crescimento do ramo $\left(\mathrm{cm} \cdot \mathrm{dia}^{-1}\right)$ para raizes de ordens 1 a 4 , para algumas profundidades de origem selecionadas. Pontos representam valores medidos experimentalmente, junto $\infty \mathrm{m}$ as

Curvas ajustadas de velocidade de crescimento do ramo $\left(\mathrm{cm} \cdot \mathrm{dia}^{-1}\right)$ para raizes de ordens 1 a 4, para algumas profundidades de origem selecionadas.

...medidos experimentalmente. Linhas representam curvas ajustadas. Os parâmetros de ajuste $d, e, f, g$ são apresentados nas rotinas do modelo (Anexo G), como Adr, Bdr, Cdr, e Ddr.

...modelagem mecanistica... 
Dados Internacionais de Catalogação na Publicação (CIP) DIVISÃo DE BIBLIOTECA E DOCUMENTAÇĀO - Campus "Luiz de Queiroz"/USP

Teruel, Dioger Alexandre

Caracterização arquitetural do sistema radicular de soja / Dioger Alexandre

Teruel. - - Piracicaba, 1999.

$106 \mathrm{p}$.

Tese (doutorado) - - Escola Superior de Agricultura Luiz de Queiroz, 1999. Bibliografia.

1. Modelo matemático 2. Nutriente 3. Produção vegetal 4. Relação soloplanta 5. Simulaçăo 6. Sistema radicular 7. Soja 1. Título

CDD 633.34

Termitula a cópla total ou parcial deste documento, desde que citada o onte 0 O utor" 


\title{
Este trabalho original de pesquisa é dedicado a
}

\author{
Jeová, \\ o excelentíssimo Projetista e Criador de todas as coisas.
}

Alguns dentro da comunidade científica apresentam uma forte reação contra a idéia de um Criador, e acreditam dogmaticamente que tudo veio a existir pela simples obra do acaso. Tais pessoas alegam que aceitar a idéia de um projetista de inteligência e poder superiores aos nossos apagaria o interesse na pesquisa científica. Contudo, a pessoa que reconhece Deus como Criador dos céus e da Terra tem uma abundância de detalhes fascinantes para descobrir e intrigantes mistérios para investigar. É como se recebesse um sinal verde para avançar numa deliciosa aventura de descobertas e aprendizado. As indagações e os labores dos cientistas são uma reação a uma necessidade tão básica para a humanidade como a de comer, abrigar-se e se vestir. É a necessidade de saber as respostas a certas perguntas pertinentes ao futuro e ao objetivo da vida.

"Vi a ocupação que Deus deu aos filhos da humanidade para se ocuparem nela. Tudo ele fez bonito no seu tempo. Pôs até mesmo tempo indefinido no seu coração, para que a humanidade nunca descobrisse o trabalho que o verdadeiro Deus tem feito do começo ao fim". (Eclesiastes 3:10,11) Isso não é uma má notícia. Significa que a humanidade jamais saberá tudo, não obstante, nunca ficará sem ter o que aprender.

"De acordo com isto, empenhei meu coração em conhecer a sabadoria... E eu vi todo o trabalho do verdadeiro Deus, que a humanidade não é capaz de descobrir o rabalho que se fez debaixo do sol; por mais que a humanidade trabalhe arduamente para procurar, ainda assim não o descobre. E mesmo que dissessem que são bastante sábios para saber, não seriam capazes de o descobrir'. (Eclesiastes 8: 16,17)

“Digno és, Jeová, sim, nosso Deus, de receber a glória, e a honra, e o poder, porque criaste todas as coisas e porque elas existiram e foram criadas por tua vontade." Revelação 4:11).

Argumentos baseados em Despertai!, v.77, n.2, p.3-14, 1996.

Os textos bíblicos citados são extraídos da Tradução do Novo Mundo das

Escrituras Sagradas, publicada pela Sociedade Torre de Vigia de Bíblias e Tratados. 


\section{AGRADECIMENTOS}

À Fundação de Amparo à Pesquisa do Estado de São Paulo (FAPESP), pelo apoio financeiro concedido (Processos n⿳9 96/02208-0, referente à Bolsa concedida e ${ }^{\circ}$ 97/11894-8, referente ao programa de aperfeiçoamento científico no exterior, junto à Universidade da Califórnia, em Davis, EUA).

Ao Prof. Dr. Durval Dourado Neto, pelo inestimável companheirismo e excelente orientação.

Ao Prof. Dr. Jan W. Hopmans, pela amizade e pelo apoio prestado em todos os momentos.

Ao Prof. Dr. T. C. Hsiao, pela orientação no delineamento experimental.

À Dra. Francesca Somma, pelos interessantes debates.

Ao Eng. Agr. Éverton Félix Teixeira, pelo apoio nas fases do trabalho de pesquisa realizadas em Piracicaba, e pelos excelentes desenhos.

Aos funcionários e colegas do Department of Land, Air, and Water Resources, da Universidade da Califórnia, em Davis, pelo interessante intercâmbio de experiências e apoio.

Ao USDA, pelo financiamento da parte do projeto de pesquisa desenvolvida em Davis, CA, EUA (NRI Proposal No. 95-37107-1602, concedido ao Dr. J. W. Hopmans).

À minha família, pelo encorajamento constante.

A todos aqueles que, embora não citados aqui, sabem que contribuíram em alguma etapa da minha vida. 


\section{SUMÁRIO}

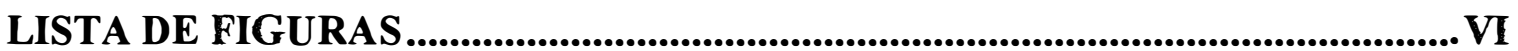

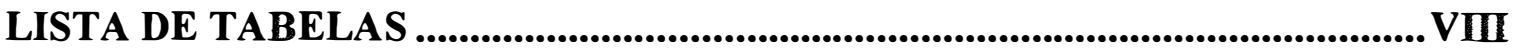

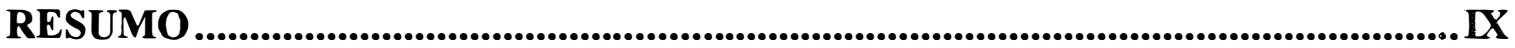

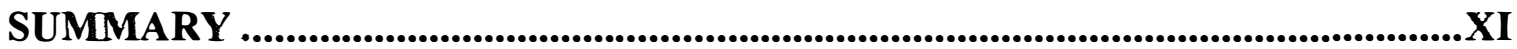

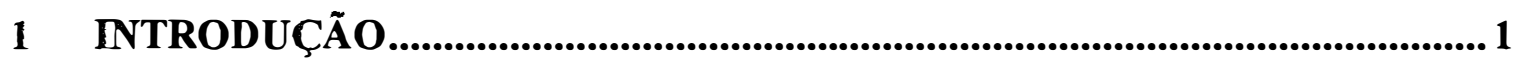

2 REVISÃO DE LITERATURA ...............................................................4

2.1 Caracterização de sistemas radiculares .................................................... 4

2.1.1 Considerações gerais ................................................................... 4

2.1.2 Sistemas de classificação.................................................................. 5

2.1.3 Classes ou ordens de desenvolvimento................................................. 6

2.1.4 Índices Topológicos......................................................................... 7

2.2 Padrão arquitetural do sistema radicular de soja ...................................... 9

2.3 Arquitetura radicular num contexto agrícola e ecológico ............................ 10

2.3.1 Aspectos gerais.................................................................... 10

2.3.2 Influência do suprimento de nutrientes do solo na arquitetura radicular .. 11

2.4 Modelagem de sistemas radiculares como objetos geométricos dinâmicos....... 12

2.5 Metodologia experimental para obtenção de parâmetros do sistema radicular... 13

3 MATERIAL E MÉTODOS ............................................................................ 16

3.1 Procedimento experimental para parcelas de campo e em casa-de-vegetação.... 16

3.1.1 Definição da metodologia utilizada .................................................. 16

3.1.2 Parcelas experimentais de campo........................................................ 17

3.1.3 Parcelas experimentais em casa-de-vegetação ...................................... 18

3.2 Experimento em câmara de germinação ............................................. 18

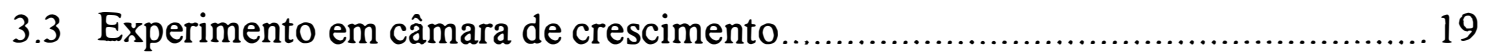

3.3.1 Procedimento de medida do sistema radicular....................................... 20 
3.4 Modelagem matemática dos processos definidores da arquitetura radicular ..... 21

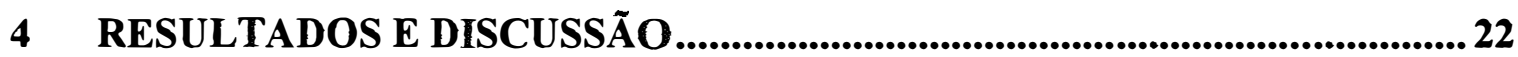

4.1 Parâmetros arquiteturais do sistema radicular de soja ................................ 22

4.1.I Parcelas experimentais de campo e em casa-de-vegetação...................... 22

4.1.2 Experimento em câmara de germinação............................................. 24

4.1.3 Experimento em câmara de crescimento............................................... 25

4.2 Análise arquitetural do sistema radicular baseada em Índices Topológicos ....... 26

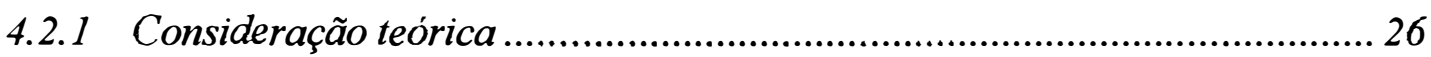

4.2.2 Magnitude do sistema radicular ......................................................... 27

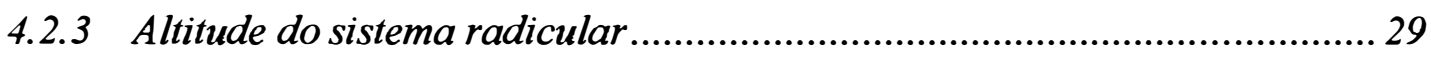

4.3 Modelo mecanístico de simulação da arquitetura radicular ........................... 31

4.3.1 Parâmetros do modelo..................................................................... 32

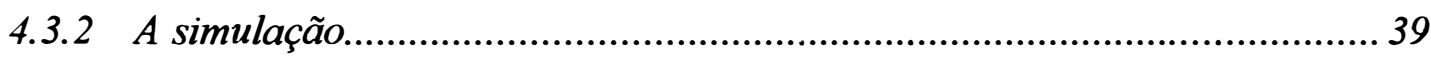

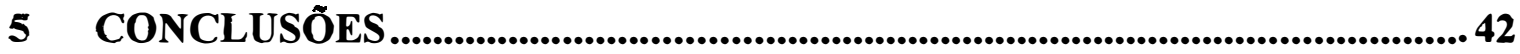

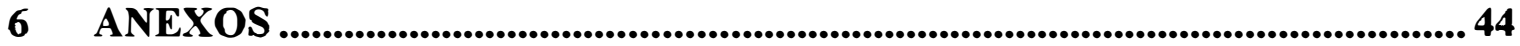

REFERÊNCIAS BIBLIOGRÁFICAS....................................................................... 102 


\section{LISTA DE FIGURAS}

Figura 1. Diagramas de sistemas radiculares mostrando valores de magnitude para cada conexão. Todos os diagramas representam sistemas radiculares de magnitude 8 , sendo B e C extremos topológicos (adaptado de Fitter, 1987) ................................ 8

Figura 2. Diagramas de sistemas radiculares mostrando os valores de caminho percorrido para cada conexão. A altitude (a) é o maior valor de caminho percorrido dentro do sistema radicular ( 5,8 e 4 , respectivamente) e o caminho percorrido total (ct) é a soma dos valores de caminhos percorridos de todas as conexões externas (33, 43 e 32, respectivamente) (Adaptado de Fitter, 1987).

Figura 3. Variação temporal da relação entre massa de matéria seca de raiz e massa de matéria seca total da planta. Pontos representam valores medidos.

Figura 4. Influência do fósforo sobre a taxa de alongamento e as tendências iniciais de ramificação do sistema radicular de soja 25

Figura 5. Variação temporal da magnitude do sistema radicular de soja, para os dois tratamentos. Pontos representam valores medidos. 28

Figura 6. (A) Curva de variação temporal da altitude do sistema radicular em função da idade da planta, para os dois tratamentos. (B) Valores estimados máximos (max) e mínimos (min) de altitude, plotados juntamente com os valores experimentais de altitude (obs), para ambos os tratamentos. 30

Figura 7. Curva de variação da altitude do sistema radicular em função da magnitude, mostrando o desvio dos valores experimentais em relação aos valores máximos, para ambos os tratamentos. 31

Figura 8. Curvas ajustadas de comprimento médio do ramo $(\mathrm{cm})$ para raízes de ordens 1 a 4, para algumas profundidades de origem selecionadas. Pontos representam valores medidos experimentalmente, junto com as respectivas barras de desvio padrão.

Figura 9. Curvas ajustadas de velocidade de crescimento do ramo $\left(\mathrm{cm} \cdot \mathrm{dia}^{-1}\right)$ para raízes de ordens 1 a 4, para algumas profundidades de origem selecionadas. Pontos representam valores medidos experimentalmente, junto com as respectivas barras de desvio padrão. 
Figura 10. Curvas ajustadas de Distância de Ramificação $(\mathrm{em} \mathrm{cm})$. Pontos representam valores medidos experimentalmente.

Figura 11. Imagens simuladas do sistema radicular de soja para concentrações de fósforo no solo alta (+P) e baixa (-P), para 5, 10, 15, 20, 25 e 30 dias após a germinação. 40

Figura 12. Caixa de acrílico com parede transparente............................................... 44

Figura 13. Câmaras de crescimento (Universidade da Califórnia, Davis, CA, EUA).....45

Figura 14. Caixas com plantas localizadas dentro de câmara de crescimento e com a superficie do solo selada para evitar evaporação de água ...................................... 46

Figura 16. Procedimento de anotação dos ângulos de orientação e deflexão dos ramos

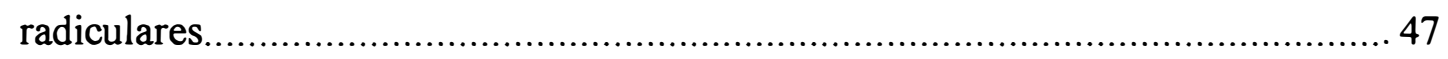

Figura 18. Sistema radicular de soja pronto para ser medido ................................... 48 


\section{LISTA DE TABELAS}

Tabela 1. Valores médios de número de raizes para cada ordem e idade de planta, seguidos dos valores médios de comprimento de raizes para cada ordem e idade de planta 


\title{
CARACTERIZAÇÃO ARQUITETURAL DO SISTEMA RADICULAR DE SOJA
}

\author{
Autor: Dioger Alexandre Teruel \\ Orientador: Durval Dourado Neto
}

\section{RESUMO}

Devido à dificuldade de observação, quantificação e interpretação de sistemas radiculares, o estado da arte do conhecimento científico nessa área está aquém do desejável. Discute-se e emprega-se diferentes metodologias experimentais para a obtenção de parâmetros que caracterizam o sistema radicular. A complexidade estrutural de sistemas radiculares faz com que a análise e a interpretação da sua arquitetura sejam impossíveis de serem realizadas pela estatística clássica, fazendo com que a modelagem numérica seja uma abordagem atrativa (Wullschleger et al., 1994 e Lynch, 1995), ao lado da análise arquitetural baseada na topologia radicular (Fitter, 1985; 1987 e Fitter et al., 1991). Formula-se um modelo mecanístico de simulação do crescimento e arquitetura radicular baseado em parâmetros medidos, e discute-se diferentes Índices Topológicos e seu significado quanto a diferentes estratégias adaptativas da planta ao ambiente edafoclimático. Existe uma grande variedade na forma ou arquitetura de sistemas radiculares dentro de uma espécie vegetal. A arquitetura radicular é um fator determinante no sucesso adaptativo de uma espécie em determinado ambiente, visto que mudanças arquiteturais no sistema radicular proporcionam à planta uma maior eficiência de exploração e utilização dos recursos do solo. Os sistemas radiculares podem alterar sua arquitetura de forma a possuir a maior eficiência de exploração do solo em busca de recursos (grande crescimento em extensão, às custas de uma menor ramificação), ou a habilidade de utilizar os recursos encontrados de maneira eficiente (sistema radicular profusamente ramificado, às custas do crescimento em extensão). Utilizou-se neste estudo plantas de soja, visto que a maioria dos trabalhos de pesquisa sobre a estrutura e fúncionamento de sistemas radiculares de culturas comerciais tem sido realizada com um pequeno número de espécies, com ênfase nas monocotiledôneas, estando as dicotiledôneas herbáceas e as espécies arbóreas ainda praticamente intocadas (McCully, 1995), e estuda-se a influência do teor de fósforo, nutriente de comum deficiência nos 
solos brasileiros, sobre a arquitetura de seu sistema radicular. Conforme esperado, os dados experimentais e as imagens simuladas pelo modelo mostram uma alocação maior de fotossintatos para as raízes de ordem 1 e 2 (responsáveis pela exploração do solo em busca do recurso escasso) no tratamento com menor teor de $\mathrm{P}$ no solo, e uma alocação maior de fotossintatos para as raizes de ordem 3 (responsáveis pela utilização do recurso disponível no solo) no tratamento com maior teor de $\mathrm{P}$ no solo. 


\section{ARCHITECTURAL CHARACTERIZATION OF THE SOYBEAN ROOT SYSTEM}

Author: Dioger Alexandre Teruel Adviser: Durval Dourado Neto

\section{SUMMARY}

Root systems are difficult to observe, quantify, and interpret, being those the reasons why the scientific knowledge about roots is so poor. Different techniques for the study of roots in soil are discussed and used. The structural complexity of root systems make root architecture impossible to be properly analyzed and understood by classical statistics, being the simulation modeling an attractive approach (Wullschleger et al., 1994; Lynch, 1995), even more if associated with architectural analysis based on topological indexes (Fitter, 1985; 1987 and Fitter et al., 1991). A mechanistic model of root growth and architecture is formulated, and topological indexes and their significance as indicators of different strategies of adaptation to an edaphic environment are discussed. There is a wide variation in the shape and architecture of root systems between individuals of a same plant species. Root architecture is a determining factor in the adaptive success of a species in a given environment, since changes in the architectural configuration allows the plant to achieve an optimum soil exploration and exploitation. Root systems can alter their architecture so that they can achieve a balance between accelerated soil exploration (extension growth) and maximum exploitation efficiency (profuse branching). The plant species studied in this project is soybean, since most of the structural and functional investigations of root systems have been done on a few species, with emphasis on the monocotyledons, being the herbaceous dicotyledons still almost untouched (McCully, 1995). Accordingly, the experimental data and the images simulated by the model show changes in root architecture in response to the soil nutrient (phosphorus) content. 


\section{INTRODUÇÃO}

Há vinte anos, afirmou-se que tempo, dinheiro e esforços intelectuais estavam sendo empregados na pesquisa científica com ênfase na exploração do comportamento vegetal em níveis extremos de organização, a saber, na explicação de fenômenos à base do comportamento de moléculas, ou, em outra extremidade, à base do comportamento de plantas inteiras ou mesmo de comunidades vegetais, sendo que todos os níveis intermediários (membrana, organela, célula, tecido e órgão) estavam sendo negligenciados, ou pelo menos não recebiam a devida atenção (Passioura, 1979). Hoje, o cenário continua praticamente o mesmo (problema de escala). Mas, sendo a pesquisa no setor agrícola financiada pelo dinheiro público na maior parte dos casos, a ética deveria motivar o pesquisador a não procurar apenas descobertas inovadoras, mas também descobertas úteis, se não para o público (pesquisa aplicada), então para seus colegas trabalhando em outros níveis de organização vegetal (pesquisa básica).

Dentre as muitas necessidades de obtenção de conhecimento dentro da pesquisa com plantas, uma área que necessita atenção, embora o interesse tenha sido renovado nos últimos anos, é o estudo do comportamento de um importante órgão vegetal, o sistema radicular.

Existe uma grande variedade na forma ou arquitetura dos sistemas radiculares. A habilidade para explorar o solo em busca de recursos escassos e a capacidade de utilizar os recursos encontrados de maneira eficiente são maximizadas por diferentes arranjos estruturais entre os diversos trechos individuais do sistema radicular. Portanto, a arquitetura final de um sistema radicular em uma determinada situação dependerá, entre outros fatores (ancoragem eficiente da planta, p.ex.), do equilíbrio otimizado entre essas duas importantes funções radiculares ligadas à absorção de água e nutrientes (Tiffney \& Niklas, 1985). 
O sistema radicular é descrito corretamente como a "metade escondida" da planta (Waisel et al., 1996), e o fato dessa porção da planta não estar facilmente acessivel à observação faz com que esse seja o órgão vegetal menos conhecido e entendido. Além da dificuldade de observação, o sistema radicular se constitui de uma estrutura geométrica tridimensional extremamente complexa, composta de milhares de eixos radiculares individuais, de diferentes classes morfológicas, fisiológicas e de desenvolvimento, tornando também complicada a quantificação de atributos e interpretação de processos relacionados a esse sistema. Segundo Lynch (1995), não existe nenhuma estrutura analítica satisfatória ou ferramentas quantitativas adequadas para sumariar e caracterizar essa complexidade do sistema radicular, visto que o crescimento e a arquitetura radicular são altamente plásticos, interagindo dinamicamente com um grande número de fatores físicos, químicos e biológicos no solo, fatores esses ainda variáveis no espaço e no tempo.

Essas dificuldades tornam a análise e a interpretação da arquitetura de sistemas radiculares impossiveis de serem realizadas pela estatística clássica, fazendo com que novas idéias e abordagens sejam mais importantes que avanços tecnológicos que permitam a obtenção mais detalhada de parâmetros do sistema radicular (Robinson, 1991).

Uma das ferramentas promissoras na quantificação e interpretação de sistemas radiculares é a modelagem matemática de processos (desenvolvimento de modelos mecanísticos de simulação), que permite integrar um grande número de informações sobre respostas de trechos individuais do sistema radicular a atributos edafoclimáticos específicos e apresentá-las de maneira que comparações possam ser feitas. Uma outra metodologia de análise promissora é aquela baseada na topologia radicular (Fitter, 1985, 1987; Fitter et al., 1991).

Utilizou-se neste estudo plantas de soja, visto que a maioria dos trabalhos de pesquisa sobre a estrutura e funcionamento de sistemas radiculares de culturas comerciais tem sido realizada num pequeno número de espécies, com ênfase nas monocotiledôneas, estando as dicotiledôneas herbáceas e as espécies arbóreas ainda praticamente intocadas (McCully, 1995). 
Experimentos preliminares realizados e dados na literatura (Drew, 1975; Robinson, 1994) mostravam um efeito pronunciado do teor de alguns nutrientes no solo, especialmente o nitrogênio e o fósforo, sobre a arquitetura de sistemas radiculares. Visto ser rara a deficiência de nitrogênio na cultura da soja, em face do uso de inoculação de sementes com a bactéria fixadora de nitrogênio Bradyrhizobium japonicum, optou-se pelo estudo do efeito do conteúdo de fósforo, nutriente de comum deficiência nos solos brasileiros, sobre o sistema radicular da cultura.

Embora não sejam discutidos neste trabalho, espera-se que os resultados e as conclusões aqui apresentadas possam orientar debates e o desenvolvimento de novas técnicas adequadas de mánejo da cultura, nas áreas de preparo do solo, aplicação de fertilizantes (especialmente os fosfatados) e irrigação.

Espera-se ainda que esta monografia desperte o interesse da comunidade científica brasileira em buscar conhecer melhor os sistemas radiculares e aumentar o entendimento dos processos e interações ocorridos no solo. Weaver et al. (1922) ${ }^{1}$, citados por Pearson (1974), afirmaram há 77 anos que: "um conhecimento exato do crescimento e desenvolvimento das raizes das plantas cultivadas, da sua posição, extensão e atividade na absorção de água e solutos em diversos estádios de crescimento, é de importância fundamental para o entendimento científico da produção vegetal". No entanto esta área vem sendo negligenciada até hoje, merecendo agora canalização de recursos humanos e financeiros para que seja realizada atividade de pesquisa intensiva, num esforço de recuperar o tempo perdido e de nos melhor equipar para enfrentar os problemas com os quais nos deparamos na produção agrícola.

O objetivo deste trabalho de pesquisa é a caracterização do sistema radicular de soja. Para tal, foram identificadas estruturas arquiteturais que representam estratégias da planta em busca de uma melhor adaptação ao ambiente (conseqüência de interações com fatores edafoclimáticos), o que reflete em maior produtividade (rendimento potencial) da planta, e, do ponto de vista agrícola, melhores rendimentos da cultura.

\footnotetext{
${ }^{1}$ WEAVER, J.E.; JEAN, F.C.; CRIST, J.W. Development and activities of roots of crop plants. Carnegie Inst.
} Wash. Publ., 316. 1922. 


\section{REVISÃO DE LITERATURA}

\subsection{Caracterização de sistemas radiculares}

\subsubsection{Considerações gerais}

Sistemas radiculares variam grandemente na sua forma. Observações revelam variação (i) na distribuição do comprimento e massa radiculares no solo, (ii) na dominância de uma raiz principal, (iii) nas dimensões relativas de diferentes trechos, e (iv) no padrão geométrico de ramificação. Além dessa variação espacial, os padrões de enraizamento variam no tempo, sendo o sistema radicular um objeto geométrico tridimensional dinâmico (Fitter, 1991).

Na caracterização de um sistema, lança-se mão de atributos que representem sua organização estrutural. Quando o objeto de estudo é o sistema radicular de uma planta ou o conjunto de sistemas radiculares de uma comunidade vegetal, os atributos comumente utilizados são morfologia, topologia, distribuição e arquitetura radiculares.

Lynch (1995) propõe a seguinte definição para esses termos: (i) Morfologia: a morfologia radicular se refere às características anatômicas externas de um trecho individual do sistema radicular (raiz ou ramo radicular), como presença de pêlos radiculares, diâmetro da raiz, padrão de aparecimento de raízes filhas (padrão de ramificação), entre outras; (ii) Topologia: a topologia do sistema radicular se refere à maneira como as raízes individuais se conectam entre si através da ramificação. Como no uso matemático, a topologia radicular é estável à deformação ou rotação das raizes individuais, e portanto é possível se ser medida em sistemas radiculares retirados do solo por escavação; (iii) Distribuição: a distribuição radicular se refere à presença, sem se importar com a orientação, das raizes num gradiente posicional. Tipicamente, estudos de distribuição radicular se preocupam com a biomassa de raizes ou o comprimento 
radicular em função de fatores como profundidade no solo e distância do caule; e (iv) Arquitetura: o termo arquitetura, quando aplicado a objetos biológicos, geralmente se refere à configuração espacial de um conjunto complexo de subunidades, que possui alguma significância funcional. A arquitetura radicular se refere à configuração espacial do sistema radicular, isto é, a distribuição detalhada de raizes individuais no espaço tridimensional. Geralmente, estudos de arquitetura radicular não incluem pequenos detalhes estruturais, como pêlos radiculares, mas se preocupam com o sistema radicular completo, ou grande parte dele.

A arquitetura é superior à topologia e distribuição, pois se a arquitetura do sistema radicular é conhecida, a sua topologia e distribuição também são conhecidas, enquanto que nem topologia nem distribuição podem ser usadas para se estimar a arquitetura radicular.

A topologia e a distribuição radiculares são mais facilmente medidas, e mais comumente utilizadas em estudos de estrutura de sistemas radiculares.

\subsubsection{Sistemas de classificação}

A viabilidade da utilização de sistemas radiculares como um meio de se identificar espécies vegetais, da mesma forma como folhas, flores e frutos podem ser usados, é questionável. Trechos individuais de um sistema radicular (ramos radiculares ou raízes) apresentam uma variação morfológica externa muito pequena (Fitter, 1987). Por outro lado, quando considera-se o completo sistema de raízes, ou sistema radicular, verifica-se uma ampla variação na sua forma ou arquitetura. A arquitetura do sistema radicular pode variar amplamente entre espécies, entre indivíduos de uma mesma espécie, ou mesmo entre diferentes porções de um sistema radicular individual. Esta variação arquitetural dos sistemas radiculares tem um caráter de adaptação ao ambiente edafoclimático aparentemente óbvio, embora a significância ecológica deste fenômeno ainda esteja relativamente obscura (Fitter, 1985; Fitter et al., 1991).

Embora sistemas tentativos de classificação tenham sido elaborados, a variação arquitetural do sistema radicular em resposta ao ambiente edafoclimático, indicando sua plasticidade morfológica, torna tais sistemas de classificação, como aquele desenvolvido 
por Cannon (1949), que classifica os sistemas radiculares em vários tipos distintivos, insatisfatórios.

Portanto, mais importante que classificar os sistemas radiculares em diferentes classes taxonômicas, seria caracterizá-los quanto aos seus padrões de ramificação e crescimento (Fitter, 1996).

\subsubsection{Classes ou ordens de desenvolvimento}

Uma plântula típica de soja produz uma raiz principal diretamente da semente, e esta se ramifica, produzindo raízes laterais. Subseqüentemente, qualquer dessas raízes laterais pode se ramificar e produzir novas laterais, de ordens superiores de desenvolvimento, até a ordem máxima. A ordem máxima de desenvolvimento é uma característica de cada espécie vegetal e se refere à classe de raízes que não mais se ramificam.

Rose (1983), baseado em outros autores, apresenta a seguinte classificação dos trechos de um sistema radicular (ramos) quanto à sua ordem de desenvolvimento: (i) as raízes produzidas diretamente a partir da base da planta são denominadas eixos (uma monocotiledônea pode ter vários eixos em seu sistema radicular, enquanto que uma dicotiledônea com sistema radicular pivotante possui apenas um eixo); (ii) as raízes laterais que emergem do(s) eixo(s) são denominadas raízes laterais de primeira ordem; e (iii) as raízes laterais que emergem das laterais de primeira ordem são denominadas laterais de segunda ordem, e assim por diante (Rose, 1983). O mesmo autor ainda sugere utilizar a denominação ordem 0 para os eixos, ordem 1 para as raízes laterais de primeira ordem, ordem 2 para as raízes laterais de segunda ordem, e assim por diante. Devido à prática comum na comunidade científica de se chamar os eixos de raízes primárias, as raízes laterais de primeira ordem de raízes secundárias, as raízes laterais de segunda ordem de raízes terciárias, e assim por diante. A denominação sugerida por Rose (1983) não tem sida aplicada corretamente.

Visando a uniformização na classificação dos ramos quanto à sua ordem de desenvolvimento, sugere-se as seguintes denominações, que serão utilizadas nesta 
monografia: (i) eixo, ou raiz principal, ou raiz de ordem 1; (ii) raiz lateral de ordem 2; (iii) raiz lateral de ordem 3; e assim sucessivamente.

\subsubsection{Indices Topológicos}

Os sistemas radiculares também podem ser descritos com base no conceito de “árvore matemática” (Fitter, 1985, 1987; Fitter et al., 1991). Nesse caso, um sistema radicular é considerado como um conjunto de conexões (em inglês, links), e essas conexões podem se denominar externas, quando se localizam entre um ponto de ramificação e um ponto de crescimento (meristema apical), ou internas (ou entrenós), quando se localizam entre dois pontos de ramificação. A essas conexões, ou a seu conjunto, pode-se definir vários índices (Fitter, 1985 e Fitter et al., 1991), que representarão atributos funcionais do sistema radicular, em termos de aquisição de recursos do solo, ancoragem, ou outra função radicular qualquer. Os índices topológicos podem ajudar a identificar a arquitetura radicular que representa o melhor desempenho numa determinada função, com o mínimo custo, isto é, a mínima quantidade de fotoassimilados direcionados para o sistema radicular.

Apresenta-se abaixo a definição dos principais índices topológicos, sendo feita uma adaptação livre baseada nos conceitos de A. H. Fitter da University of York, Reino Unido (Fitter, 1985 e Fitter, 1987).

Cada conexão pode ser caracterizada por sua magnitude e seu caminho percorrido, e cada sistema radicular pode ser caracterizado por sua magnitude, seu caminho percorrido total e sua altitude.

A magnitude de uma conexão $(m c)$ é dada pelo número de pontos de crescimento (meristemas apicais) se desenvolvendo a partir dela, portanto todas as conexões externas têm magnitude 1, e a magnitude de qualquer conexão interna é igual ao número total de pontos de crescimento que se originam dela. A magnitude de um sistema radicular ( $m$ ) tem o mesmo valor de magnitude da conexão basal (aquela que se liga à parte aérea da planta), e é equivalente ao número total de meristemas apicais ou de conexões externas do sistema radicular (Figura 1). 


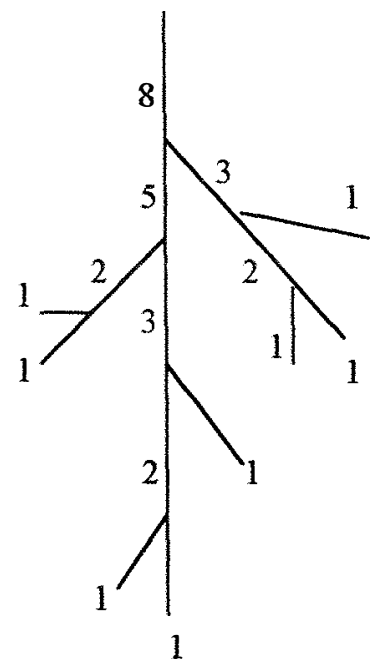

$\mathbf{A}$

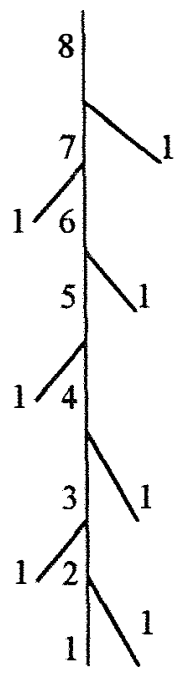

B

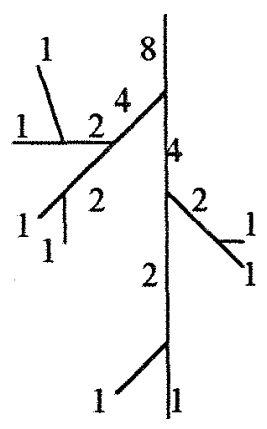

C

Figura 1. Diagramas de sistemas radiculares mostrando valores de magnitude para cada conexão. Todos os diagramas representam sistemas radiculares de magnitude 8, sendo B e C extremos topológicos (adaptado de Fitter, 1987).

O caminho percorrido de uma conexão $(c c)$ é a soma do número de conexões entre ela e a conexão basal (que se conecta à parte aérea da planta), incluindo-se a conexão em questão e a conexão basal na soma. O caminho percorrido total de um sistema radicular ( $c t$ ) é a soma dos valores de caminhos percorridos de todas as conexões externas, e é um número maior e diferente da soma do número de conexões do sistema, pois algumas conexões fazem parte de diversos caminhos percorridos (a conexão basal, por exemplo, faz parte dos caminhos percorridos de todas as outras conexões).

A altitude de um sistema radicular $(a)$ é o maior valor de caminho percorrido de uma conexão no sistema, e representa o maior caminho, quanto ao número de conexões, que um recurso do solo teria que percorrer de uma conexão externa até a parte aérea da planta (Figura 2). 


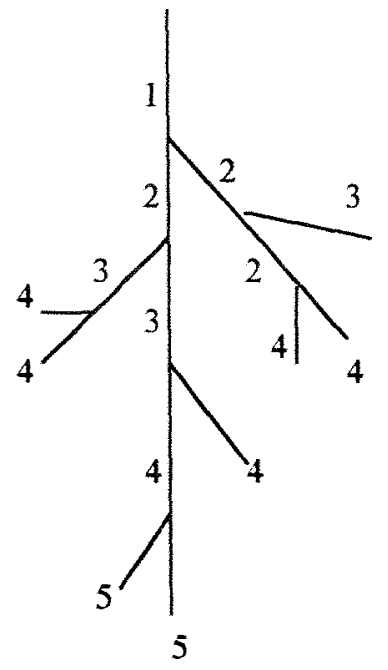

$\mathbf{A}$

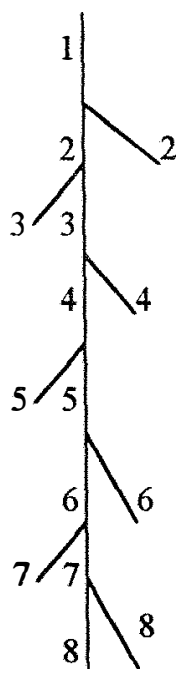

B

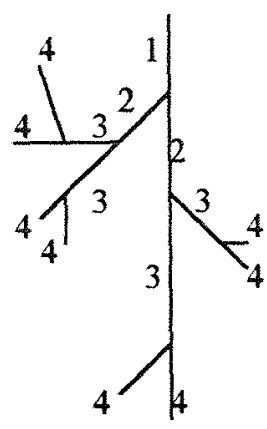

C

Figura 2. Diagramas de sistemas radiculares mostrando os valores de caminho percorrido para cada conexão. A altitude (a) é o maior valor de caminho percorrido dentro do sistema radicular ( 5,8 e 4 , respectivamente) e o caminho percorrido total (ct) é a soma dos valores de caminhos percorridos de todas as conexões externas (33, 43 e 32, respectivamente) (Adaptado de Fitter, 1987).

Sistemas radiculares topologicamente idênticos, isto é, com índices topológicos idênticos, podem ter aparências bastante distintas, se diferirem nos aspectos métricos de sua geometria (Fitter, 1987). O comprimento das conexões externas representa a distância atrás do ápice radicular onde começa a ocorrer ramificação, e o comprimento das conexões internas representa a distância de ramificação, sendo seu inverso a freqüência de ramificação.

\subsection{Padrão arquitetural do sistema radicular de soja}

A radícula da soja emerge da semente e cresce num ângulo estritamente vertical, desenvolvendo-se rapidamente numa raiz pivotante positivamente gravitrópica ("geotrópica"), que cresce numa velocidade de 2,5 a 5,0 $\mathrm{cm}^{-d_{i a}{ }^{-1}}$ sob condições favoráveis de conteúdo de água e pressão parcial de de oxigênio do solo (Mitchell \& Russell, 1971). A raiz principal pivotante pode penetrar a mais de $150 \mathrm{~cm}$ de 
profundidade, mas geralmente condições adversas de solo restringem o crescimento a profundidades menores, sendo que o sistema radicular se concentra nos $60 \mathrm{~cm}$ superficiais do perfil do solo (Mitchell \& Russell, 1971). As raizes pivotantes da soja são tetrarcas (o xilema primário da raiz possui quatro cordões ou pólos de protoxilema Esau, 1974), portanto as raízes laterais emergem em ângulos de $90^{\circ}$ ao redor da circunferência da raiz pivotante.

Quatro a sete raizes laterais bastante ramificadas se originam nos primeiros centimetros da raiz pivotante, sendo denominadas raizes basais. Essas raizes crescem num ângulo característico, que depende do cultivar e da temperatura do solo (Stone \& Taylor, 1983). Essas raizes geralmente crescem lateralmente, num ângulo próximo à vertical, por 20 a $36 \mathrm{~cm}$, e então abruptamente se curvam para baixo e crescem horizontalmente, até profundidades superiores a $180 \mathrm{~cm}$ (Mitchell \& Russell, 1971). As raizes basais possuem diâmetros variando de 0,2 a $0,3 \mathrm{~cm}$. Segundo Rendig \& Taylor (1989), as raizes basais crescem em velocidades maiores que as raizes pivotantes.

As demais raizes laterais de ordem 2 são mais finas que as raizes basais, possuindo diâmetros entre 0,065 a $0,075 \mathrm{~cm}$. As raízes de ordens 3 e 4 possuem diâmetros ainda menores. Tais raizes se desenvolvem quando as condições ambientais são adequadas e morrem quando o solo ao seu redor fica deplecionado em água ou nutrientes (Rendig \& Taylor, 1989).

\subsection{Arquitetura radicular num contexto agrícola e ecológico}

\subsubsection{Aspectos gerais}

Três das principais funções do sistema radicular dependem de sua arquitetura: a ancoragem, a absorção de água e a absorção de nutrientes.

Até o momento, muito pouco é conhecido dos processos fisiológicos que promovem uma determinada arquitetura radicular. A arquitetura radicular é um agregado de características geradas por diversos processos distintos que ocorrem em cada eixo radicular, sendo que apenas alguns são conhecidos e entendidos, sendo os principais, segundo Lynch (1995): (i) o crescimento em extensão de eixos radiculares individuais; (ii) o aparecimento de raizes filhas sobre cada eixo radicular; (iii) a direção do 
crescimento de cada eixo radicular; (iv) a senescência ou mortalidade dos eixos radiculares; e (v) a plasticidade desses processos em resposta a condições edafoclimáticas, tais como resistência do solo à penetração, disponibilidade de nutrientes e conteúdo de água e oxigênio do solo.

O solo é um ambiente bastante heterogêneo e muitos de seus recursos são distribuídos de maneira desuniforme e sujeitos a depleção localizada, de maneira que o posicionamento estratégico de trechos individuais do sistema radicular garante a habilidade da planta de utilizar tais recursos. Zonas com maior teor de nutrientes pouco móveis no solo, como o fósforo, podem existir no solo. Gradientes fortes de temperatura, pressão parcial de oxigênio, disponibilidade hídrica, $\mathrm{pH}$, massa específica e teor de nutrientes podem ocorrer no perfil do solo numa escala de centímetros. Geralmente esses gradientes apresentam restrições e oportunidades conflitantes da perspectiva de aquisição do recurso do solo pela planta; por exemplo, as camadas superficiais do solo tendem a ser mais ricas em nutrientes, mas, por outro lado, mais secas e mais sujeitas a extremos de temperatura. A própria atividade das raízes pode criar fortes gradientes no solo que rodeia as raízes, através do desenvolvimento de zonas de depleção de nutrientes de baixa difusividade no solo, como os fosfatos (Lynch, 1995).

\subsubsection{Influência do suprimento de nutrientes do solo na arquitetura radicular}

Quando o suprimento de nutrientes no solo é desuniforme, as raízes da planta geralmente apresentam um desenvolvimento preferencial nas regiões do solo que contém os teores mais favoráveis. Tais respostas estão bem documentadas, merecendo destaque o trabalho clássico de Drew (1975), e os trabalhos mais recentes de Gersani \& Sachs (1992) e de Robinson (1996a, 1996b), além da interessante compilação de resultados experimentais publicados em diversas fontes apresentada em Robinson (1994).

Alguns nutrientes, especialmente os nitratos, movimentam-se com relativa liberdade nos solos úmidos, tornando pouco importante a proximidade das superficies radiculares de absorção à fonte do recurso. Já para nutrientes com baixas taxas de difusão no solo, como os fosfatos, a proximidade entre a superficie absortiva da raiz e a 
fonte do recurso é muito importante (Harper et al., 1991). No primeiro caso, uma profusa ramificação traria poucos benefícios, sendo favorecido o crescimento em extensão, enquanto que no segundo caso, um padrão arquitetural que compreendesse uma ramificação mais acentuada, em sacrifício do crescimento em extensão, seria o ideal.

Ainda, segundo Harper et al. (1991), o crescimento em extensão e a ramificação provavelmente representam estratégias alternativas na exploração e utilização de volumes de solo pelos sistemas radiculares, com diferentes conseqüências. Um sistema radicular pouco ramificado, com grande crescimento em extensão não consegue fazer uso otimizado do recurso encontrado, enquanto que sistemas radiculares muito ramificados não podem descobrir novos recursos. Tiffney \& Niklas (1985) afirmam que os sistemas radiculares podem, portanto, alterar sua arquitetura de forma a possuir a habilidade para explorar o solo em busca de recursos (grande crescimento em extensão, às custas de uma menor ramificação), ou a habilidade de utilizar os recursos encontrados de maneira eficiente (sistema radicular profusamente ramificado às custas do crescimento em extensão).

No caso específico do fósforo, existe uma tendência de diminuição na densidade de ramificação (isto é, raizes laterais mais espaçadas) e de variação do ângulo de orientação dessas laterais para ângulos mais próximos da vertical, em condições de baixos níveis de fósforo no solo. Por outro lado, em solos ricos em fósforo verifica-se uma tendência oposta (raizes laterais em maior número numa determinada camada de solo e em ângulos mais próximos da horizontal). A aparência arquitetural do sistema radícular na condição pobre em fósforo parece ser uma estratégia adaptativa da planta para explorar um maior volume de solo gastando o mínimo possível de fotoassimilados para crescimento e formação de estruturas radiculares (Nielsen et al., 1994; Lynch, 1995 e Bonser et al., 1996).

\subsection{Modelagem de sistemas radiculares como objetos geométricos dinâmicos}

Apesar do grande avanço na modelagem de sistemas radiculares como objetos geométricos dinâmicos, como constatado pela evolução de tais, desde os modelos 
pioneiros de Hackett \& Rose (1972) e de Lungley (1973), passando pelos de Rose (1983) e de Porter et al. (1986), até chegar aos modelos mais recentes de Diggle (1988), Pages et al. (1989), Clausnitzer \& Hopmans (1993), Lynch et al. (1997) e Somma et al. (1998), citados entre os muitos existentes, a modelagem das implicações funcionais da arquitetura radicular ainda está no estágio de desenvolvimento metodológico, e ainda não é de forma alguma uma ferramenta completamente validada e utilizável para

previsão (Lynch, 1995). Uma descrição detalhada da evolução histórica de tais modelos é apresentada em Lynch \& Nielsen (1996).

A modelagem e a simulação têm um valor heurístico, ajudando o pesquisador a formular hipóteses sobre processos e interações relevantes, a quantificar o impacto de varáveis simples sobre o desempenho do sistema, e a sugerir novas necessidades de experimentação (Wullschleger et al., 1994). A experimentação pode ajudar a refinar um modelo, mas o modelo pode sugerir experimentação adicional, num processo iterativo que acaba produzindo um modelo com validade suficiente para ser usado em cenários de previsão ou como módulos de modelos integrativos, como modelos de rendimento de culturas (Lynch et al., 1997).

\subsection{Metodologia experimental para obtenção de parâmetros do sistema radicular}

As raízes crescem no solo, um meio opaco do qual elas não podem ser diretamente observadas nem extraídas sem que se introduza algum artefato, destruindo a arquitetura nativa do sistema radicular, ou impedindo análises subseqüentes de um mesmo indivíduo (Lynch, 1995).

Harper et al. (1991) comentam que mais energia pode ter sido gasta no desenvolvimento de tecnologias que permitam o estudo dos sistemas radiculares que no estudo de raízes em si. É mais do que inconveniente que as raízes cresçam geralmente no solo (existem exceções, como as plantas aquáticas), dificultando nossa observação. Embora tenham sido realizados, devido à facilidade de observação, estudos sobre a arquitetura radicular realizados em meio hidropônico produzem resultados sem sentido. Uma característica fundamental dos solos é que são um meio heterogêneo na escala de raiz, enquanto que meios aquosos são homogêneos. 
Uma série de procedimentos foram desenvolvidos e utilizados para a obtenção dos parâmetros imprescindíveis à caracterização de um sistema radicular. Nenhuma técnica desenvolvida até agora é capaz de propiciar a obtenção de uma ampla gama de parâmetros que permitam a caracterização de todos os aspectos do crescimento e estrutura radiculares.

Segundo Mackie-Dawson \& Atkinson (1991), os métodos disponíveis podem ser divididos em três grandes grupos: (i) Métodos de extração de raizes, onde parte ou a totalidade do sistema radicular é removida do solo. Os principais procedimentos deste grupo, seus usos e limitações, conforme descritos por Böhm (1979), são: 1. métodos de escavacão: nesses métodos o sistema radicular inteiro ou parte dele é exposto no perfil do solo por escavação e limpeza com escovas ou uso de ar ou água sob pressão. Essa técnica possibilita a descrição da morfologia, extensão e ramificação do sistema radicular, mas tem como grande limitação o tempo e trabalho consumidos; 2 . métodos do monolito: permitem análises quantitativas do sistema radicular. Amostras de solo de diferentes tamanhos são retiradas do perfil do solo, o solo é retirado das raízes e as raízes são coletadas em peneiras. Após a remoção dos detritos, a massa e comprimento das raízes são determinados. $\mathrm{O}$ método mais simples de se retirar monolitos é pela escavação com pás, mas uma técnica mais eficiente é a remoção de camada por camada do solo a partir da parede lateral de uma trincheira. Também podem ser usados amostradores especiais, como caixas e armações metálicas (as chamadas "camas de pregos"). Esse último procedimento permite a combinação da análise quantitativa do sistema radicular com a sua representação pictorial (localização no espaço tridimensional) (Schuurman et al., 1971); 3. métodos de tradagem: são usados para se tomar amostras volumétricas de solo-raiz com o uso de um trado, diretamente a partir da superficie do solo, sem a escavação de uma trincheira. A análise das raízes é feita como no método do monolito; 4. métodos de estudo do perfil de uma trincheira: o sistema radicular é exposto em uma parede vertical de uma trincheira com o uso de ferramentas e água ou ar sob pressão. As raízes, fixas em sua posição original, são contadas e seu comprimento é estimado, e seu posicionamento pode ser plotado num filme plástico transparente ou pode ser plotado a partir de fotos; (ii) Métodos de observação, onde parte do sistema radicular é observada 
sem que o mesmo seja retirado do solo, através de uma superfície de observação. Essa superfície de observação pode se constituir de pequenas paredes de vidro verticais ou inclinadas em contato com o solo (Böhm, 1979), tubos de vidro inseridos inclinadamente no solo (Waddington, 1971), ou mesmo grandes instalações, como os rhizotrons (van de Geijn et al., 1994 e Smit et al., 1994). Esses métodos permitem a observação da taxa de crescimento das raízes visíveis em intervalos curtos de tempo; (iii) Métodos indiretos, onde a presença e a atividade de raízes é inferida a partir de medidas indiretas relacionadas com seu funcionamento, geralmente a absorção de água e nutrientes. Podem ser citadas como exemplo as técnicas que empregam soluções traçadoras radioativas.

Os métodos clássicos para estudo de raiz, por exemplo monolito com o uso de amostradores especiais, estudo do perfil de uma trincheira, estudo das raízes cultivadas em hidroponia, podem ser aliados a novos procedimentos, como uso de mini-rhizotrons (Upchurch et al., 1984), processamento de imagens obtidas por vídeo-câmera (Crestana et al., 1994), ressonância magnética nuclear (Posadas et al., 1996), e tomografia computadorizada por Raios-X (Heeraman et al., 1997) de forma combinada ou não, para a obtenção de parâmetros caracterizadores do sistema radicular.

Cada um desses métodos possui inúmeras vantagens e desvantagens e cada um deles se aplica melhor para uma determinada finalidade. Dentre os muitos fatores a serem considerados na escolha do método de estudo, o principal deve ser o objetivo do estudo, e depois a disponibilidade de equipamentos, mão de obra e instalações, o tipo de solo onde se realizará o estudo, e a espécie vegetal que está sendo investigada. 


\section{MATERIAL E MÉTODOS}

\subsection{Procedimento experimental para parcelas de campo e em casa-de-vegetação}

\subsubsection{Definição da metodologia utilizada}

$\mathrm{Na}$ definição da metodologia experimental para as parcelas de campo e casa-devegetação, procurou-se optar por uma técnica que fosse operacionalmente viável e permitisse a obtenção de todos os parâmetros necessários à caracterização do sistema radicular de soja. Para isso, procedeu-se a uma análise crítica das técnicas de estudo de sistemas radiculares disponiveis.

Nesse sentido, pensou-se em duas técnicas não destrutivas que permitiriam amostragens em intervalos curtos, a tomografia por ressonância magnética e o uso de mini-rhizotrons, no entanto elas foram descartadas, visto que a primeira ainda não fornece imagens do sistema radicular com definição suficiente para a obtenção dos parâmetros, e a segunda necessitaria várias calibrações antes de poder ser utilizada, sem garantia de viabilidade na obtenção dos parâmetros (embora os coeficientes de variação sejam altos em qualquer método de estudo de raizes, no caso de mini-rhizotrons eles podem chegar a valores tão altos como $189 \%$ da média, para um parâmetro como comprimento de raízes, fazendo com que apenas diferenças de $95 \%$ ou mais possam ser detectadas (Mackie-Dawson \& Atkinson, 1991).

Foi verificado então, que com a tecnologia hoje existente, a melhor maneira de se obter os parâmetros nas parcelas de campo e casa-de-vegetação seria a análise de imagens digitalizadas, capturadas a partir de câmara fotográfica ou de vídeo, sendo, portanto, necessário utilizar uma técnica destrutiva para expor o sistema radicular.

Testes prévios mostraram que o uso de trincheiras para a exposição das raizes não permitia a obtenção de imagens adequadas para o propósito deste trabalho, embora 
seja o procedimento mais comum para obtenção de imagens visando estudo da distribuição do sistema radicular por camadas de solo (Crestana et al., 1994). Portanto, verificou-se a necessidade de um procedimento que expusesse todo o sistema radicular, e não apenas um plano deste, sendo por isso adotada a retirada de plantas juntamente com um bloco de solo, método que, embora trabalhoso, mostrou-se o mais satisfatório para os propósitos do trabalho, naquela ocasião.

\subsubsection{Parcelas experimentais de campo}

Parcelas experimentais de campo foram instaladas em 3 épocas diferentes (semeaduras em 12 de novembro de 1996, 19 de dezembro de 1996, e 14 de março de 1997) na Fazenda Areão, localizada no campus da ESALQ/USP, em Piracicaba, SP.

Foram utilizados três cultivares de soja (Glycine max (L.) Merrill): IAC-12, IAC17 e IAC-19. A população de plantas escolhida foi 400.000 plantas/ha, com espaçamento entre linhas de $50 \mathrm{~cm}$.

Aproximadamente um mês após a semeadura (para cada época), iniciaram-se amostragens quinzenais visando a obtenção dos parâmetros do sistema radicular, além de dados da fenologia da planta e de sua parte aérea. Em cada data de amostragem foram coletadas 10 plantas de cada parcela, junto com um bloco de solo contendo todo o sistema radicular de cada planta. No laboratório, a terra era separada do sistema radicular, escolhendo-se 2 das 10 plantas coletadas (as que apresentavam o sistema radicular mais intacto), sendo então capturada a imagem de suas raízes com câmera de vídeo padrão VHS-C, para posterior digitalização (utilizando-se microcomputador equipado com placa digitalizadora "Video Blaster RT300" com resolução de imagem de 320x240 dpi) e determinação dos parâmetros através de análise visual e com auxílio de um programa computacional de análise de imagens. A totalidade das 10 plantas coletadas tinha então seu estádio fenológico determinado, além da determinação do número de folhas, massa de matéria seca de discos foliares com diâmetro conhecido (para estimativa do Índice de Área Foliar), massa de matéria seca de folhas, hastes e raízes, além de vagens e sementes quando houvesse. 


\subsubsection{Parcelas experimentais em casa-de-vegetação}

Com a finalidade de se estudar a influência do teor de fósforo do solo sobre os parâmetros arquiteturais do sistema radicular de soja (Glycine max (L.) Merr. cv. IAC19), foram instalados três tratamentos em casa-de-vegetação, com semeadura em canteiros, nas dependências do Departamento de Produção Vegetal, da ESALQ/USP, em Piracicaba. O volume subterrâneo dos canteiros era grande o suficiente para não apresentar restrição física sobre o crescimento radicular.

As plantas foram submetidas a três teores de fósforo no solo: $10 \mathrm{ppm}, 15 \mathrm{ppm}$ e $75 \mathrm{ppm}$.

As parcelas foram instaladas em 9 de setembro de 1997, com população equivalente a 400.000 plantas por hectare ( 20 plantas por metro em linhas espaçadas de $50 \mathrm{~cm}$ ), sendo avaliadas com freqüência de 15 dias, até 60 dias após a semeadura. Em cada avaliação eram amostradas 6 a 9 plantas por tratamento, em procedimento similar ao adotado nas parcelas de campo.

\subsection{Experimento em câmara de germinação}

Com a finalidade de se determinar a influência do fósforo sobre a taxa de alongamento radicular e as tendências iniciais de ramificação do sistema radicular de soja, foram realizados experimentos dentro de câmara de germinação, com temperatura constante de $25^{\circ} \mathrm{C}$, nas dependências do Departamento de Produção Vegetal, da ESALQ/USP, em Piracicaba, durante os meses de agosto e setembro de 1997.

Sementes eram deixadas a germinar entre folhas de papel de filtro umedecidas, montadas em uma armação desenvolvida especialmente para essa finalidade, e os tratamentos consistiam de pontos ou faixas representando zonas com concentração localizada de fósforo, em diversas posições em relação à semente. As raízes das respectivas plântulas eram observadas durante os 10 dias subseqüentes, sendo realizados desenhos de seus sistemas radiculares para posterior comparação. 


\subsection{Experimento em câmara de crescimento}

Tal fase do projeto de pesquisa foi desenvolvida nas dependências da Universidade da Califórnia, em Davis, CA, EUA, durante os meses de janeiro a junho de 1998.

Plantas de soja (Glycine max L. Merrill cv. Williams 82) foram cultivadas em caixas de acrílico preto, com paredes laterais inclinadas de acrílico transparente, coberta por outra placa de acrílico preto. Era possível a observação do crescimento e desenvolvimento das raízes através da parede transparente (Figura 12, ANEXO A). Tais caixas foram localizadas em câmara de crescimento (Figura 13, ANEXO B) com todas as variáveis ambientais atmosféricas e de solo controladas, restando apenas a concentração de $P$ variável entre os tratamentos. Foram feitos 2 tratamentos, ambos com concentração ideal de nutrientes, com exceção da concentração de fósforo. A temperatura do ar dentro da câmara de germinação foi mantida variando entre um valor máximo diário de $27^{\circ} \mathrm{C}$ e um mínimo diário de $19^{\circ} \mathrm{C}$, com fotoperíodo constante de 15 horas durante todo o período experimental, de até 30 dias. As caixas foram preenchidas com substrato inerte seco, constituído de uma mistura 1:1 em volume de areia (mesh 41) e Sunshine mix \#1 (Sun Gro Horticulture Inc.), composto de 70 a $80 \%$ de esfagno, além de perlita, gesso, agente molhante e calcário dolomítico para ajuste do $\mathrm{pH}$. O conteúdo desejado de nutrientes foi conseguido pela adição de solução nutritiva até um conteúdo volumétrico de água de $0,34 \mathrm{~cm}^{3} \cdot \mathrm{cm}^{-3}$, atingindo concentração uniforme de todos os nutrientes, variando apenas a concentração de fósforo, de acordo com os tratamentos (alta concentração de fósforo e baixa concentração de fósforo, aqui designadas por $+\mathrm{P}$ e -P, respectivamente). A massa específica do substrato dentro das caixas foi de 1,23 g. $\mathrm{cm}^{-3}$ após o preenchimento, para ambos os tratamentos. A composição da solução

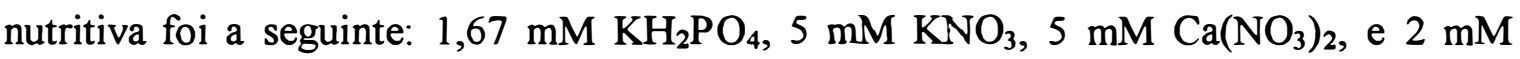
$\mathrm{MgSO}_{4}$ para o tratamento $+\mathrm{P}$, e $0,33 \mathrm{mM} \mathrm{KH}_{2} \mathrm{PO}_{4}, 6,67 \mathrm{mM} \mathrm{KNO}_{3}, 5 \mathrm{mM} \mathrm{Ca}\left(\mathrm{NO}_{3}\right)_{2}$, e $2 \mathrm{mM} \mathrm{MgSO}_{4}$ para o tratamento -P. Em ambas as soluções, os micronutrientes foram adicionados nas seguintes concentrações: 0,5 ppm B, 0,5 ppm Mn, 0,05 ppm Zn, 0,02 ppm Cu, e 0,01 ppm Mo (solução de Hoagland \& Arnon, de acordo com Gauch, 1972). Embora a concentração de $\mathrm{P}$ nas soluções fosse de $51,6 \mathrm{ppm}$, e 10,3 ppm para os 
tratamentos $+\mathrm{P}$ e $-\mathrm{P}$, respectivamente, a concentração alcançada nas caixas, após adsorção pelo substrato sólido, foi de 15,5 ppm P, e 8,5 ppm P (Bray-P).

As caixas de acrílico tinham dois compartimentos $(35 \mathrm{~cm}$ de altura, $39 \mathrm{~cm}$ de comprimento, $7 \mathrm{~cm}$ de largura no topo e $2 \mathrm{~cm}$ de largura no fundo), um para o tratamento $-\mathrm{P}$ e outro para o tratamento $+\mathrm{P}$, sendo apenas uma semente colocada em cada compartimento. Embora não observado, se uma semente falhasse em germinar e emergir, aquela repetição seria substituída. As caixas foram seladas logo após a emergência das plantas para evitar evaporação de água pela superficie do substrato (Figura 14, ANEXO C).

O desenvolvimento dos sistemas radiculares era observado pelas paredes inclinadas de acrílico transparente, sendo feitas anotações dos ângulos de ramificação durante o período experimental (Figura 15, ANEXO D). Para as medidas de densidade de ramificação e comprimento dos trechos radiculares (raiz principal de ordem 1, e raízes laterais de ordens 2 a 4) as plantas eram removidas do solo a cada 5 dias $(5,10$, $15,20,25$ e 30 dias após emergência) e seu sistema radicular era cuidadosamente medido (Figura 16, ANEXO E). Sendo esse um procedimento destrutivo de análise, após cada avaliação uma nova semente era semeada.

\subsubsection{Procedimento de medida do sistema radicular}

O sistema radicular, após retirado cuidadosamente do solo, evitando-se o rompimento de algum trecho do mesmo, era lavado por imersão em água. Em seguida à lavagem, iniciava-se o procedimento de medida.

A raiz principal pivotante (ordem 1) tinha seu comprimento determinado, após o que o sistema radicular era dividido em trechos de $5 \mathrm{~cm}$ de comprimento ao longo da raiz principal. Eram então contados os números de raízes laterais de ordem 2 em cada trecho de $5 \mathrm{~cm}$ da raiz principal, e em seguida 6 raizes de ordem 2 eram retiradas de cada trecho, completamente ao acaso, e tinham seu comprimento determinado, com a finalidade de estimativa do comprimento médio de acordo com sua posição de origem na raiz principal. Em seguida eram escolhidos 6 trechos de $3 \mathrm{~cm}$ ao longo das raizes de ordem 2 identificadas de acordo com sua posição de origem, e era contado o número e 
medido o comprimento das raízes de ordem 3, para estimativa do número médio de raizes de ordem 3 por centímetro de raiz de ordem 2, e seu comprimento médio. $\mathrm{O}$ mesmo procedimento era adotado para as raízes de ordem 4 , quando existentes.

Sendo assim, para cada tratamento e data de amostragem eram obtidos: (i) comprimento da raiz principal (ordem 1), e (ii) de acordo com a posição de origem na raiz principal, os respectivos números e comprimentos médios das raízes laterais das ordens 2,3 e 4 .

Como o delineamento experimental contava com 3 repetições para cada idade de planta avaliada $(5,10,15,20,25$, e 30 dias após a germinação), também foram calculados os valores médios das 3 repetições.

\subsection{Modelagem matemática dos processos definidores da arquitetura radicular}

A modelagem numérica constitui-se de uma excelente ferramenta de análise que permite resumir a enorme quantidade de dados experimentais coletados, que representam os parâmetros e os processos definidores da arquitetura radicular, e apresentá-los de uma maneira em que comparações possam ser feitas.

Para tal, desenvolveu-se algoritmos representando cada processo definidor das características de crescimento e arquitetura radiculares, na linguagem de programação Visual Basic para Windows (versão 6.0), construindo-se um modelo de simulação. 


\section{RESULTADOS E DISCUSSÃO}

\subsection{Parâmetros arquiteturais do sistema radicular de soja}

\subsubsection{Parcelas experimentais de campo e em casa-de-vegetação}

Os procedimentos adotados permitiram a obtenção de imagens digitalizadas de sistemas radiculares de soja com qualidade satisfatória quanto à obtenção dos parâmetros caracterizadores do sistema radicular.

A partir das imagens digitalizadas referentes a cada experimento e tratamento, foram extraídos valores de comprimento e ângulos de orientação e deflexão de ramos radiculares de ordens 1 e 2 .

No entanto, comparações com os resultados obtidos pela metodologia empregada no experimento em câmara de crescimento, que serão apresentados e discutidos em item posterior, revelaram que a metodologia empregada a campo e em casa-de-vegetação foi inadequada para a obtenção de sistemas radiculares intactos e apropriados para servirem de fonte para a medida de parâmetros.

A afirmação de Harper et al. (1991) de que mais tempo e esforços são consumidos no desenvolvimento de metodologias apropriadas do que no estudo propriamente dito de sistemas radiculares se revelou verdadeira também neste projeto de pesquisa.

O método de escavação utilizado a campo e em casa-de-vegetação não só não permitiu a medida de parâmetros relativos às raizes de ordem 3 , o que era esperado, pois essa metodologia recupera uma porcentagem muito pequena das raízes mais finas, mas também não permitiu a caracterização apropriada das raízes de ordem 1 e 2, pois apenas parte delas foram recuperadas do solo. 
Embora todo o processo de escavação e retirada das raízes do solo, bem como o procedimento de lavagem tenham sido realizados com o máximo de zelo, a própria característica textural do solo (solo de textura argilosa) tornou impossível a retirada de sistemas radiculares intactos.

O método de escavação não pode ser utilizado para a caracterização arquitetural de sistemas radiculares (i) porque após a escavação é impossível saber os ângulos de orientação e deflexão originais dos ramos radiculares, com exceção daqueles que já apresentam crescimento secundário (maior diâmetro e suberizados), e (ii) porque grande porção do sistema não é recuperada do solo. O método de escavação não é apropriado nem mesmo para a estimativa do comprimento radicular.

Todos esses problemas, aliados ao grande consumo de força física e tempo, tornam esse método inviável para análises quantitativas precisas e exatas do sistema radicular. No entanto, a falta de outros métodos adequados para o estudo de sistemas radiculares de plantas crescendo em condições reais (campo), conforme já discutido no item 3.1.1, faz com que essa seja a única alternativa viável em muitos casos. Sugere-se que dados obtidos a campo sirvam de base para o desenvolvimento de modelos conceituais, não quantitativos, à base de comparações visuais de sistemas radiculares escavados, e que a partir desse ponto, as hipóteses formuladas sejam testadas sob condições que permitam um maior controle.

Embora a inviabilidade do método tenha sido discutida, Mackie-Dawson \& Atkinson (1991) afirmam que escavações podem ser utilizadas para a estimativa da relação entre a massa de raízes e a massa dos componentes aéreos da planta. Sendo assim, apresenta-se um interessante gráfico mostrando a variação temporal da relação entre massa de matéria seca de raiz e massa de matéria seca total da planta, construído a partir de dados obtidos em casa-de-vegetação para o cultivar IAC-19 (Figura 3). 


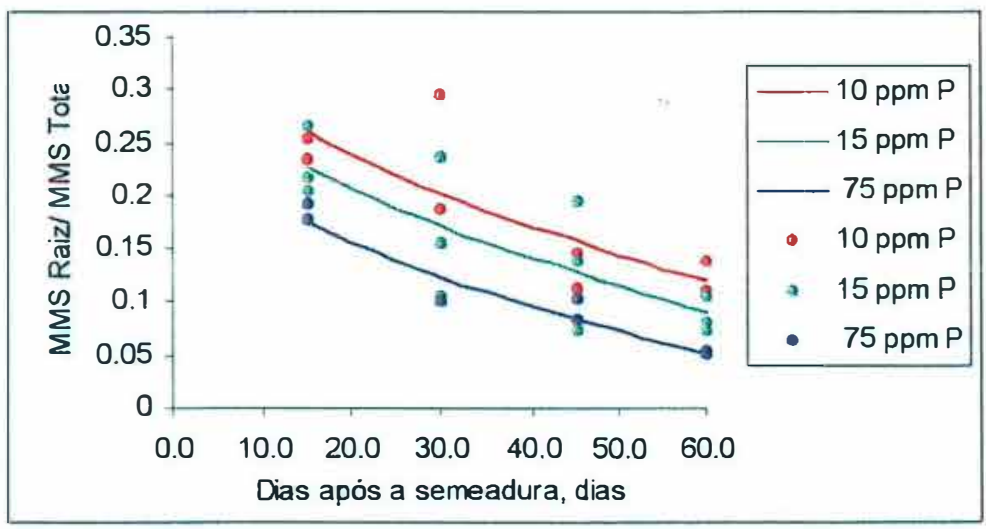

Figura 3. Variação temporal da relação entre massa de matéria seca de raiz e massa de matéria seca total da planta. Pontos representam valores medidos.

Verifica-se uma clara tendência de favorecimento do sistema radicular na partição de fotoassimilados conforme se diminui o teor de fósforo no solo. Isso reflete o fato de que plantas crescendo em solos ricos em nutrientes geralmente apresentam um sistema radicular menor (expresso pela fração da massa de matéria seca total da planta que é constituída de raízes) em relação a plantas crescendo em condições onde $\mathrm{N}, \mathrm{P}$, ou K são limitantes (Robinson, 1994).

\subsubsection{Experimento em câmara de germinação}

Os resultados obtidos no experimento em câmara de germinação foram bastante interessantes e serviram como elemento motivador para o experimento em câmara de crescimento.

Observou-se uma aceleração na taxa de alongamento das raízes crescendo na zona livre de fósforo, e, por outro lado, um aumento na taxa de formação de novos ramos radiculares na zona com maior teor de fósforo (Figura 4). 


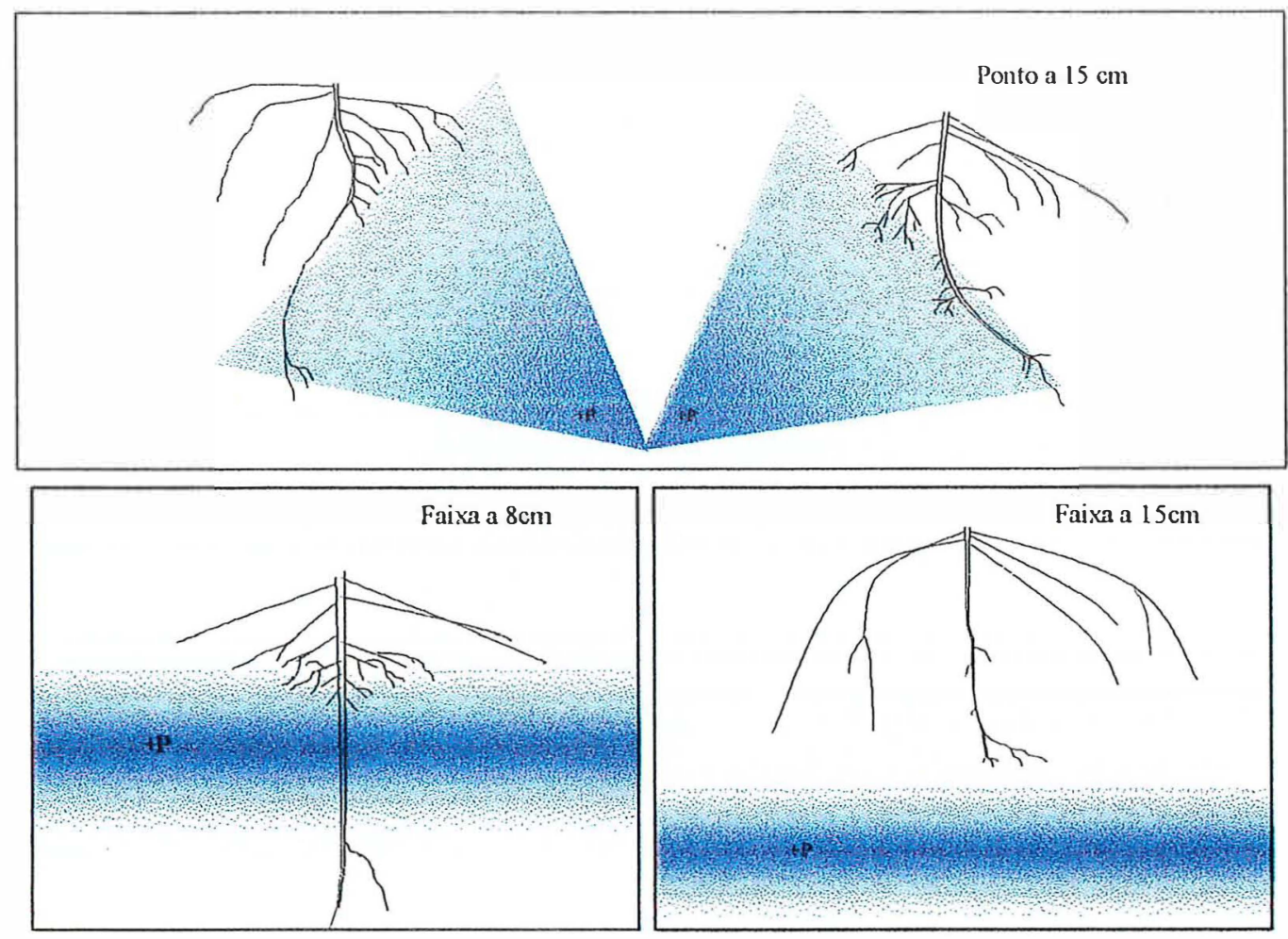

Figura 4. Influência do fósforo sobre a taxa de alongamento e as tendências iniciais de ramificação do sistema radicular de soja

Tais resultados de natureza qualitativa comprovam a tendência de alongamento das raízes laterais em resposta à baixa disponibilidade de fósforo (Lynch, 1995), e de estimulação na formação de raízes laterais em resposta à uma maior disponibilidade relativa de fósforo (Drew, 1975). Uma explicação mais aprofundada sobre essa resposta típica da planta será elaborada nos próximos itens.

\subsubsection{Experimento em câmara de crescimento}

O uso de caixas de acrílico com paredes laterais transparentes inclinadas se mostrou bastante apropriado para a obtenção dos parâmetros arquiteturais do sistema radicular de soja. Além da possibilidade de observação dos ângulos de orientação e deflexão dos ramos radiculares através da parede inclinada, o método permitiu a retirada de sistemas radiculares intactos, visto que a mesma parede inclinada se deslizava para cima, permitindo a perfeita retirada do bloco raiz + substrato. 
Embora possa se argumentar que o método de medida de trechos radiculares com régua seja muito tediosa e consuma muito tempo, o mesmo permite uma precisão que nenhum outro método propicia (análise de imagens digitalizadas, p.ex.).

Para cada tratamento e data de amostragem, através das medidas feitas eram obtidos: (i) comprimento da raiz principal (ordem 1), e (ii) de acordo com a posição de origem na raiz principal, os respectivos números e comprimentos médios das raízes laterais das ordens 2, 3 e 4 (ANEXO F).

Como o delineamento experimental contava com 3 repetições para cada idade de planta avaliada $(5,10,15,20,25$, e 30 dias após a germinação), também foram calculados os valores médios das 3 repetições.

Com base nos valores de comprimento e número médio de raízes, estimou-se uma série de parâmetros definidores e caracterizadores da arquitetura radicular de uma planta de soja. Tais parâmetros e seu significado funcional e estratégico na adaptação da planta ao ambiente edafoclimático serão discutidos nos próximos itens.

\subsection{Análise arquitetural do sistema radicular baseada em Índices Topológicos}

O grau de ramificação de sistemas radiculares é geralmente mencionado sem que seu sentido fique claro ao leitor. Um sistema radicular "mais ramificado" significa que o mesmo possui um maior número total de ramificações, uma maior freqüência de ramificações (isto é, entrenós mais curtos), ou um maior número de ordens de desenvolvimento (isto é, um sistema com raizes de ordem 4 é mais ramificado que um sistema com número de ordem máximo igual a 3). Fitter (1985) formula essas mesmas questões e depois afirma que conceitos de topologia radicular ajudam a esclarecer tais controvérsias.

\subsubsection{Consideração teórica}

Os sistemas radiculares são capazes de apresentar mudanças em sua arquitetura em resposta às condições do solo, como resistência fisica à penetração, teor de nutrientes ou suprimento hídrico. Essas mudanças arquiteturais podem ser medidas pela variação na topologia radicular (aspectos não métricos da estrutura de ramificação), bem como 
por variações no comprimento das conexões, nos ângulos de ramificação, e no diâmetro das conexões.

Dentre os índices topológicos discutidos previamente, o caminho percorrido total do sistema ( $c t$ ), e a sua altitude $(a)$ variam dentro de limites estabelecidos, para cada valor de magnitude, sendo seus valores mínimos associados com um sistema de ramificação puramente dicótomo (cada conexão parental dá origem a duas conexões filhas) e seus valores máximos associados com um padrão de ramificação estritamente "espinha de peixe" (raizes laterais de ordem 2 se originando de uma raiz principal pivotante, de ordem 1). Como esperado, esses índices não são uma característica fixa para cada espécie vegetal, mais variam de acordo com as condições edáficas (Fitter, 1987).

A topologia "espinha de peixe" ocorre quando a formação de novos ramos é confinada à raiz principal, enquanto que um sistema dicótomo se desenvolve quando a geração de novos ramos ocorre com probabilidade igual em todos as conexões externas (Fitter, 1991). Num sistema radicular real, como o de soja, existe a probabilidade de ramificação em todas as conexões, sejam externas ou internas, exceto naquelas conexões pertencentes à ordem máxima de desenvolvimento (ordem 4 , no caso da soja).

\subsubsection{Magnitude do sistema radicular}

Conforme visto, a magnitude de um sistema radicular é equivalente ao número de meristemas apicais ou de conexões externas do sistema radicular. Para efeito de cálculo, a magnitude de um sistema radicular em uma determinada data é o próprio número total de raizes do sistema naquela ocasião. Os valores experimentais de $m$ em intervalos de 5 dias, até 30 dias após a germinação, para os dois teores de fósforo no substrato, são apresentados na Figura 5. 


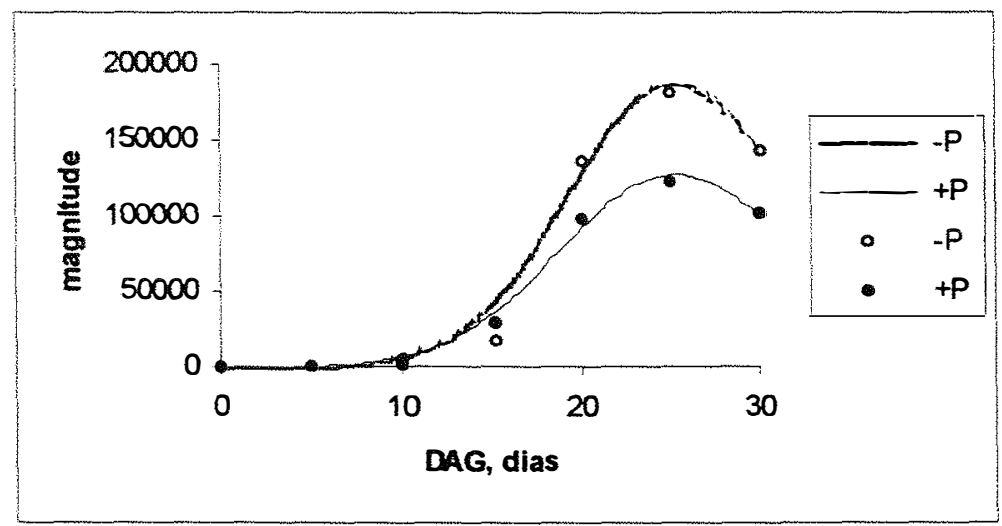

Figura 5. Variação temporal da magnitude do sistema radicular de soja, para os dois tratamentos. Pontos representam valores medidos.

Verifica-se, na condição de menor fertilidade (-P), uma magnitude pronunciadamente maior em relação à condição de maior fertilidade $(+\mathrm{P})$, refletindo um maior número de pontos de crescimento, estratégia adaptativa adotada pela planta para melhor explorar o solo em busca do nutriente escasso, nesse caso um nutriente altamente imóvel no solo, o fósforo. Para nutrientes altamente móveis no solo, como o nitrato, não seria esperada a mesma alteração arquitetural do sistema radicular, pois ramos em grande número acabariam competindo entre si pelo mesmo recurso escasso. O que explica essa hipótese é o diâmetro da zona de depleção do nutriente escasso que se forma ao redor de cada ramo de absorção do sistema radicular $\left(x=2 . D^{1 / 2} \cdot t^{1 / 2}\right.$; sendo $\mathrm{x} o$ diâmetro da zona de depleção, em $\mathrm{cm}, \mathrm{D}$ o coeficiente de difusão do nutriente em questão, em $\mathrm{cm}^{2} \cdot \mathrm{s}^{-1}$, e t o tempo, em s). Nutrientes com difusividade baixa no solo, como o fosfato, apresentam zonas de depleção com diâmetro bastante reduzido, portanto um grande número de ramos produzidos proporcionaria uma melhor exploração do solo em busca de tal recurso, já que eles não competiriam entre si. Por outro lado, no caso dos nutrientes com alta difusividade no solo, desenvolvem-se zonas de depleção com maiores diâmetros ao redor dos ramos radiculares de absorção, e se as zonas de depleção de dois ramos se encontrassem, a eficiência de utilização do nutriente (massa de 
nutriente absorvido por massa de tecido radicular produzido) seria reduzida. Robinson (1991) apresenta uma interessante abordagem sobre zonas de depleção.

Para nutrientes móveis, a melhor estratégia para melhorar a eficiência de exploração seria o aumento do comprimento das conexões internas (aumento da distância de ramificação). Em concordância com a hipótese, não se verificou diferença significativa nas distâncias de ramificação entre os dois tratamentos empregados no presente estudo (diferentes concentrações de fósforo, um nutriente imóvel no solo).

\subsubsection{Altitude do sistema radicular}

Como já visto, a altitude de um sistema radicular representa o caminho com o maior número de conexões que um nutriente ou a água teria de percorrer de uma conexão externa até a parte aérea da planta, sendo seu valor máximo associado à uma arquitetura "espinha de peixe" (exploração acelerada de um grande volume de solo em busca do recurso escasso) e seu valor mínimo associado a uma arquitetura dicótoma (alta eficiência de utilização de um recurso em um volume restrito de solo). Sistemas radiculares reais apresentam uma arquitetura intermediária entre esses dois extremos, visto que a melhor estratégia adaptativa da planta é um equilíbrio entre eficiência de exploração e eficiência de utilização, tendendo mais para um dos lados dependendo do genótipo e das condições edáficas.

Para uma determinada magnitude do sistema, pode-se calcular os valores máximos e mínimos de altitude. Equações de estimativa se encontram em Werner \& Smart (1973) e Fitter (1985).

Os valores experimentais de $a$ foram calculados através em intervalos de 5 dias, até 30 dias após a germinação, para as duas concentrações de fósforo no substrato, são apresentados na Figura 6., juntamente com as estimativas de valores máximos e mínimos. 

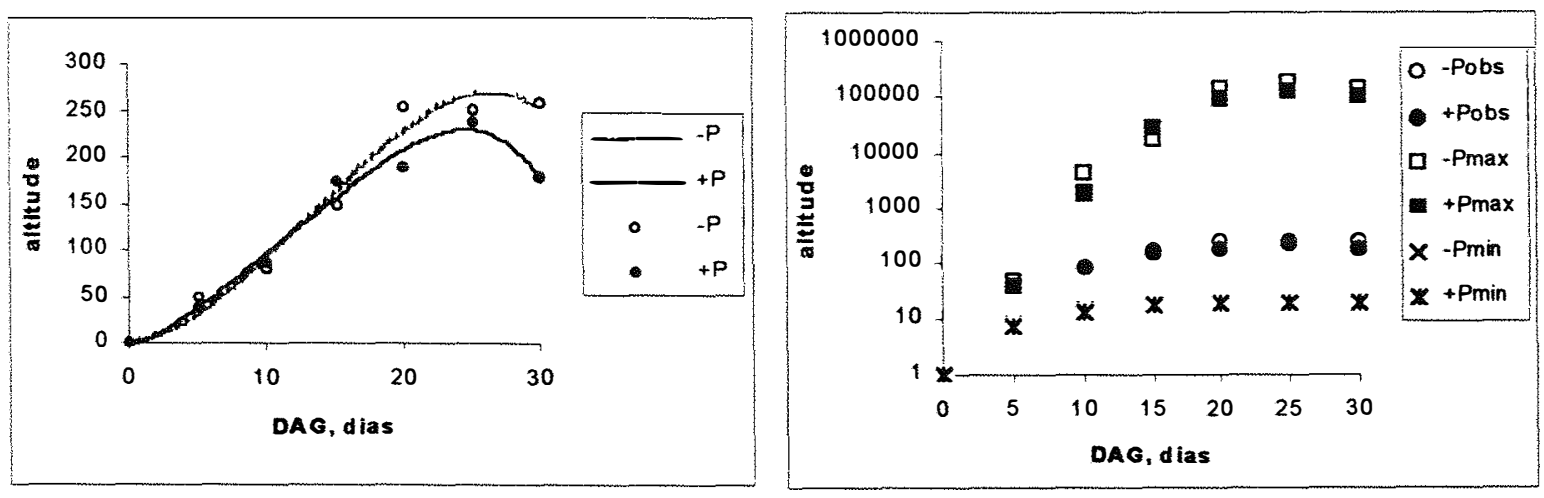

Figura 6. (A) Curva de variação temporal da altitude do sistema radicular em função da idade da planta, para os dois tratamentos. (B) Valores estimados máximos (max) e mínimos (min) de altitude, plotados juntamente com os valores experimentais de altitude (obs), para ambos os tratamentos.

Pela Figura 6a verifica-se que no tratamento com menor teor de fósforo no solo, houve exploração mais acelerada do solo, refletida pelos maiores valores de altitude. No entanto, quando se comparam os valores medidos de $a$ com os valores máximos e mínimos calculados (Figura 6b), verifica-se que em ambos os tratamentos a estratégia da planta é mais voltada para eficiência de utilização (os valores medidos são mais próximos dos valores mínimos que dos máximos), possivelmente uma característica da espécie ou do genotipo.

Um outro fator interessante é que se a planta tendesse muito para a arquitetura "espinha de peixe", seu sistema radicular seria muito suscetível a danos físicos, pois cada conexão interna seria ponto de passagem de água e nutrientes provenientes de um grande número de outras conexões. Na Figura 7 verifica-se que a arquitetura radicular desvia-se da forma "espinha de peixe" em ambos os tratamentos, conforme indicado pelo desvio dos valores medidos em relação ao valores máximos. 


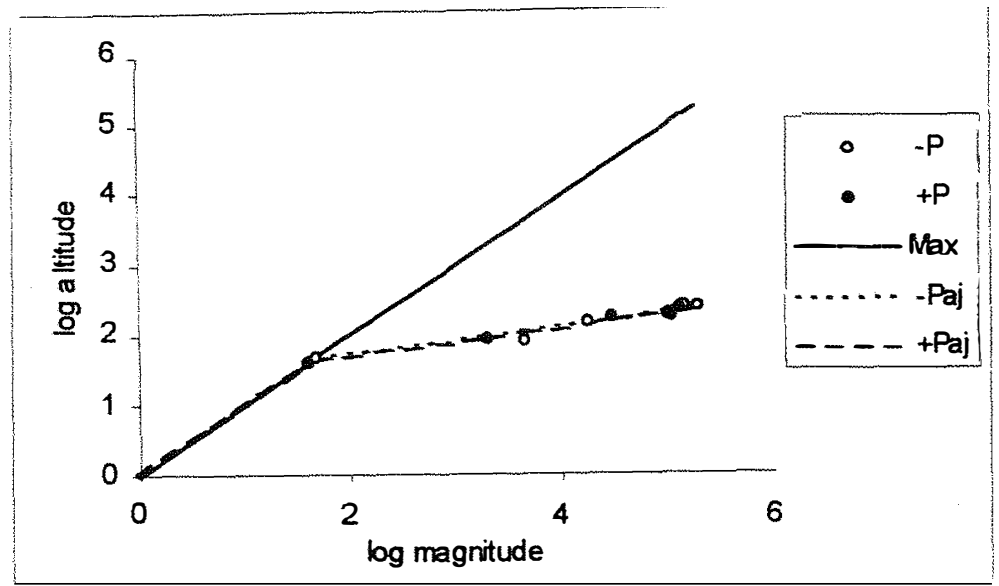

Figura 7. Curva de variação da altitude do sistema radicular em função da magnitude, mostrando o desvio dos valores experimentais em relação aos valores máximos, para ambos os tratamentos.

\subsection{Modelo mecanístico de simulação da arquitetura radicular}

Robinson (1991) enfatiza que o avanço científico no entendimento de como as raízes interceptam e absorvem os nutrientes seria muito pequeno se se tentasse reconstruir com exatidão detalhada, às custas de muito tempo, esforços e recursos financeiros despendidos, a intrincada estrutura tridimensional de um sistema radicular real. Novas idéias e abordagens imaginativas são mais importantes que avanços tecnológicos que permitam uma caracterização mais detalhada do sistema radicular, e sua exata reconstrução através de modelos de simulação. Sistemas radiculares devem ser simplificados conceitualmente, e a modelagem numérica pode ser utilizada como uma excelente ferramenta de síntese. Por essa razão, o objetivo deste trabalho é utilizar a modelagem numérica como um meio de resumir a enorme quantidade de dados experimentais coletados, representando os processos definidores da arquitetura radicular, e apresentá-los de uma maneira em que comparações possam ser feitas. 


\subsubsection{Parâmetros do modelo}

\subsubsection{Comprimento de ramos}

Denomina-se ramo um trecho radicular entre o ponto de origem (semente, parte aérea ou ponto de ramificação) e o meristema apical. Ajustou-se curvas de comprimento médio do ramo (CR) para cada ordem e profundidade de origem (de $5 \mathrm{em} 5 \mathrm{~cm}$ ), e para os dois tratamentos de $\mathrm{P}$ no solo (15 ppm e $8 \mathrm{ppm}$ ), em função da idade da planta, utilizando-se a seguinte equação:

$$
C R=\frac{a}{1+\left(\frac{D A G}{b}\right)^{c}}
$$

em que a, b e c são os parâmetros de ajuste, e DAG a idade da planta, em dias após a germinação.

O ajuste foi feito em função da idade da planta e não da idade do ramo por uma questão de adequação ao modelo numérico de simulação da arquitetura radicular que foi desenvolvido (ver sub-item "Duração da não-ramificação do ápice”).

As curvas de comprimento médio dos ramos de todas as ordens, para algumas profundidades escolhidas, são apresentadas na Figura 8, juntamente com as barras de desvio padrão. A maioria das curvas ajustadas teve valores de coeficiente de regressão acima de 0,95 . 

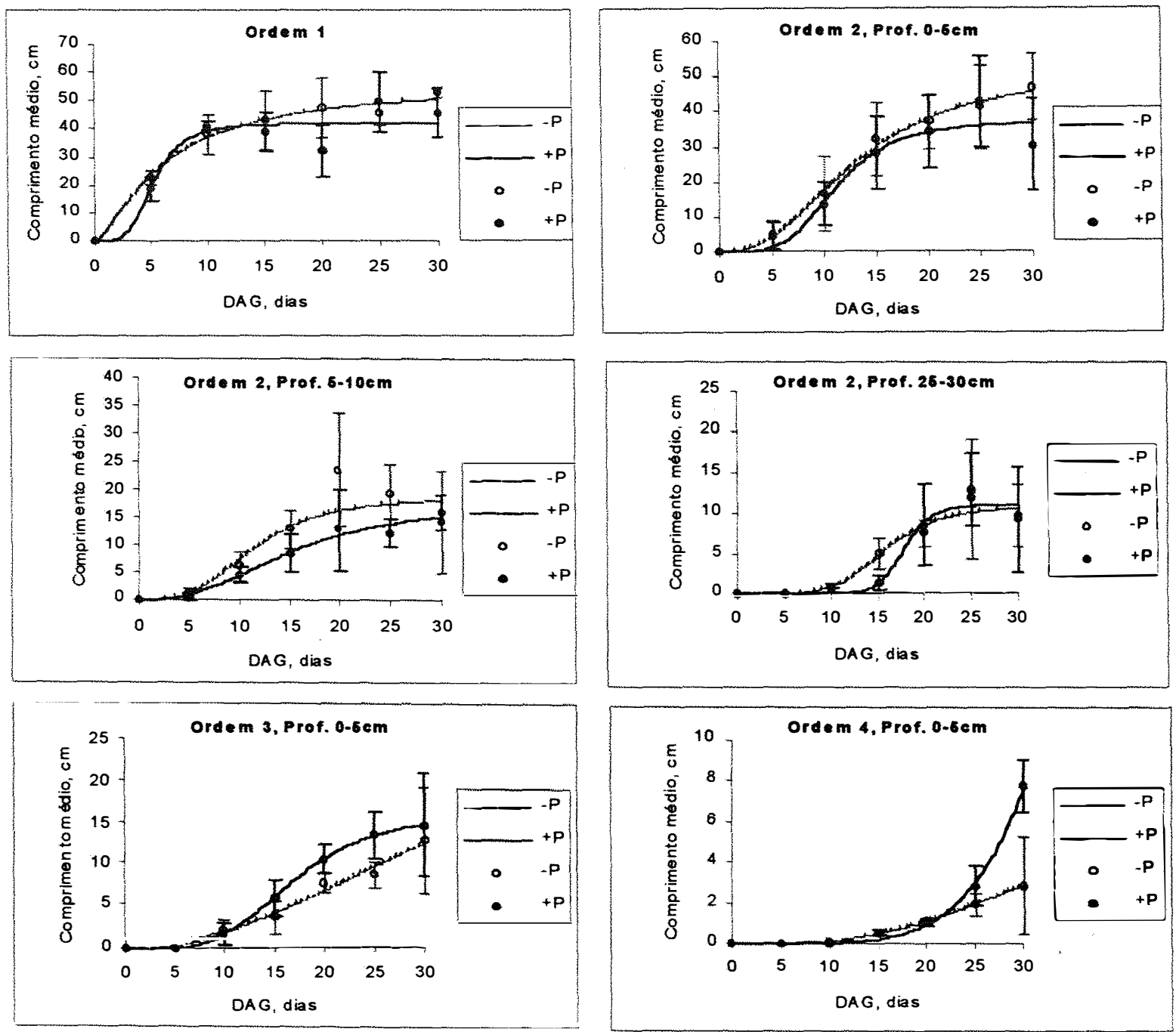

Figura 8. Curvas ajustadas de comprimento médio do ramo $(\mathrm{cm})$ para raizes de ordens 1 a 4, para algumas profundidades de origem selecionadas. Pontos representam valores medidos experimentalmente, junto com as respectivas barras de desvio padrão.

\subsubsection{Velocidade de Crescimento}

Os termos "velocidade de crescimento", ou "taxa de alongamento radicular", que se aproxima do comumente utilizado termo inglês "root elongation rate", descrevem o 
parâmetro de acréscimo médio diário no comprimento de um ramo (em centímetros por dia).

A velocidade de crescimento (VC) é um parâmetro dependente de vários fatores edafoclimáticos, como temperatura e umidade do solo, resistência do solo à penetração $\mathrm{e}$ características químicas do solo, entre outros, além de fatores da planta, como genótipo, idade do ramo, ordem de desenvolvimento do ramo (raiz principal pivotante, de ordem 1, ou raizes laterais, de ordem 2,3 , ou 4, no caso da soja), e, para as raizes laterais, profundidade de origem do ramo de ordem 2 ou profundidade do ponto de conexão com a raiz principal para as ramificações de ordens 3 e 4 .

As curvas de VC foram derivadas a partir das equações ajustadas de comprimento médio de ramo (Figura 8), sendo apresentadas na Figura 9, e descritas pela seguinte equação:

$$
V C=\frac{-a \cdot\left[\cdot\left\{\left(\frac{1}{b}\right)^{c} \cdot D A G^{c-1}\right\}\right]}{\left\{1+\left(\frac{D A G}{b}\right)^{c}\right\}^{2}}
$$



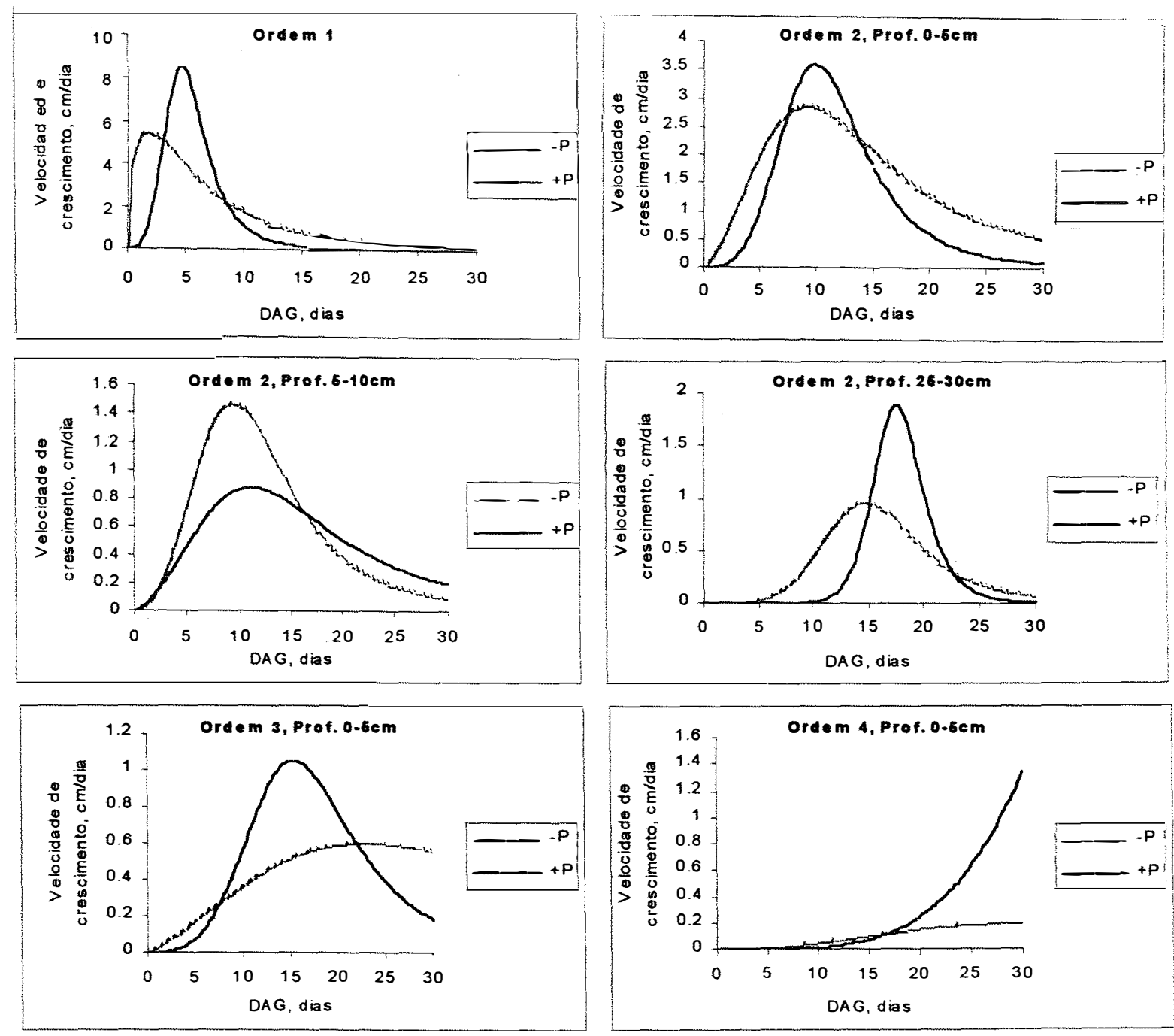

Figura 9. Curvas ajustadas de velocidade de crescimento do ramo $\left(\mathrm{cm} \cdot \mathrm{dia}^{-1}\right)$ para raízes de ordens 1 a 4, para algumas profundidades de origem selecionadas. Pontos representam valores medidos experimentalmente, junto com as respectivas barras de desvio padrão.

O delineamento experimental não permitiu ajuste das curvas de VC em função da temperatura, conteúdo de água e resistência do solo à penetração. Em futuros projetos pretende-se empregar delineamentos experimentais que permitirão variar um desses 
fatores ambientais mantendo-se todos os outros fixos, proporcionando ajuste da curva de VC em função de cada um dos mesmos.

\subsubsection{Distância de Ramificação}

Verificou-se variação significativa na distância entre dois pontos de ramificação, aqui denominada Distância de Ramificação (DR), em função da profundidade de origem (ramificações sobre a raiz de ordem 1), ou em função da profundidade de conexão com a raiz de ordem 1 (ramificações sobre as raízes de ordens 2 e 3). Não se verificou ramificação sobre as raízes de ordem 4. Não se verificou variação significativa entre os tratamentos de $\mathrm{P}$. As curvas de DR para os dois tratamentos de $\mathrm{P}$ no solo são apresentadas na Figura 10, e foram ajustadas à seguinte equação:

$$
D R=d+e . V P^{2}+f . V P^{2} \cdot \log (V P)+g \cdot \operatorname{Exp}(V P)
$$

em que d, e, f, g se referem aos parâmetros de ajuste, e VP à variável de profundidade, sendo igual à profundidade de origem, para as ramificações sobre a raiz de ordem 1 , ou igual à profundidade de conexão com a raiz de ordem 1, para as ramificações sobre as raizes de ordens 2 e 3 . 

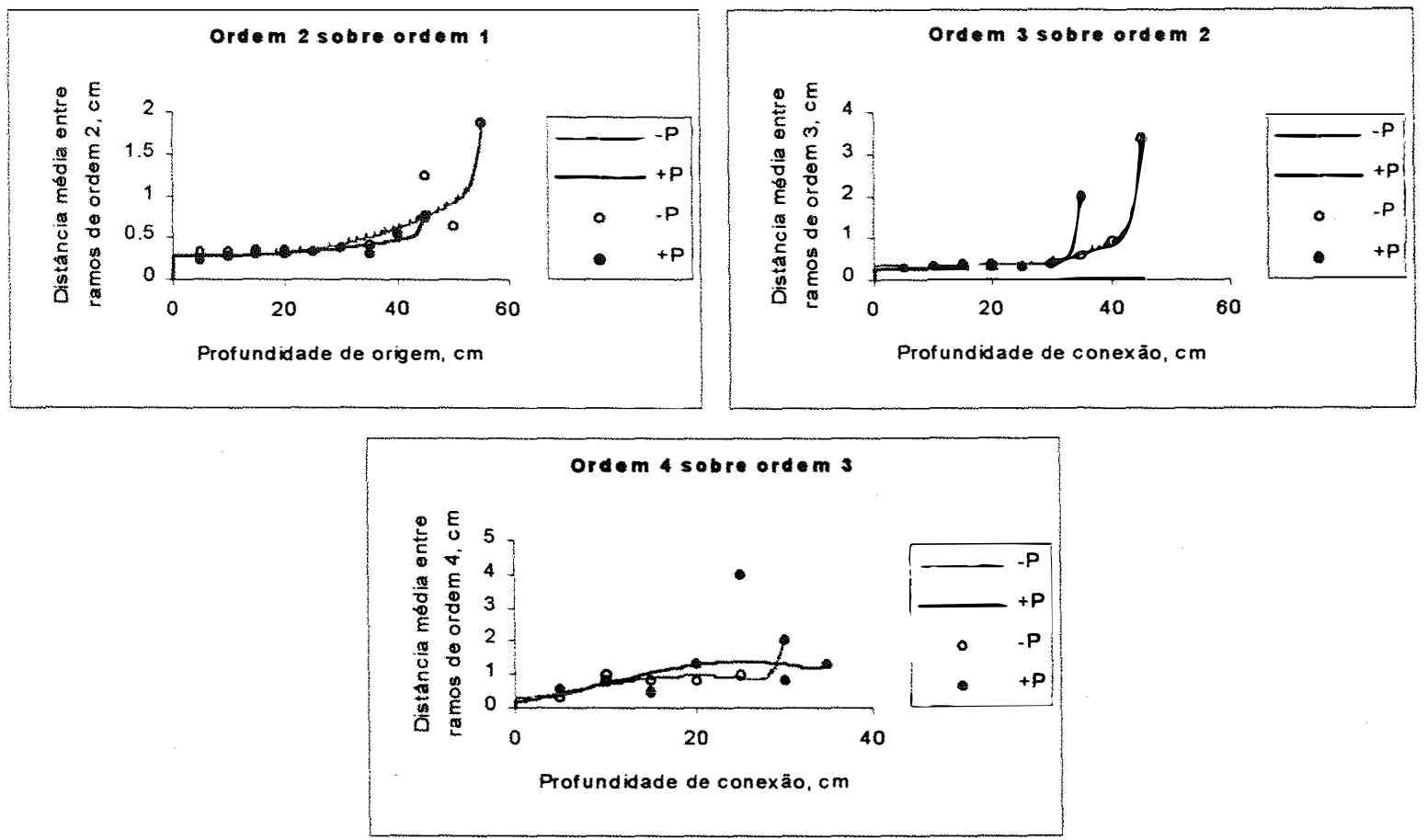

Figura 10. Curvas ajustadas de Distância de Ramificação $(\mathrm{em} \mathrm{cm})$. Pontos representam valores medidos experimentalmente.

\subsubsection{Duração da não ramificação do ápice}

Essa terminologia utilizada em modelos bem conceituados de simulação do crescimento e arquitetura radiculares, como o de Diggle (1988), transmite a idéia errônea de que o ápice dos ramos radiculares poderia se ramificar. Um potencial ponto de ramificação (dado pela DR) começa a desenvolver um novo ramo a partir de uma idade determinada. $\mathrm{O}$ fenômeno é representado adequadamente no presente modelo pelo ajuste das curvas de $\mathrm{VC}$ em função da idade da planta e para cada profundidade de origem (verificar na Figura 9 como algumas curvas de VC não partem do zero na idade 0 , mas em épocas posteriores).

\subsubsection{Parâmetros afetando a direção de crescimento}

A cada novo incremento no comprimento de um ramo, a direção na qual a ponta da raiz cresce segue um ângulo de orientação que pode variar dentro de uma faixa de 
deflexão. $\mathrm{O}$ ângulo de orientação depende da reação gravitrópica do ramo, ou seja, sua preferência de crescimento num ângulo vertical. A reação gravitrópica, por sua vez, depende da ordem de desenvolvimento do ramo e de sua idade. Na cultura de soja, o ramo de ordem 1 (raiz principal pivotante) tem uma alta reação gravitrópica, ou seja, cresce num ângulo estritamente vertical, apresentando apenas pequenas deflexões durante seu crescimento. Os ramos de ordem 2 (raízes laterais de ordem 2) não apresentam nenhuma reação gravitrópica quando surgem, aumentando essa reação com o aumento de sua idade. Os ramos de ordens 3 e 4 não apresentam reação gravitrópica em nenhuma fase de sua vida, ou seja, surgem em ângulos perpendiculares à raiz mãe e apresentam apenas variações deflectivas.

O presente modelo não usa como parâmetros Índices de Geotropismo (Gravitropismo) e Deflexão, como a maioria dos modelos existentes, mas sim ângulos de orientação, com possibilidade de variação aleatória dentro de uma faixa (faixa de deflexão). Sendo assim, obteve-se os seguintes valores experimentais: a raiz principal pivotante cresce verticalmente ( $0^{\circ} \mathrm{com}$ a normal), podendo defletir em até mais ou menos $10^{\circ}$ durante cada novo acréscimo no comprimento. As raízes laterais de ordem 2 se originam perpendicularmente à raiz de ordem $1\left(90^{\circ}\right.$ com a normal) e apresentam ângulos progressivamente menores em relação à normal a cada acréscimo de comprimento $\left(90^{\circ}\right.$ até $1 \mathrm{~cm}, 65^{\circ}$ de 1 a $5 \mathrm{~cm}, 55^{\circ}$ de 5 a $10 \mathrm{~cm}, 35^{\circ}$ de 10 a $15 \mathrm{~cm}, 25^{\circ}$ de 15 a $20 \mathrm{~cm}, 15^{\circ}$ de 20 a $25 \mathrm{~cm}, 5^{\circ}$ de 25 a $30 \mathrm{~cm}$, e $0^{\circ}$ a partir de $30 \mathrm{~cm}$ de distância da raiz principal), podendo ainda apresentar uma deflexão de até mais ou menos $15^{\circ}$ a cada novo trecho crescido. As raízes laterais de ordens 3 e 4 se originam perpendicularmente em relação à sua raiz mãe e podem apresentar deflexão de até mais ou menos $40^{\circ}$ a cada novo trecho crescido.

Embora observado em experimentos preliminares, não se verificou influência significativa da concentração de fósforo no substrato sobre os ângulos de orientação. 


\subsubsection{A simulação}

A análise de regressão, e a comparação de médias e desvios padrão, componentes da estatística clássica, embora possam ser úteis para explicar diferenças em pequenos trechos do sistema radicular, como visto na Figura 8 e Figura 9, não permitem que se compare diferentes arquiteturas radiculares, e se explique as diferentes estratégias adaptativas adotadas pelas plantas em face de restrições edafoclimáticas. Por outro lado, a modelagem numérica permite a agregação de todos os parâmetros e processos e o cálculo de sua influência sobre o sistema radicular inteiro, permitindo a comparação entre diferentes arquiteturas radiculares.

No caso específico deste trabalho, a comparação é visual, a partir das imagens simuladas pelo modelo. Tais imagens simuladas não são previsões de arquitetura radicular em resposta a um conjunto de fatores edafoclimáticos, mas simplesmente a reprodução, de forma esquemática e simplificada, dos sistemas radiculares reais observados.

Não estavam ativos durante o processamento dos dados e a simulação, os algoritmos do modelo que representam os processos que definem o surgimento e o crescimento das raízes de ordem 4, visto que a capacidade de processamento dos microcomputadores disponíveis foi insuficiente (memória insuficiente). De qualquer forma, a apresentação de tais ramos nas imagens simuladas reduziria a clareza das mesmas para fins comparativos. Para se ativar as rotinas relativas à ordem 4 , seriam necessários microcomputadores com alta capacidade de processamento e memória superior a $64 \mathrm{Mb}$. As rotinas doi modelo são apresentadas no Anexo G.

As imagens simuladas são apresentadas para os dois tratamentos, a intervalos de 5 dias, até 30 dias após a germinação, na Figura 11. 

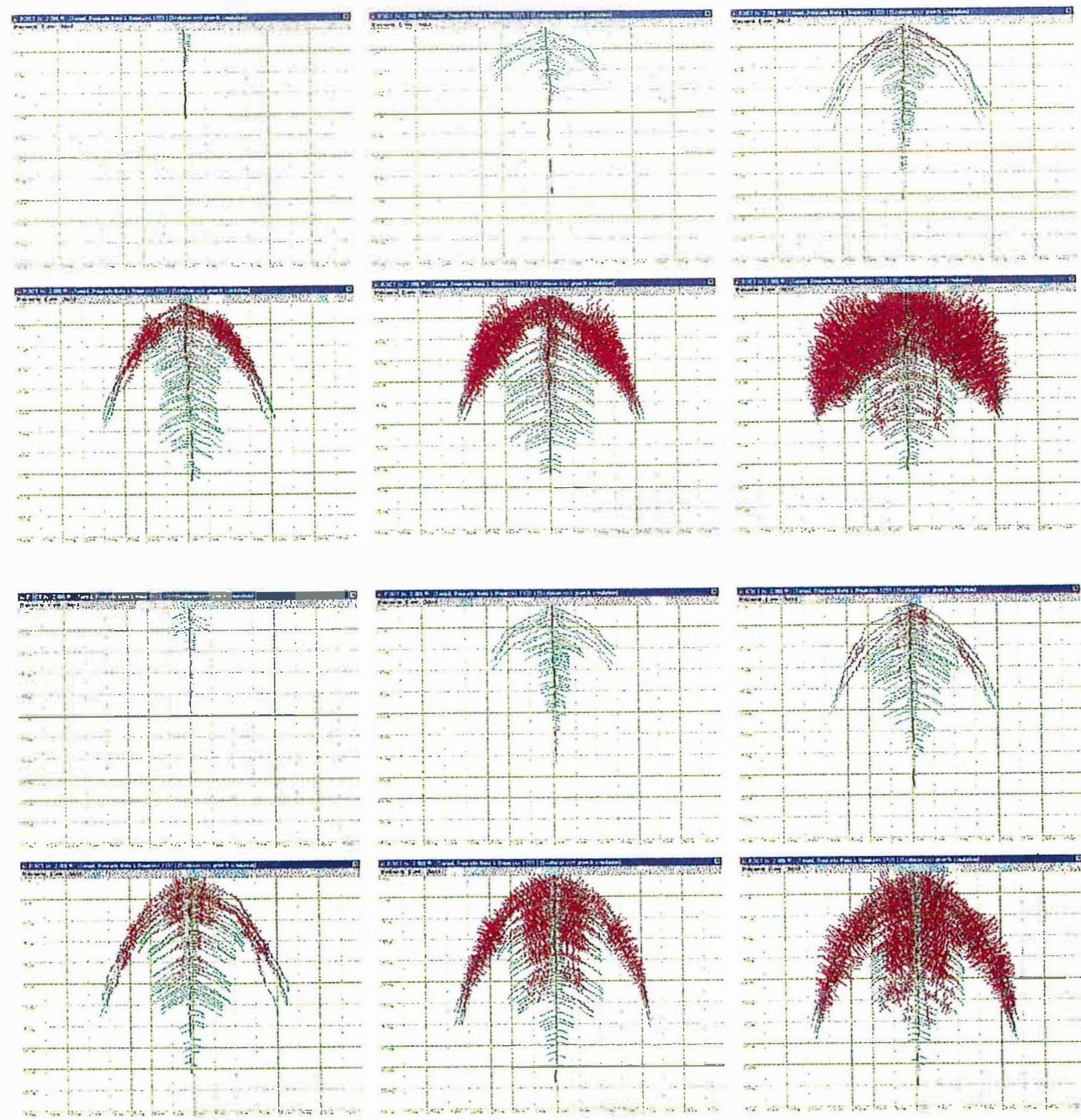

$+\mathrm{P}$
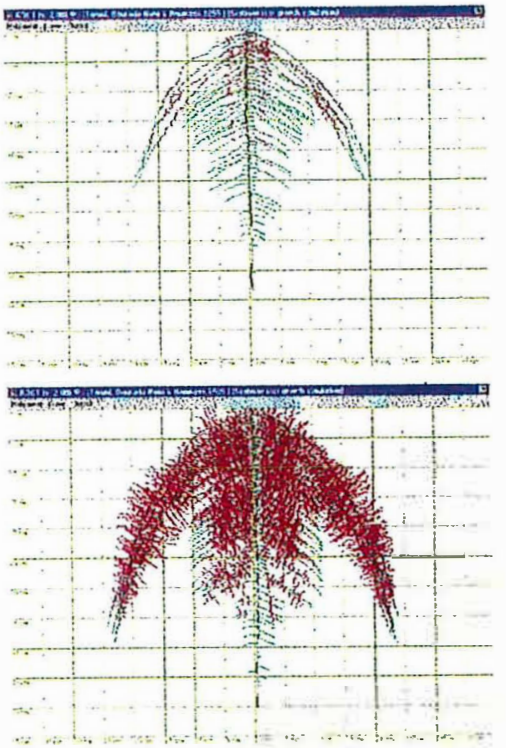

Figura 11. Imagens simuladas do sistema radicular de soja para concentrações de fósforo no solo alta (+P) e baixa (-P), para 5, 10, 15, 20, 25 e 30 dias após a germinação. 
Cabe esclarecer o significado de dois termos que estão sendo utilizados na discussão: "exploração do solo" e "utilização do solo". O primeiro traduz o termo inglês "soil exploration", e representa o volume de solo explorado pelo sistema radicular de uma planta. O segundo traduz o termo inglês "soil exploitation", e representa a quantidade de nutrientes e água absorvidos por massa ou volume de raiz produzidos.

Uma maior eficiência de exploração é conseguida por um crescimento acelerado da raiz principal, de ordem 1, e das raízes basais (raízes laterais de ordem 2 que se desenvolvem nos $5 \mathrm{~cm}$ superficiais do solo e que apresentam um desenvolvimento bastante pronunciado em relação às demais). Para nutrientes imóveis no solo, como o fosfato, uma maior eficiência de utilização é conseguida por um sistema radicular que apresente uma maior produção de raízes de ordem 3 e 4 em zonas de maior fertilidade no solo, devido à grande capacidade de absorção dessas raízes.

$\mathrm{Na}$ condição de menor teor de fósforo no solo, espera-se uma maximização da exploração do solo, na procura pelo recurso escasso, enquanto que na condição de maior teor de fósforo no solo, espera-se uma maximização da utilização do solo, para uso do recurso existente, estratégia conseguida através da priorização de crescimento da raiz principal e das basais, no primeiro caso, e das raízes de ordem 3, no segundo.

Conforme esperado, os dados experimentais e as imagens simuladas pelo modelo mostram uma alocação maior de fotossintatos para as raízes de ordem 1 e 2 (responsáveis pela exploração do solo em busca do recurso escasso) no tratamento com menor teor de $\mathrm{P}$ no solo, e uma alocação maior de fotossintatos para as raízes de ordem 3 (responsáveis pela utilização do recurso disponível no solo) no tratamento com maior teor de P no solo. 


\section{CONCLUSÕES}

A arquitetura radicular é um fator determinante no sucesso adaptativo de uma espécie em determinado ambiente, visto que mudanças arquiteturais no sistema radicular proporcionam à planta uma maior eficiência de exploração e utilização dos recursos do solo. A plasticidade do sistema radicular quanto à sua arquitetura permite que a planta destine uma fração mínima de fotoassimilados às raizes para conseguir a quantidade adequada de cada recurso do solo, em diferentes condições edafoclimáticas encontradas, possibilitando maiores rendimentos de frutos e sementes.

Há necessidade urgente de uso de ferramentas analíticas mais eficientes na caracterização e interpretação de sistemas radiculares. Estratégias adaptativas da planta ao ambiente edafoclimático resultam em diferentes arquiteturas radiculares. Tais estratégias podem passar despercebidas ou serem interpretadas incorretamente pelos métodos estatísticos clássicos de análise de médias e variâncias. $\mathrm{O}$ uso de ferramentas analíticas inadequadas pode inclusive induzir o pesquisador a medir dados inúteis e deixar de medir parâmetros fundamentais ao entendimento dos processos envolvidos.

A modelagem matemática representa uma promissora metodologia de análise de dados de sistemas radiculares, que possibilita uma adequada visualização, quantificação e interpretação de diferentes estratégias adaptativas da planta, conforme refletidas pelas diferentes arquiteturas radiculares produzidas em cada condição edafoclimática, principalmente se associada à análise de arquiteturas radiculares baseada em índices topológicos.

O modelo mecanístico de simulação é uma ferramenta útil no teste de hipóteses derivadas de resultados experimentais, permitindo um aumento na capacidade de entendimento de fenômenos naturais. $\mathrm{O}$ modelo pode ser utilizado na definição de prioridades de pesquisa e para ressaltar a necessidade de trabalho multidisciplinar em 
certas áreas, pois permite a identificação de pontos cujo conhecimento e entendimento ainda é falho.

O suprimento de água e nutrientes das plantas depende das interações entre os complexos processos fisiológicos e celulares ocorrentes no sistema radicular, que resultam numa arquitetura específica (habilidade da planta adquirir os recursos do solo), e dos não menos complexos processos iônicos e de transporte ocorrentes no solo (disponibilidade dos recursos do solo às raizes). $\mathrm{O}$ atual conhecimento e entendimento de tais processos e de suas interações ainda é insatisfatório, tomando-se urgente a união de forças entre pesquisadores trabalhando com fisiologia do crescimento radicular, caracterização experimental de sistemas radiculares, fisica, química e biologia de solos e profissionais trabalhando com modelagem matemática. 


\section{ANEXOS}

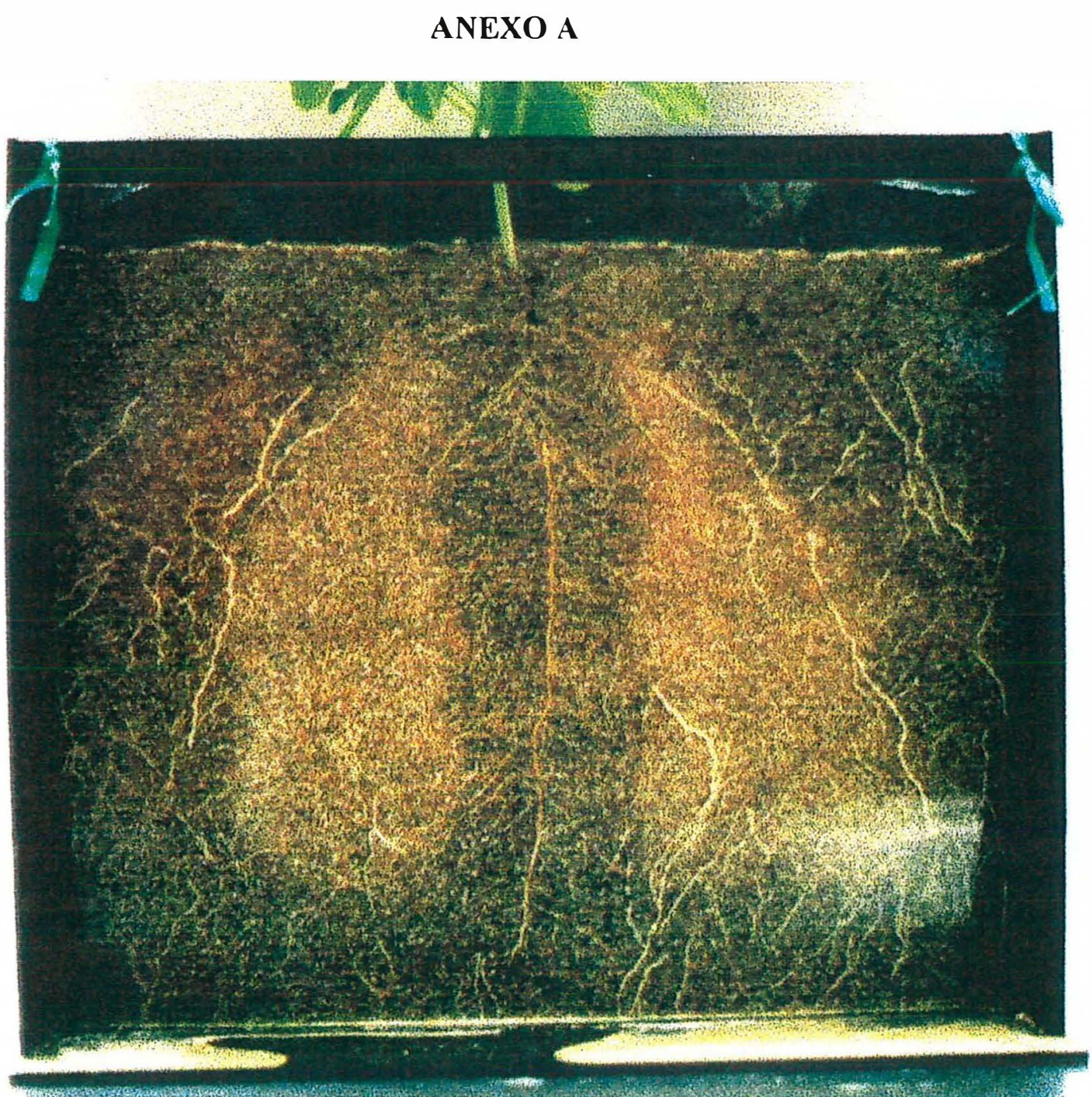

Figura 12. Caixa de acrílico com parede transparente 


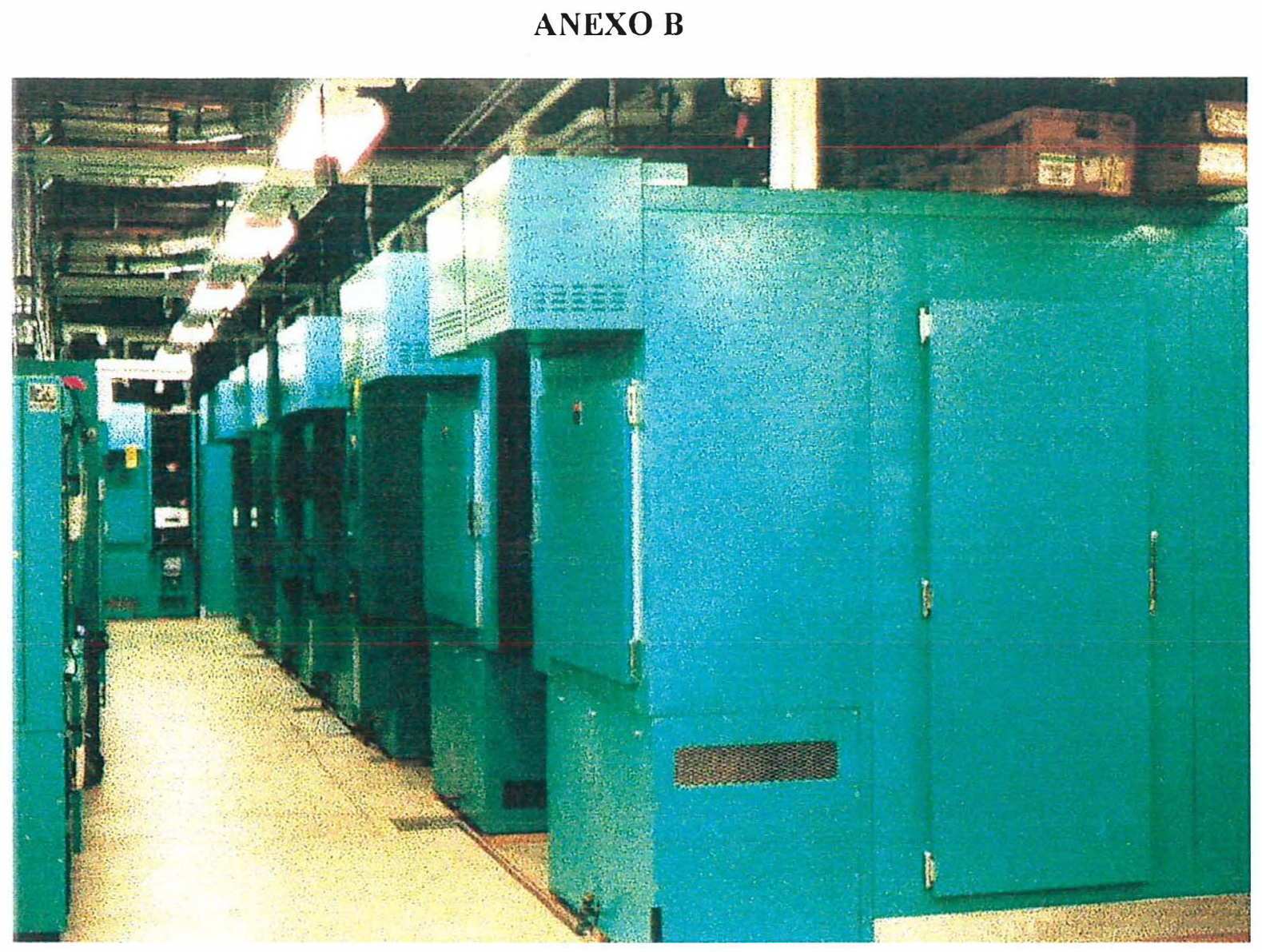

Figura 13. Câmaras de crescimento (Universidade da Califórnia, Davis, CA, EUA) 


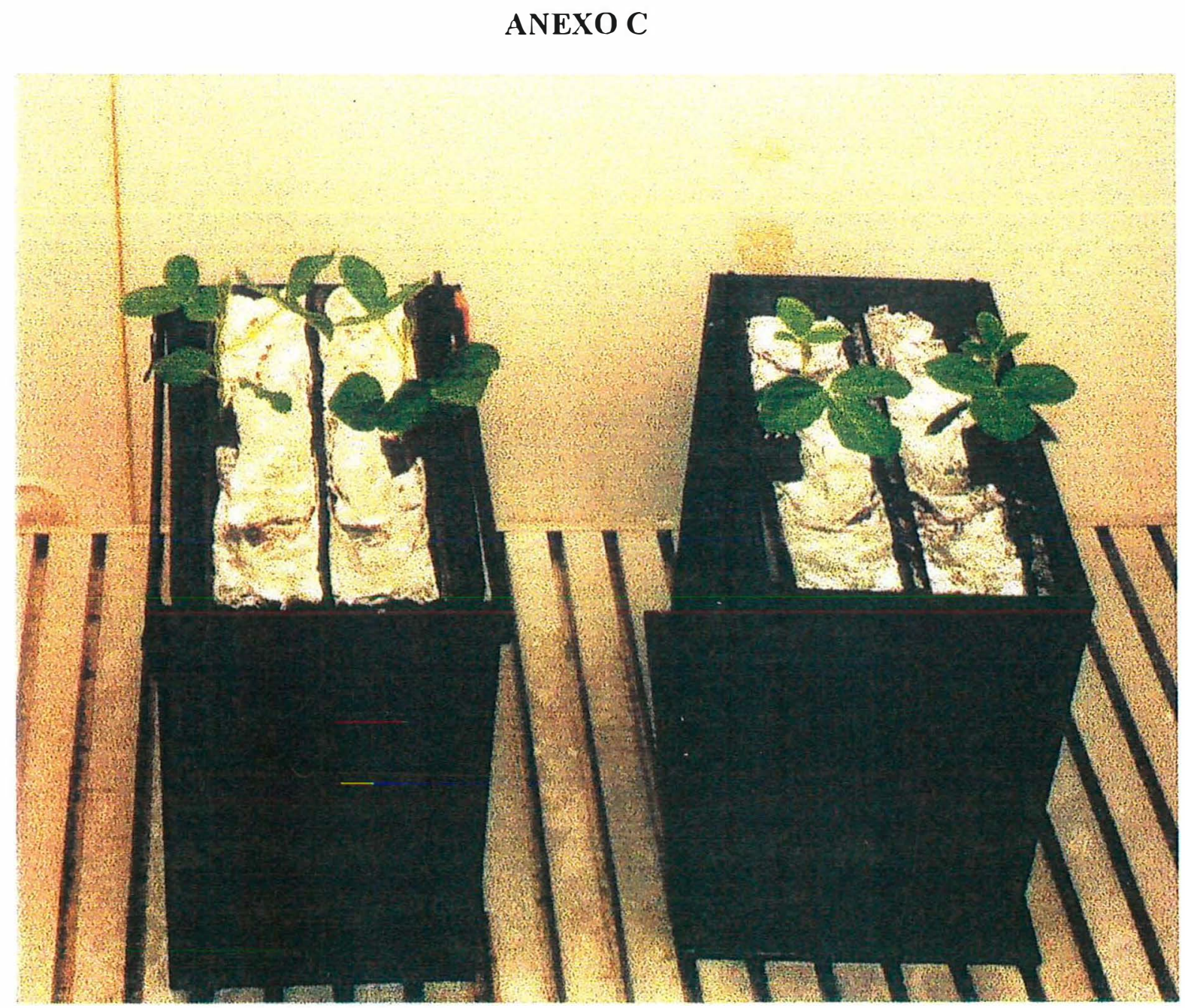

Figura 14. Caixas com plantas localizadas dentro de câmara de crescimento e com a superfície do solo selada para evitar evaporação de água 


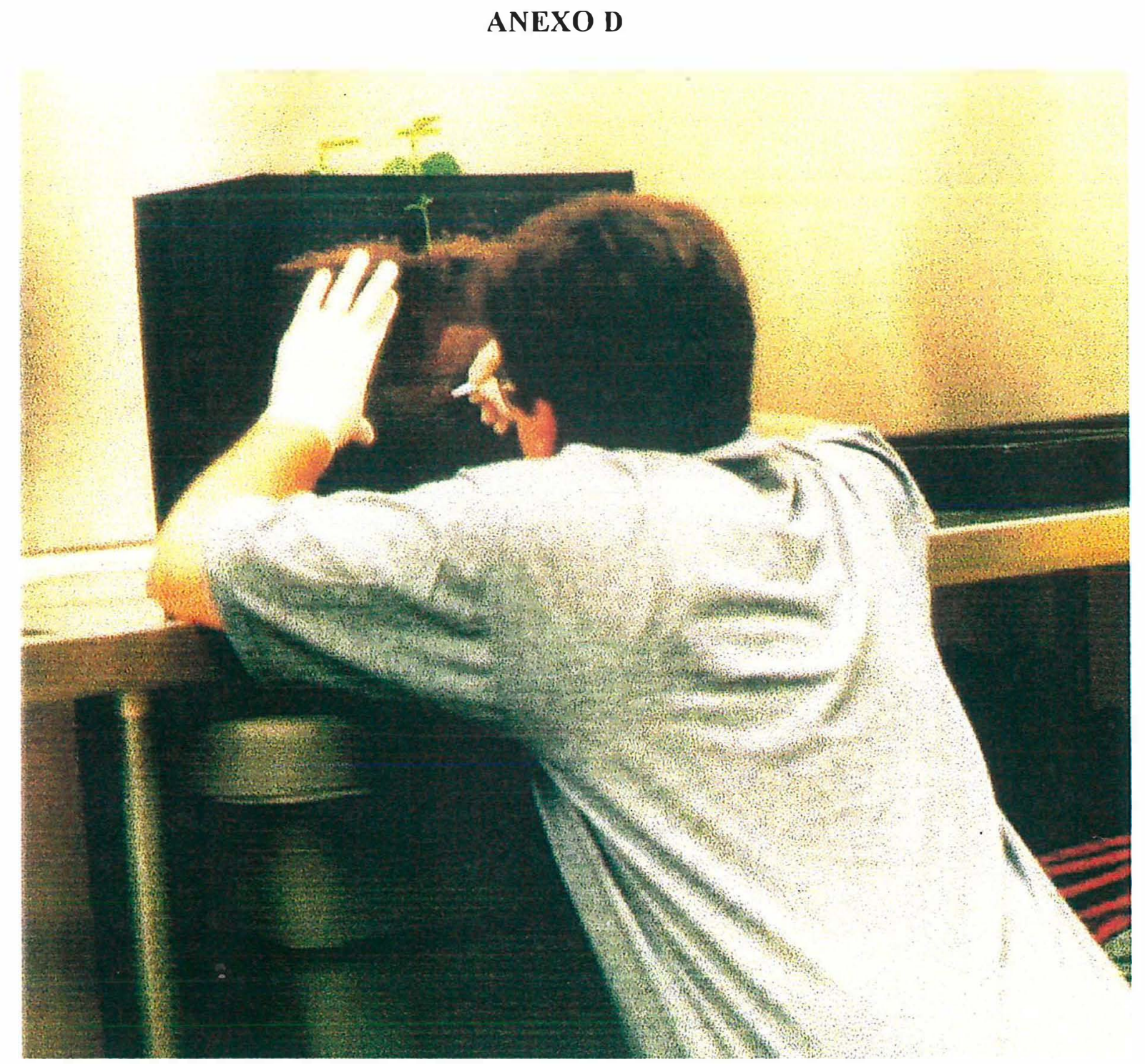

Figura 15. Procedimento de anotação dos ângulos de orientação e deflexão dos ramos radiculares 


\section{ANEXO E}

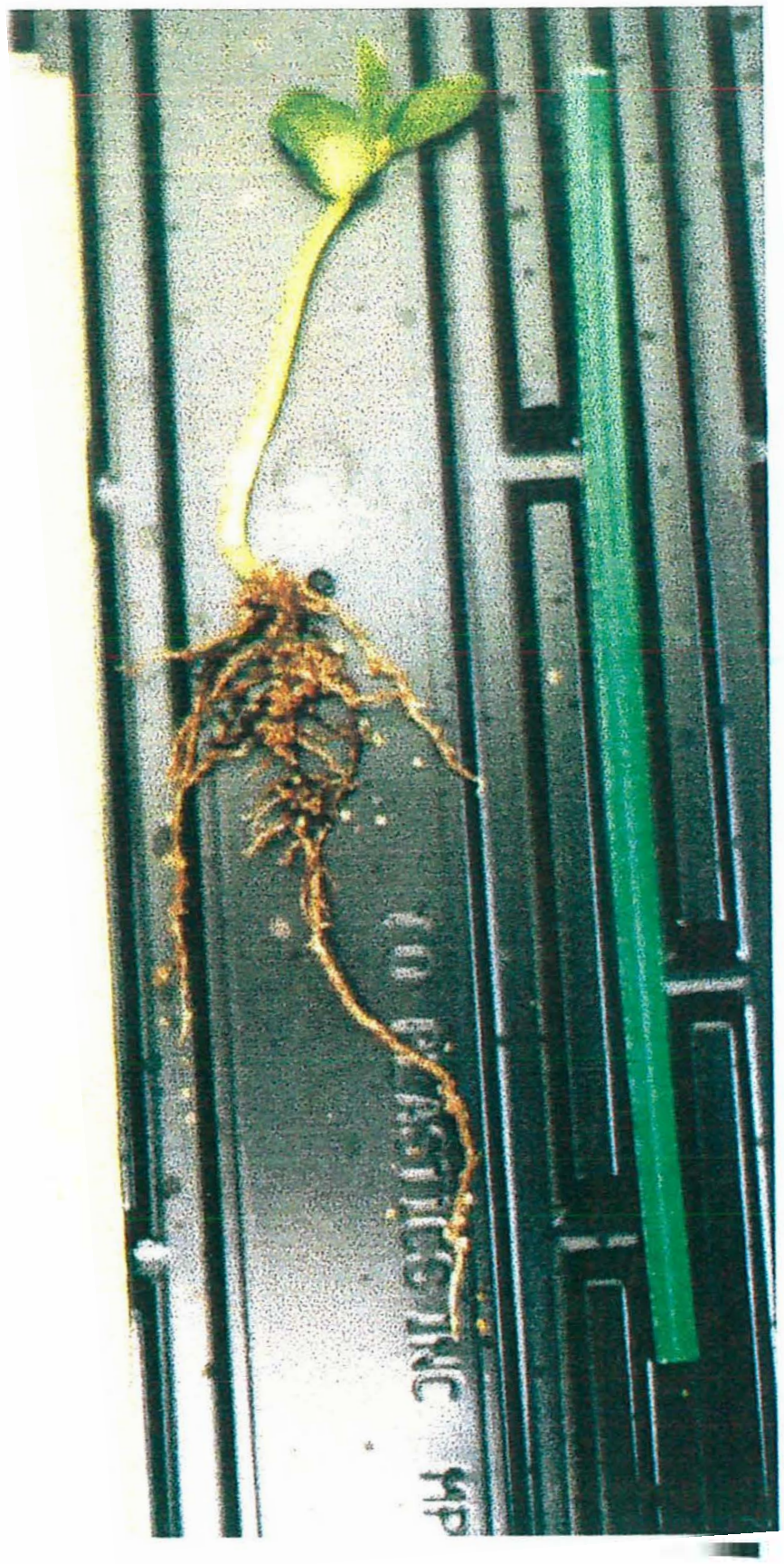

Figura 16. Sistema radicular de soja pronto para ser medido 


\section{ANEXO F}

Tabela 1. Valores médios de número de raizes para cada ordem e idade de planta, seguidos dos valores médios de comprimento de raizes para cada ordem e idade de planta 


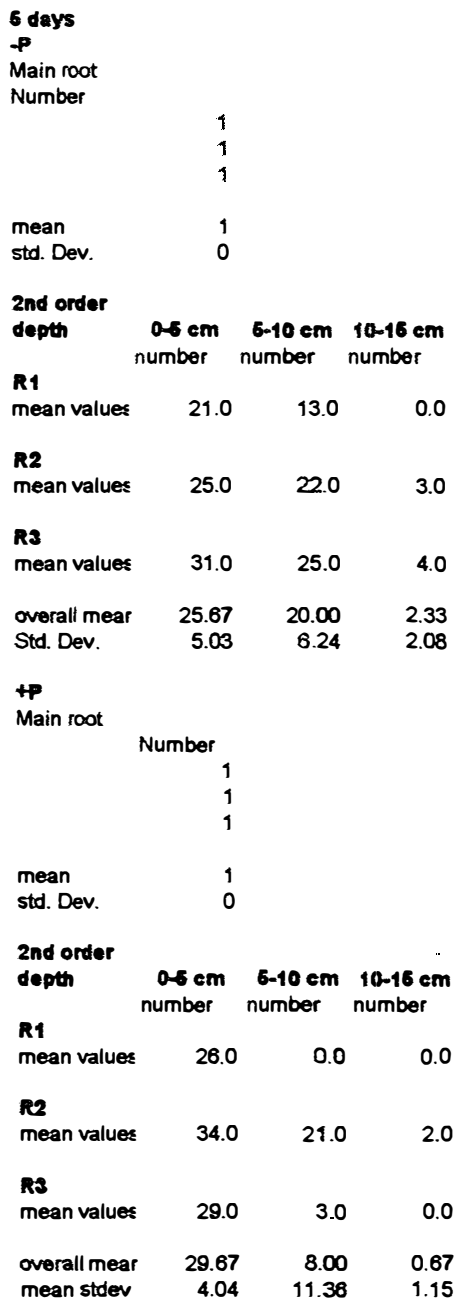




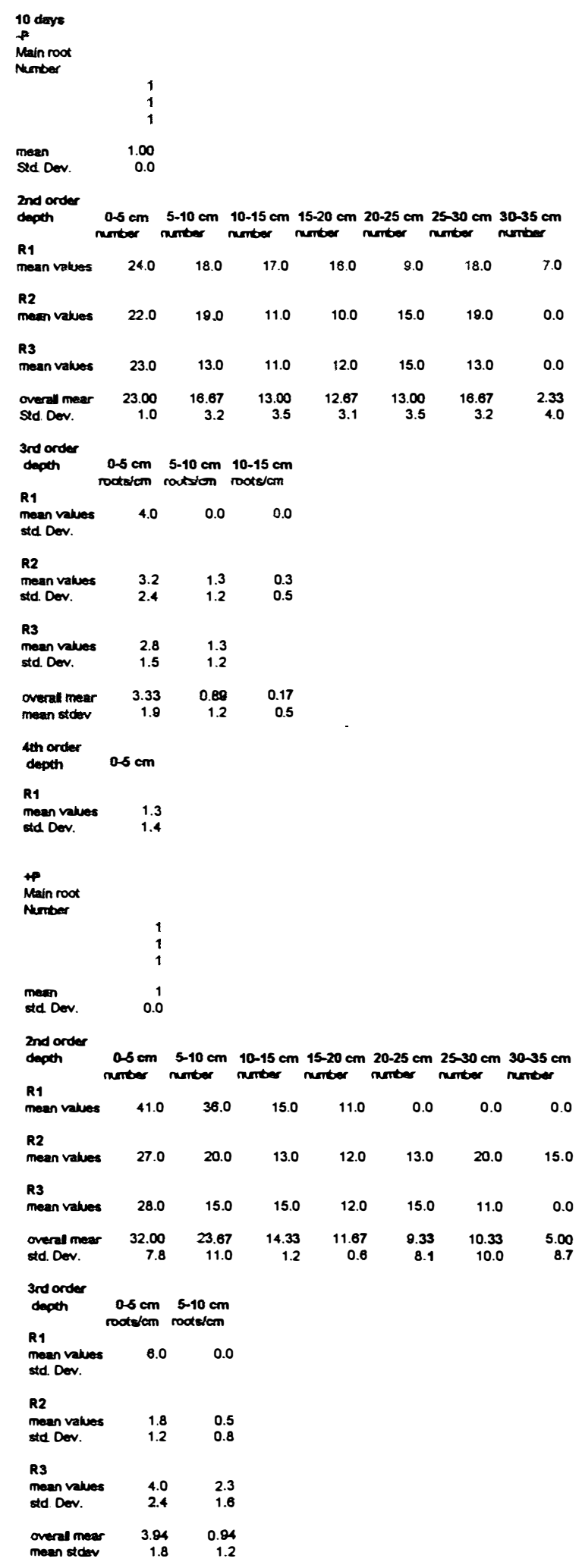




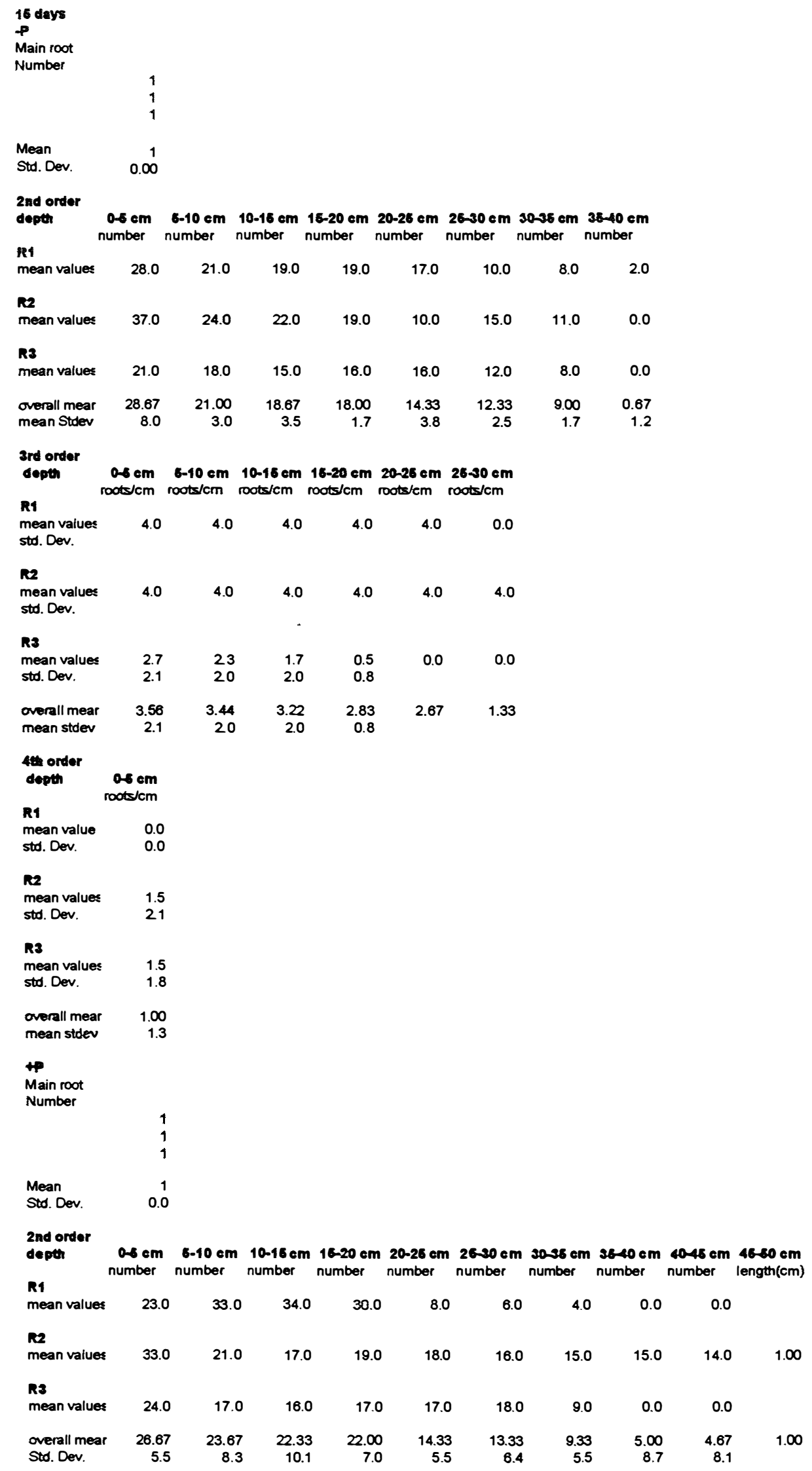




\begin{tabular}{|c|c|c|c|c|c|}
\hline $\begin{array}{l}\text { 3rd order } \\
\text { depth }\end{array}$ & $\begin{array}{l}0-8 \mathrm{~cm} \\
\mathrm{roots} / \mathrm{cm}\end{array}$ & $\begin{array}{l}5-10 \mathrm{~cm} \\
r 00 t 5 / \mathrm{cm}\end{array}$ & $\begin{array}{l}10-16 \mathrm{~cm} \\
100 t 5 / \mathrm{cm}\end{array}$ & $\begin{array}{l}16-20 \mathrm{~cm} \\
\mathrm{roots} / \mathrm{cm}\end{array}$ & $\begin{array}{l}20-26 \mathrm{~cm} \\
\text { roots } / \mathrm{cm}\end{array}$ \\
\hline $\begin{array}{l}\text { R1 } \\
\text { mean values } \\
\text { std. Dev. }\end{array}$ & $\begin{array}{l}6.0 \\
2.8\end{array}$ & $\begin{array}{l}4.0 \\
1.4\end{array}$ & $\begin{array}{l}2.5 \\
2.1\end{array}$ & $\begin{array}{l}1.8 \\
0.4\end{array}$ & 0.0 \\
\hline $\begin{array}{l}\text { R2 } \\
\text { mean values } \\
\text { std. Dev. }\end{array}$ & $\begin{array}{l}5.0 \\
0.0\end{array}$ & $\begin{array}{l}4.0 \\
0.0\end{array}$ & $\begin{array}{l}2.0 \\
0.0\end{array}$ & $\begin{array}{l}1.9 \\
0.0\end{array}$ & $\begin{array}{l}0.9 \\
0.0\end{array}$ \\
\hline $\begin{array}{l}\text { R3 } \\
\text { mean values } \\
\text { std. Dev. }\end{array}$ & $\begin{array}{l}3.8 \\
1.0\end{array}$ & $\begin{array}{l}2.0 \\
2.3\end{array}$ & $\begin{array}{l}1.0 \\
1.3\end{array}$ & $\begin{array}{l}1.5 \\
1.6\end{array}$ & $\begin{array}{l}1.5 \\
1.0\end{array}$ \\
\hline $\begin{array}{l}\text { overall mear } \\
\text { mean stdev }\end{array}$ & $\begin{array}{l}4.94 \\
1.27\end{array}$ & $\begin{array}{l}3.33 \\
1.23\end{array}$ & $\begin{array}{l}1.83 \\
1.13\end{array}$ & $\begin{array}{l}1.72 \\
0.67\end{array}$ & $\begin{array}{l}0.80 \\
0.52\end{array}$ \\
\hline $\begin{array}{l}\text { 4th order } \\
\text { depth }\end{array}$ & $\begin{array}{l}0.8 \mathrm{~cm} \\
r 00 t \mathrm{~cm} / \mathrm{cm}\end{array}$ & & & & \\
\hline $\begin{array}{l}\text { R1 } \\
\text { mean values } \\
\text { std. Dev. }\end{array}$ & 0.0 & & & & \\
\hline $\begin{array}{l}\text { R2 } \\
\text { mean values } \\
\text { std. Dev. }\end{array}$ & $\begin{array}{l}2.5 \\
0.7\end{array}$ & & & & \\
\hline $\begin{array}{l}\text { R3 } \\
\text { mean values } \\
\text { std. Dev. }\end{array}$ & $\begin{array}{l}0.8 \\
1.0\end{array}$ & & & & \\
\hline $\begin{array}{l}\text { overall mear } \\
\text { mean stdev }\end{array}$ & $\begin{array}{r}1.11 \\
0.8\end{array}$ & & & & \\
\hline
\end{tabular}




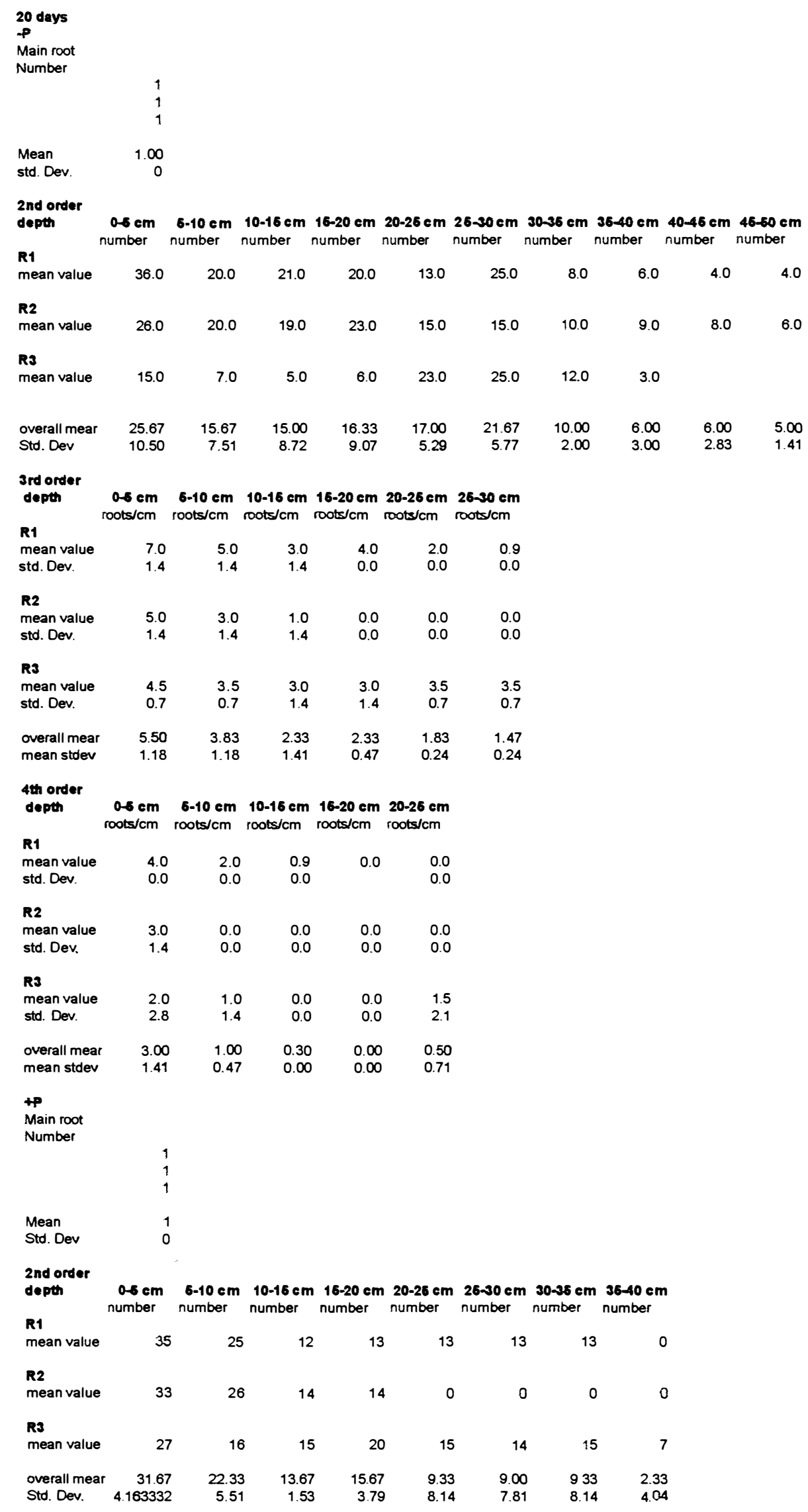




\begin{tabular}{|c|c|c|c|c|c|c|}
\hline $\begin{array}{l}\text { 3rd order } \\
\text { depth }\end{array}$ & $\begin{array}{l}0.6 \mathrm{~cm} \\
r 00 t s / \mathrm{cm}\end{array}$ & $\begin{array}{l}6-10 \mathrm{~cm} \\
\mathrm{roots} / \mathrm{cm}\end{array}$ & $\begin{array}{l}10-16 \mathrm{~cm} \\
\mathrm{roots} / \mathrm{cm}\end{array}$ & $\begin{array}{l}16-20 \mathrm{~cm} \\
\mathrm{roots} / \mathrm{cm}\end{array}$ & $\begin{array}{l}20-26 \mathrm{~cm} \\
\mathrm{roots} / \mathrm{cm}\end{array}$ & $\begin{array}{l}26-30 \mathrm{~cm} \\
\mathrm{roOts} / \mathrm{cm}\end{array}$ \\
\hline \multicolumn{7}{|c|}{ R4 } \\
\hline mean value & 5.0 & 5.0 & 3.0 & 2.0 & 1.9 & 0.0 \\
\hline std. Dev. & 1.4 & 1.4 & 1.4 & 0.0 & 0.0 & 0.0 \\
\hline \multicolumn{7}{|l|}{ R2 } \\
\hline mean value & 3.0 & 3.0 & 1.0 & 0.0 & 0.0 & 0.0 \\
\hline std. Dev. & 0.0 & 1.4 & 1.4 & 0.0 & 0.0 & 0.0 \\
\hline mean value & 4.0 & 3.0 & 2.0 & 2.5 & 2.5 & 2.0 \\
\hline std. Dev. & 0.0 & 1.4 & 2.8 & 0.7 & 0.7 & 2.8 \\
\hline overall mear & 4.00 & 3.67 & 2.00 & 1.50 & 1.47 & 0.67 \\
\hline mean stdev & 0.5 & 1.4 & 1.9 & 0.2 & 0.2 & 0.9 \\
\hline \multicolumn{7}{|l|}{ 4th order } \\
\hline depth & $\begin{array}{r}0.6 \mathrm{~cm} \\
r 00 t s / \mathrm{cm}\end{array}$ & $\begin{array}{l}6-10 \mathrm{~cm} \\
\mathrm{roots} / \mathrm{cm}\end{array}$ & $\begin{array}{l}10-16 \mathrm{~cm} \\
\text { roots } / \mathrm{cm}\end{array}$ & & & \\
\hline \multicolumn{7}{|c|}{ 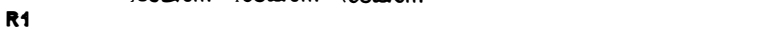 } \\
\hline mean value & 2.0 & 0.0 & 2.0 & & & \\
\hline std. Dev. & 2.8 & & 0.0 & & & \\
\hline \multicolumn{7}{|l|}{ R2 } \\
\hline mean value & 2.0 & 0.0 & 0.0 & & & \\
\hline std. Dev. & 0.0 & & 0.0 & & & \\
\hline \multicolumn{7}{|l|}{ R3 } \\
\hline mean value & 2.0 & 0.0 & 1.0 & & & \\
\hline std. Dev. & 2.8 & & 1.4 & & & \\
\hline $\begin{array}{l}\text { overall mear } \\
\text { mean stdev }\end{array}$ & $\begin{array}{r}2.00 \\
1.9\end{array}$ & 0.00 & $\begin{array}{r}1.00 \\
0.5\end{array}$ & & & \\
\hline
\end{tabular}




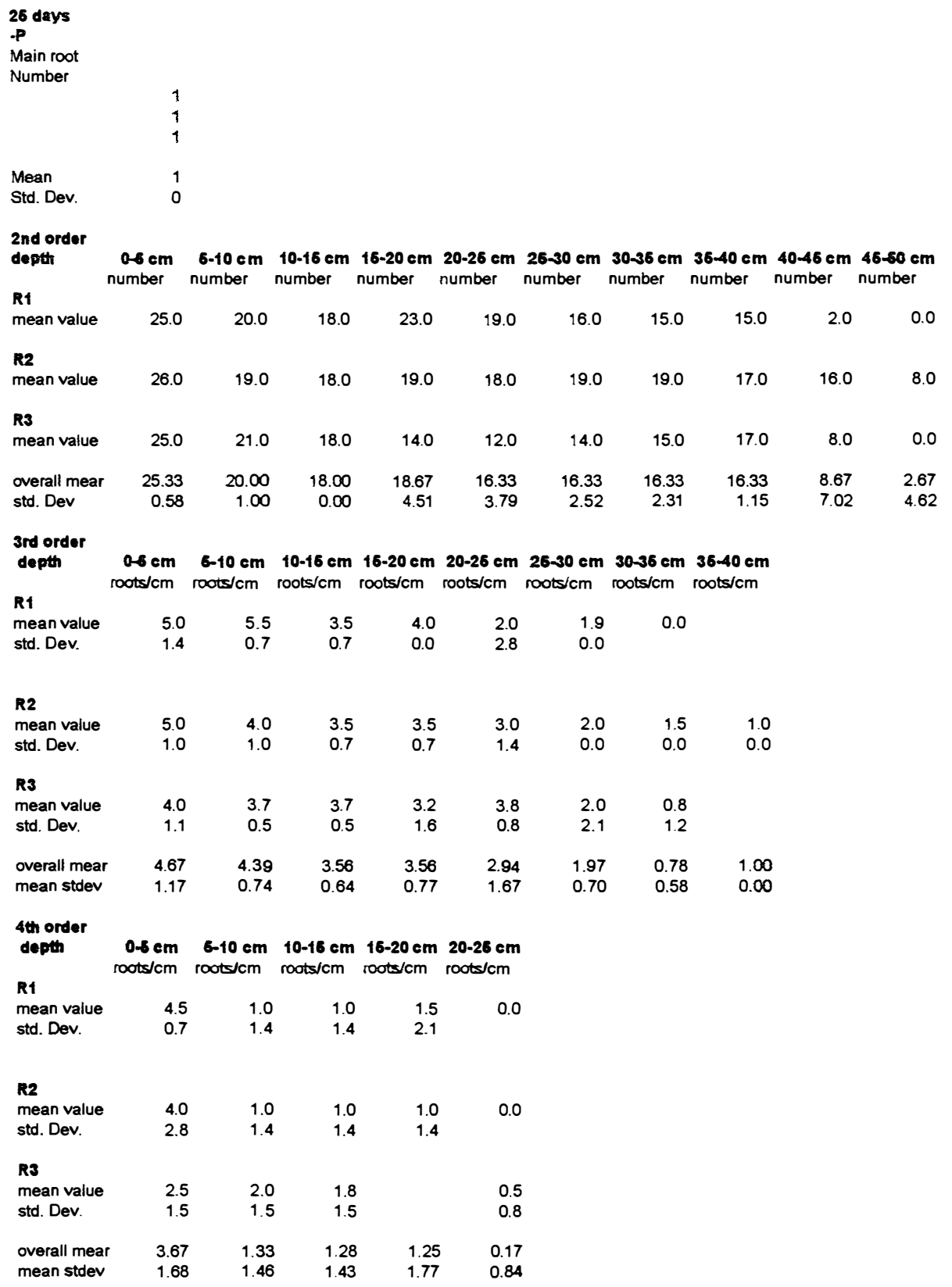


$+p$

Main root

Number

Mean

Std. Dev $\quad 0$

2nd order

depth $0.6 \mathrm{~cm}$

cm $10-16 \mathrm{~cm} 16-20 \mathrm{~cm} 20-26 \mathrm{~cm} 26-30 \mathrm{~cm} 30-36 \mathrm{~cm} 36-40 \mathrm{~cm} 40-46 \mathrm{~cm} 46-50 \mathrm{~cm} 60-66 \mathrm{~cm}$

mean value

R2

R3

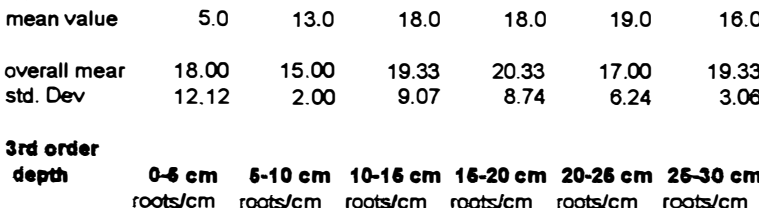

R1

$\begin{array}{lllllll}\text { mean value } & 4.5 & 0.9 & 0.9 & 3.0 & 0.9 & 0.0\end{array}$

std. Dev

$0.7 \quad 0.0$

mean value

std. Dev

R3

mean value

std. Dev

overall mear

mean stdev

4th order

depth

$0-6 \mathrm{~cm} \quad 6-10 \mathrm{~cm} \quad 10-16 \mathrm{~cm} \quad 16-20 \mathrm{~cm}$

R1

roots $/ \mathrm{cm}$ roots $/ \mathrm{cm}$ roots $/ \mathrm{cm}$ roots $/ \mathrm{cm}$

$\begin{array}{lllll}\text { mean value } & 4.00 & 0.00 & 0.00 & 0.00\end{array}$

$\begin{array}{lllll}\text { std. Dev } & 0.00 & 0.00 & 0.00 & 0.00\end{array}$

R2

mean value $\quad 2.00$

std. Dev 2.83

R3

mean value $\quad 1.67 \quad 1.00$

$\begin{array}{lll}\text { std. Dev } & 1.21 & 0.89\end{array}$

$\begin{array}{lllll}\text { overall mear } & 2.56 & 0.00 & 0.00 & 0.50\end{array}$

$\begin{array}{lllll}\text { mean stdev } & 1.35 & 0.00 & 0.00 & 0.45\end{array}$




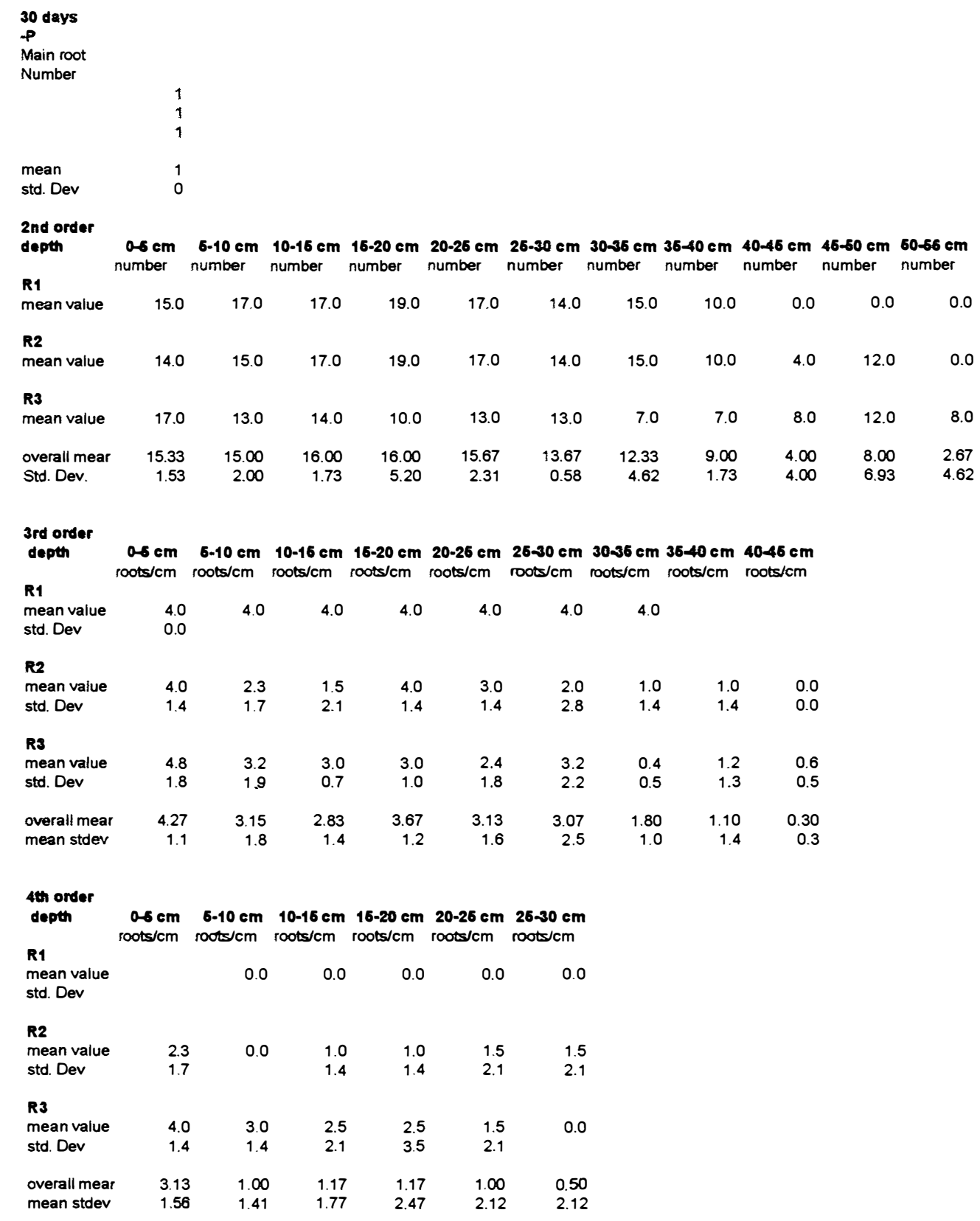




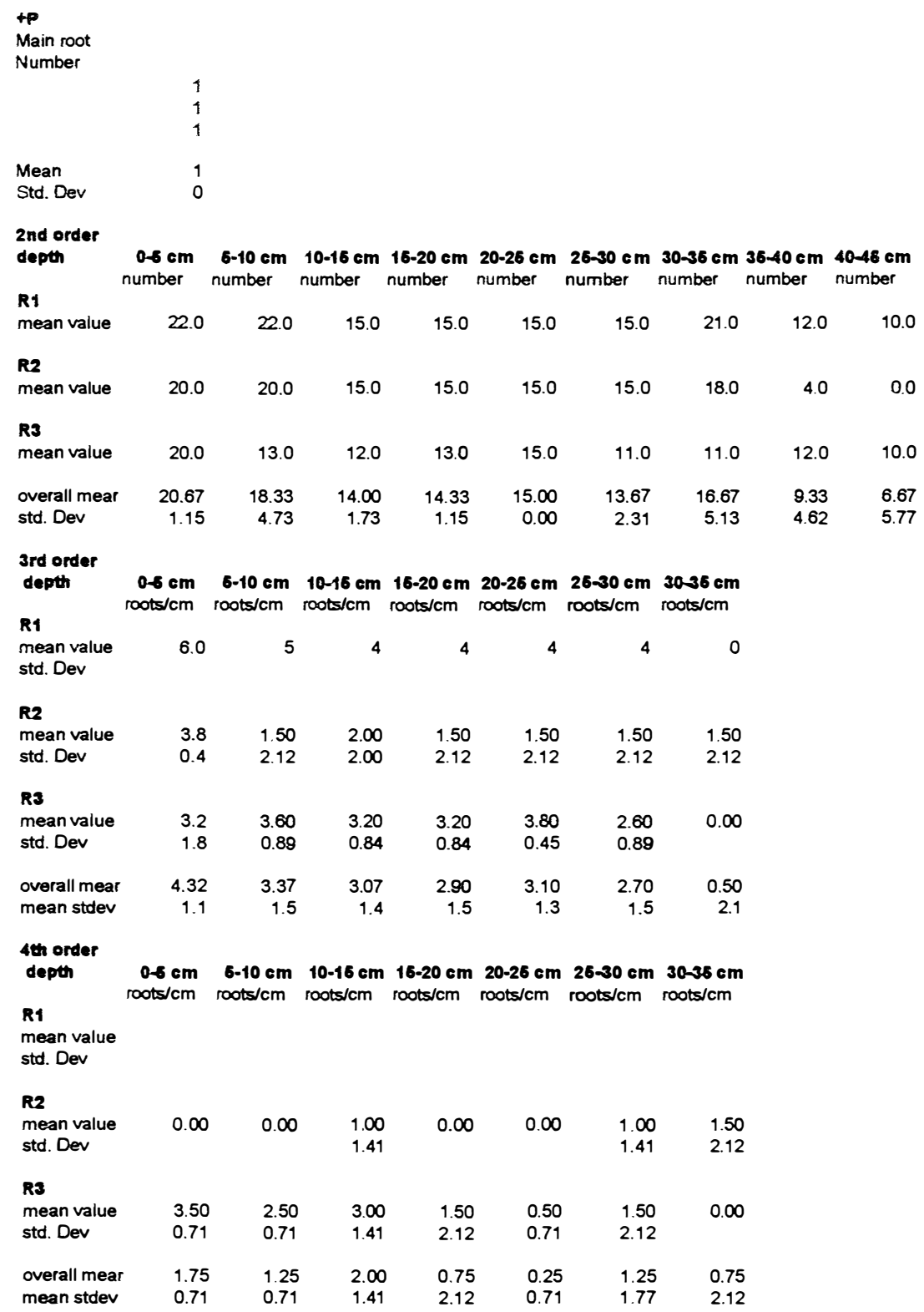




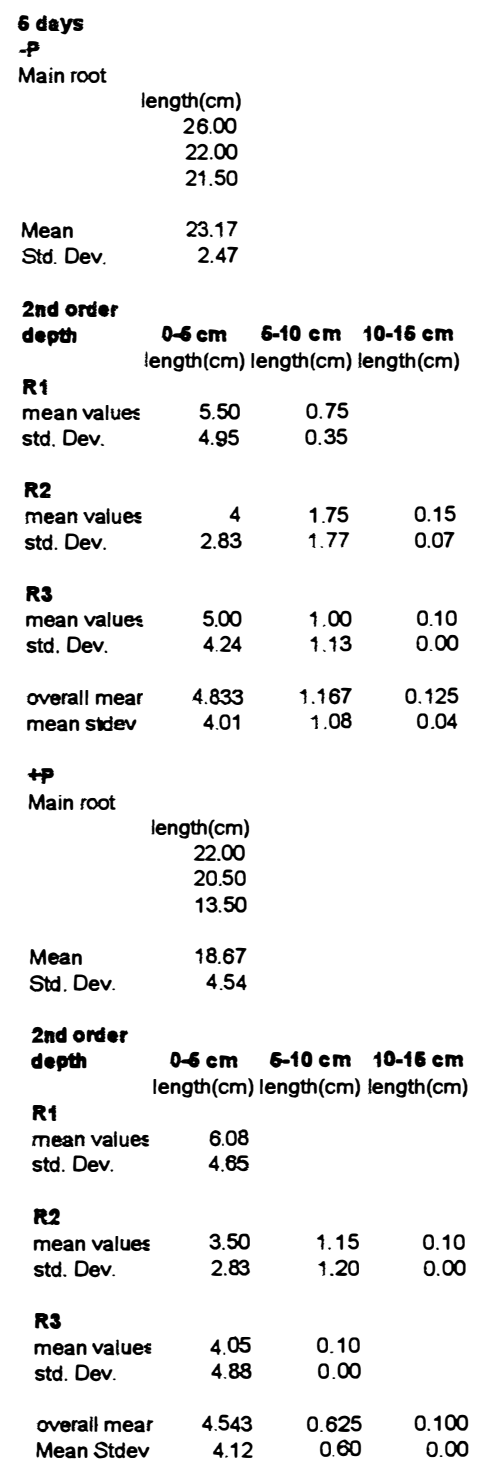




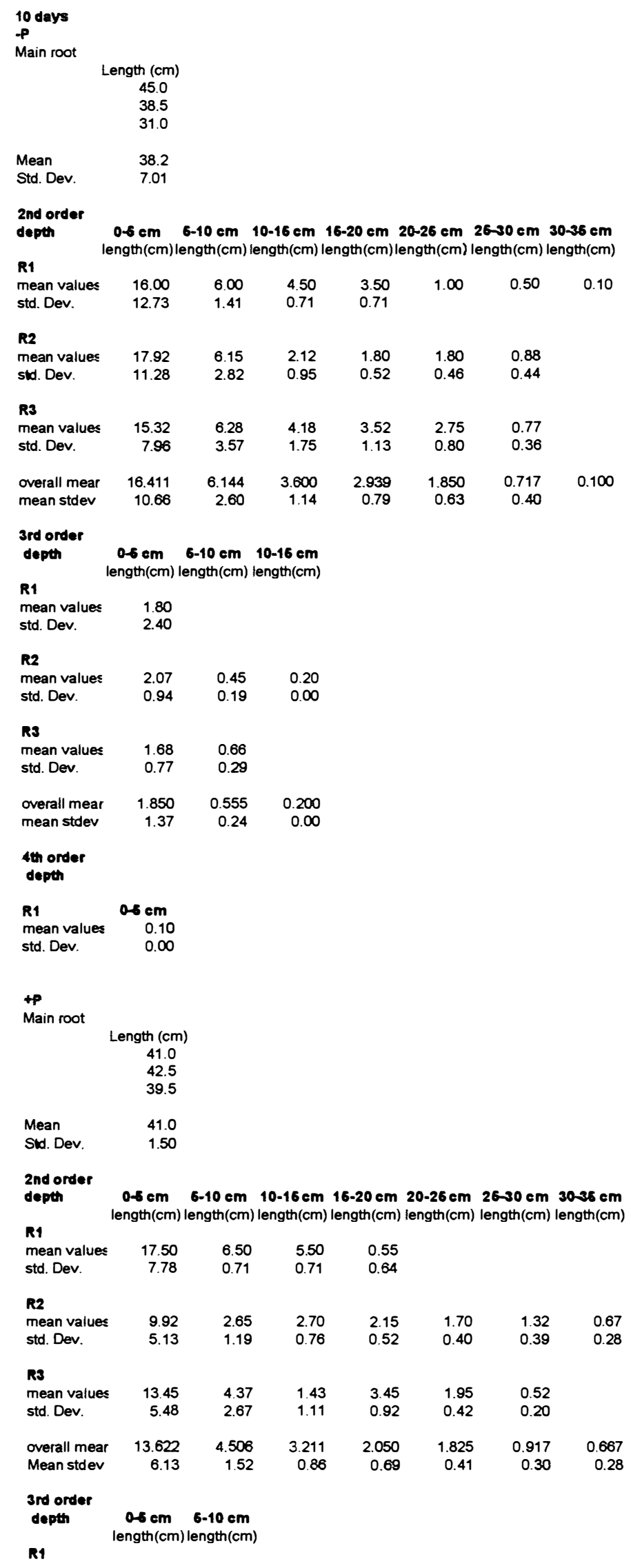




\begin{tabular}{|c|c|c|}
\hline $\begin{array}{l}\text { mean values } \\
\text { std. Dev. }\end{array}$ & $\begin{array}{l}1.80 \\
2.40\end{array}$ & \\
\hline \multicolumn{3}{|l|}{ R2 } \\
\hline $\begin{array}{l}\text { mean values } \\
\text { std. Dev. }\end{array}$ & $\begin{array}{l}0.55 \\
0.21\end{array}$ & $\begin{array}{l}0.20 \\
0.13\end{array}$ \\
\hline \multicolumn{3}{|l|}{$\mathbf{R} 3$} \\
\hline $\begin{array}{l}\text { mean values } \\
\text { std. Dev. }\end{array}$ & 2.35 & $0 . \infty$ \\
\hline std. Dev. & 0.68 & 0.31 \\
\hline overall $\pi$ & 1.567 & 0.400 \\
\hline mean stdev & 1.10 & 0.22 \\
\hline
\end{tabular}




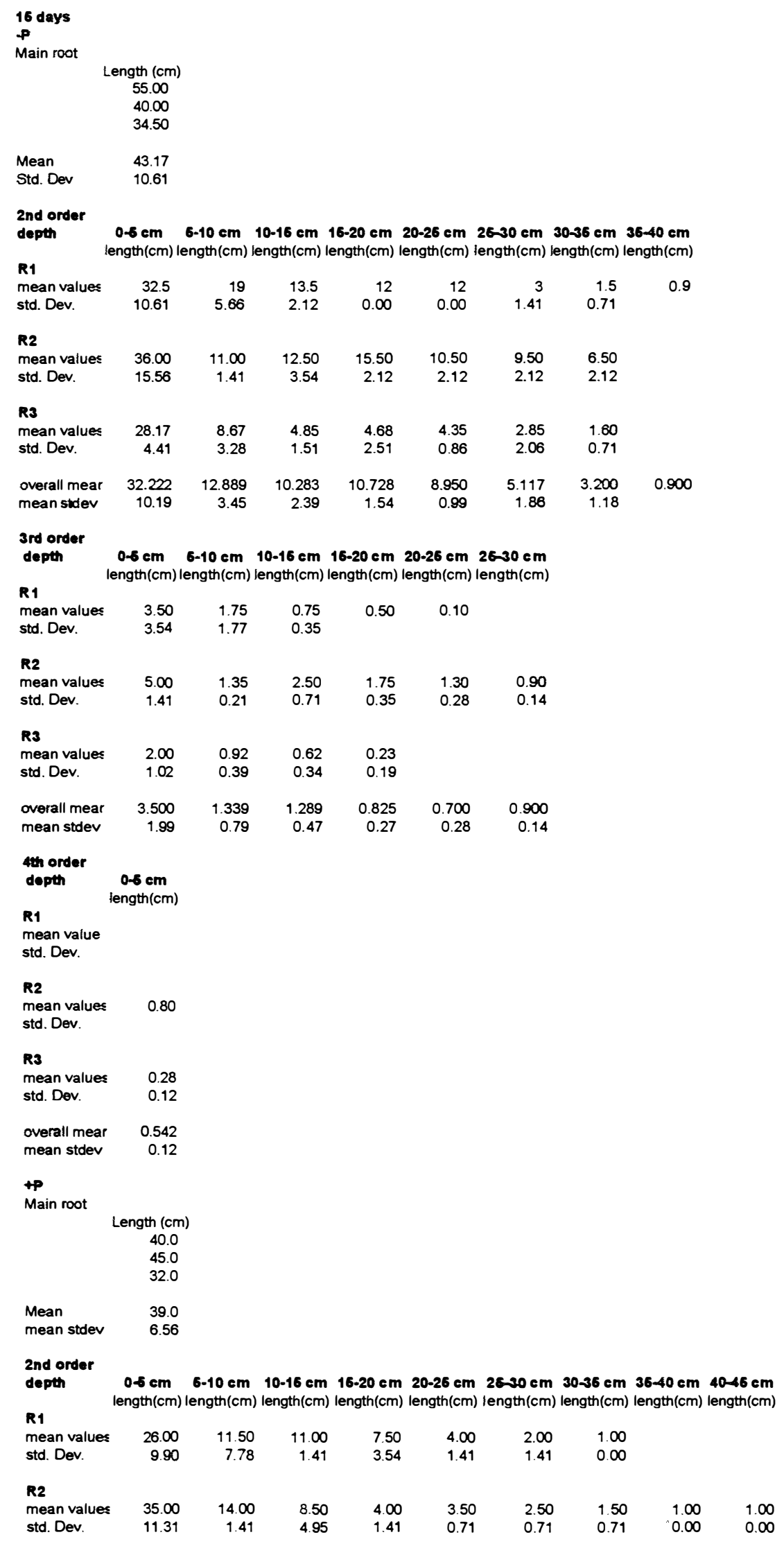

R3 


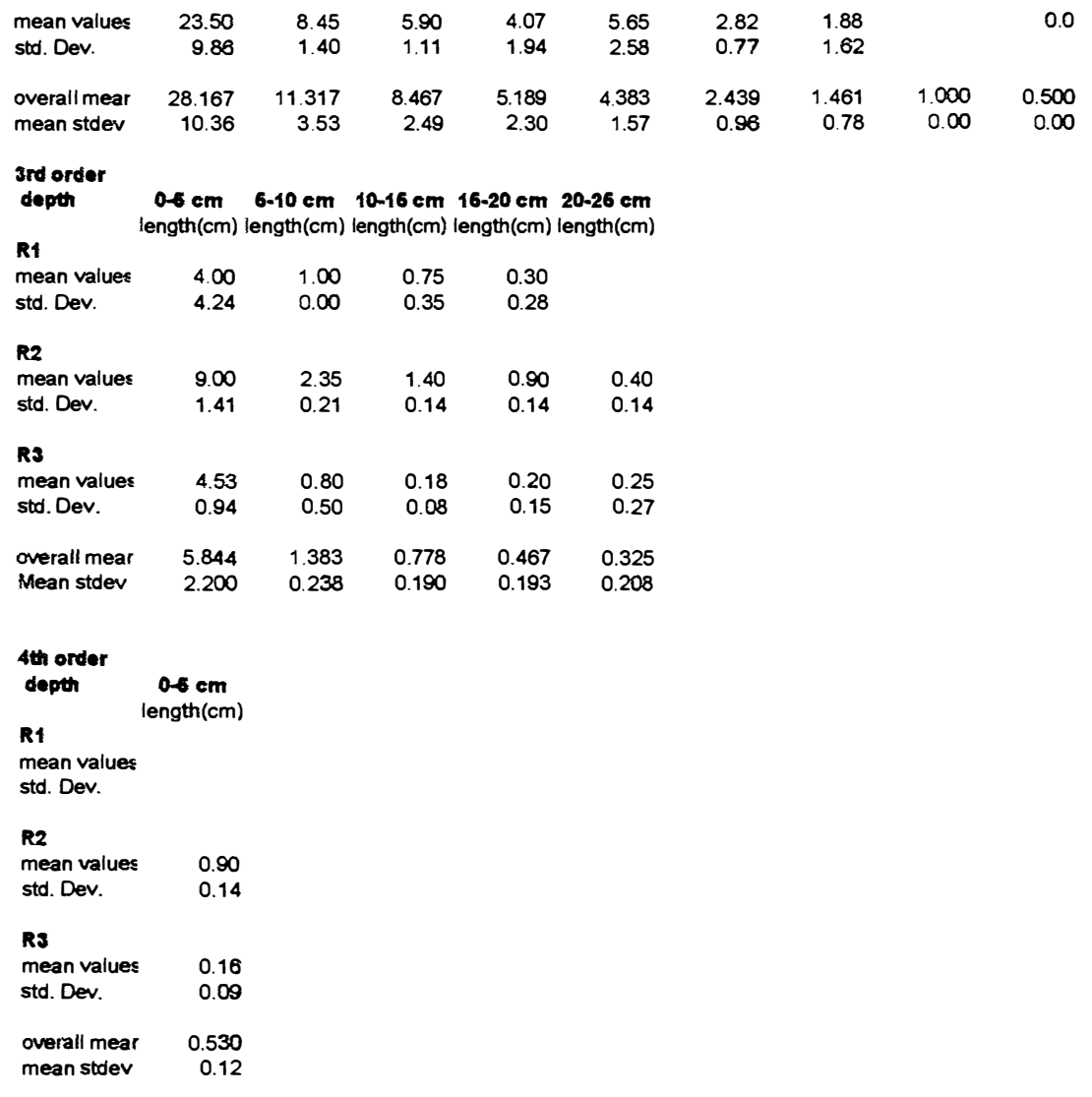




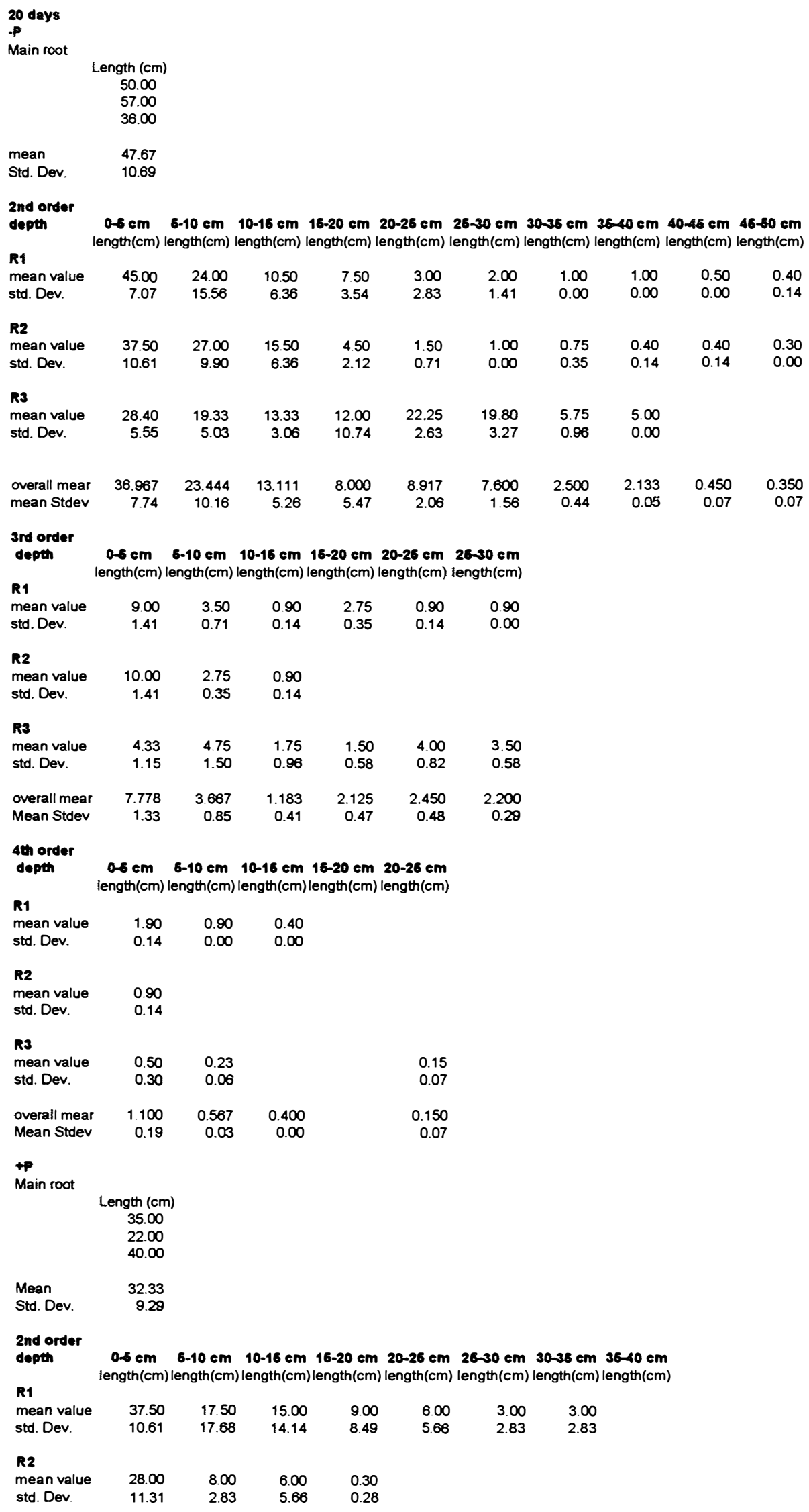




\begin{tabular}{|c|c|c|c|c|c|c|c|c|}
\hline \multicolumn{9}{|l|}{ R3 } \\
\hline $\begin{array}{l}\text { mean value } \\
\text { std. Dev }\end{array}$ & $\begin{array}{r}37.20 \\
9.93\end{array}$ & $\begin{array}{r}12.60 \\
1.67\end{array}$ & $\begin{array}{r}11.60 \\
3.65\end{array}$ & $\begin{array}{l}3.40 \\
1.67\end{array}$ & $\begin{array}{r}18.00 \\
5.43\end{array}$ & $\begin{array}{r}14.20 \\
7.26\end{array}$ & $\begin{array}{l}7.60 \\
3.65\end{array}$ & $\begin{array}{l}2.00 \\
0.71\end{array}$ \\
\hline $\begin{array}{l}\text { overall mear } \\
\text { mean stdev }\end{array}$ & $\begin{array}{r}34.233 \\
10.62\end{array}$ & $\begin{array}{r}12.700 \\
7.39\end{array}$ & $\begin{array}{r}10.867 \\
7.82\end{array}$ & $\begin{array}{r}4.233 \\
3.48\end{array}$ & $\begin{array}{r}12.000 \\
5.54\end{array}$ & $\begin{array}{r}8.600 \\
5.04\end{array}$ & $\begin{array}{r}5.300 \\
3.24\end{array}$ & $\begin{array}{r}2.000 \\
0.71\end{array}$ \\
\hline $\begin{array}{l}\text { 3rd order } \\
\text { depth }\end{array}$ & $\begin{array}{l}0.5 \mathrm{~cm} \\
\text { length }(\mathrm{cm}) \mathrm{le}\end{array}$ & $\begin{array}{l}6-10 \mathrm{~cm} \\
\text { length }(\mathrm{cm}) \mathrm{l}\end{array}$ & $\begin{array}{l}10-16 \mathrm{~cm} \\
\text { length }(\mathrm{cm}) \mid\end{array}$ & $\begin{array}{l}16-20 \mathrm{~cm} \\
\text { length }(\mathrm{cm}) \mid\end{array}$ & $\begin{array}{l}20-26 \mathrm{~cm} \\
\text { length }(\mathrm{cm}) \text { ! }\end{array}$ & $\begin{array}{l}26-30 \mathrm{~cm} \\
\text { length }(\mathrm{cm})\end{array}$ & & \\
\hline $\begin{array}{l}\text { R1 } \\
\text { mean value } \\
\text { std. Dev }\end{array}$ & $\begin{array}{l}9.00 \\
1.41\end{array}$ & $\begin{array}{l}2.40 \\
0.85\end{array}$ & $\begin{array}{l}3.50 \\
0.71\end{array}$ & $\begin{array}{l}0.90 \\
0.14\end{array}$ & $\begin{array}{l}0.90 \\
0.14\end{array}$ & & & \\
\hline $\begin{array}{l}\text { R2 } \\
\text { mean value } \\
\text { std. Dev. }\end{array}$ & $\begin{array}{r}14.00 \\
1.41\end{array}$ & $\begin{array}{l}1.90 \\
0.14\end{array}$ & $\begin{array}{l}0.40 \\
0.14\end{array}$ & & & & & \\
\hline $\begin{array}{l}\text { mean value } \\
\text { std. Dev. }\end{array}$ & $\begin{array}{l}8.67 \\
2.58\end{array}$ & $\begin{array}{l}1.23 \\
0.25\end{array}$ & $\begin{array}{l}1.50 \\
0.50\end{array}$ & $\begin{array}{l}1.33 \\
1.04\end{array}$ & $\begin{array}{l}3.00 \\
1.58\end{array}$ & $\begin{array}{l}0.93 \\
0.40\end{array}$ & & \\
\hline $\begin{array}{l}\text { overall mear } \\
\text { Mean Stdev }\end{array}$ & $\begin{array}{r}10.556 \\
1.80\end{array}$ & $\begin{array}{r}1.844 \\
0.41\end{array}$ & $\begin{array}{r}1.800 \\
0.45\end{array}$ & $\begin{array}{r}1.117 \\
0.59\end{array}$ & $\begin{array}{r}1.950 \\
0.86\end{array}$ & $\begin{array}{r}0.933 \\
0.40\end{array}$ & & \\
\hline $\begin{array}{l}\text { 4th order } \\
\text { depth }\end{array}$ & $\begin{array}{c}0-5 \mathrm{~cm} \\
\text { length }(\mathrm{cm})\end{array}$ & $\begin{array}{l}6-10 \mathrm{~cm} \\
\text { length }(\mathrm{cm}) \mid\end{array}$ & $\begin{array}{l}10-16 \mathrm{~cm} \\
\text { length }(\mathrm{cm})\end{array}$ & & & & & \\
\hline $\begin{array}{l}\text { R1 } \\
\text { mean value } \\
\text { std. Dev. }\end{array}$ & $\begin{array}{l}1.90 \\
0.14\end{array}$ & & $\begin{array}{l}0.45 \\
0.07\end{array}$ & & & & & \\
\hline $\begin{array}{l}\text { R2 } \\
\text { mean value } \\
\text { std. Dev. }\end{array}$ & $\begin{array}{l}0.90 \\
0.14\end{array}$ & & & & & & & \\
\hline $\begin{array}{l}\text { R3 } \\
\text { mean value } \\
\text { std. Dev. }\end{array}$ & $\begin{array}{l}0.27 \\
0.21\end{array}$ & & $\begin{array}{l}0.10 \\
0.00\end{array}$ & & & & & \\
\hline $\begin{array}{l}\text { overall mear } \\
\text { mean stdev }\end{array}$ & $\begin{array}{r}1.022 \\
0.16\end{array}$ & & $\begin{array}{r}0.275 \\
0.04\end{array}$ & & & & & \\
\hline
\end{tabular}




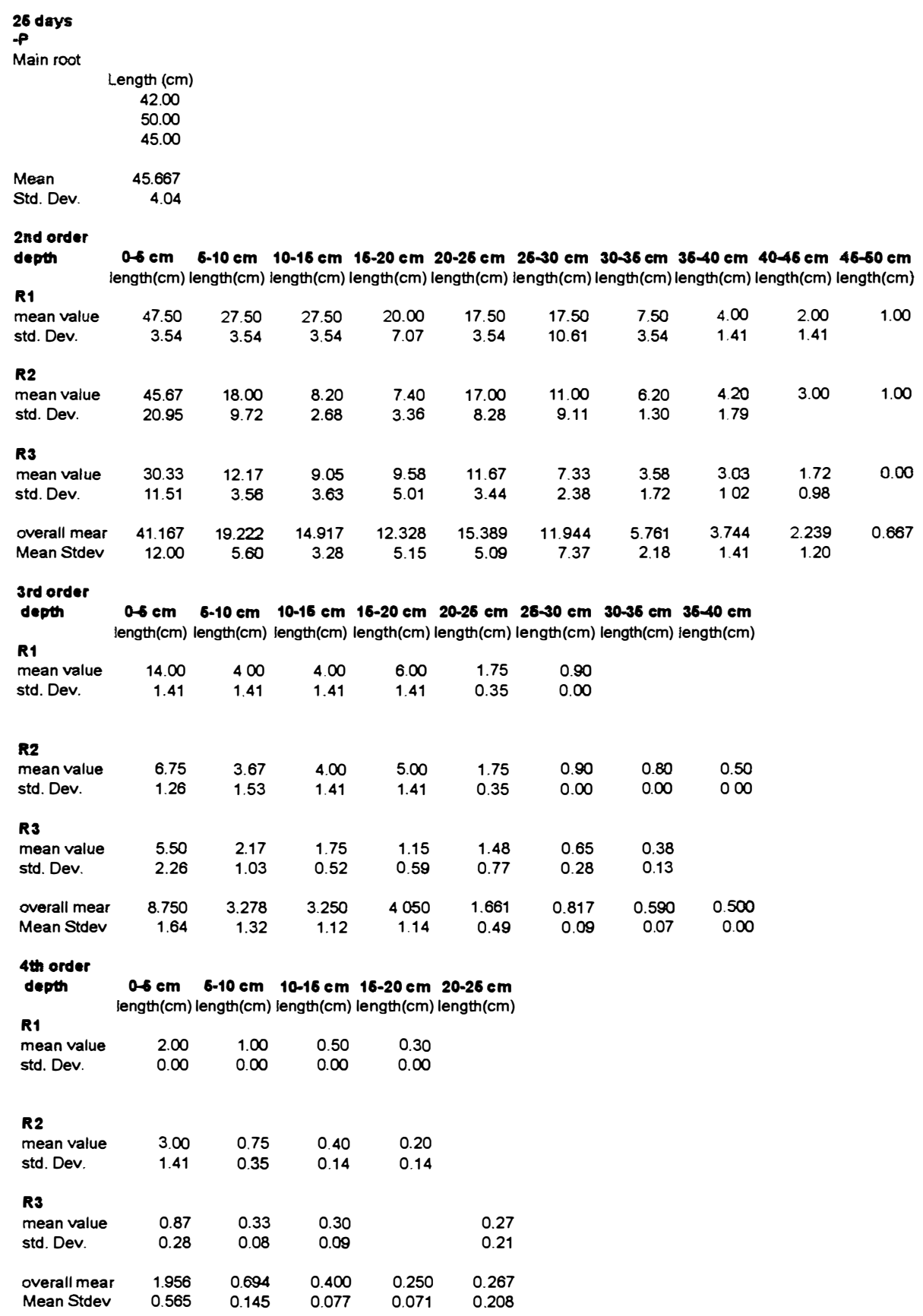


$+$

Main root

Length $(\mathrm{cm})$

39.00

49.00

60.00

Mean 49.333

Std. Dev. $\quad 10.50$

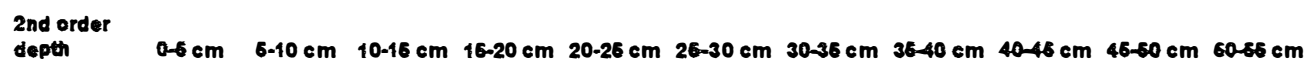

length $(\mathrm{cm})$ length $(\mathrm{cm})$ length $(\mathrm{cm})$ length $(\mathrm{cm})$ length $(\mathrm{cm})$ length $(\mathrm{cm})$ length $(\mathrm{cm})$ length $(\mathrm{cm})$ length $(\mathrm{cm})$ length $(\mathrm{cm})$ length $(\mathrm{cm})$

$\begin{array}{lrrrrrrrr}\text { mean value } & 52.50 & 27.50 & 27.50 & 27.50 & 17.50 & 12.50 & 11.50 & 10.00 \\ \text { std. Dev } & 10.61 & 3.54 & 3.54 & 3.54 & 3.54 & 3.54 & 2.12 & 0.00\end{array}$

mean value $\quad 53.40 \quad 7.40$

$\begin{array}{lllllllll}7.40 & 7.40 & 7.40 & 14.00 & 19.00 & 19.00 & 7.00 & 5.00 & 5.00\end{array}$

$10.36 \quad 2$.

R3

mean value 21.80

std. Dev

1.92

7.40
2.88
4.5

$\begin{array}{rrr}7.40 & 14.00 & 19.00 \\ 2.88 & 5.29 & 7 . \\ 6 & 6 & \end{array}$

overall mear $\quad 42.567 \quad 12.272 \quad 13.32$

$\begin{array}{llll}5.08 & 10.50 & 6.50 & 7.58\end{array}$

Mean Stdev

$12.84 \quad 2.43$

2.73

6.09

$1.05-7.58$

19.00
7.39
4.5

$\begin{array}{llll}5.83 & 3.75 & 4.25 & 1.75\end{array}$

1.00

$\begin{array}{rrrrrrrr}15.133 & 12.667 & 13.028 & 12.111 & 6.917 & 4.625 & 3.375 & 1.000\end{array}$ 


\begin{tabular}{|c|c|c|c|c|c|c|}
\hline depth & $\begin{array}{c}0-6 \mathrm{~cm} \\
\text { length }(\mathrm{cm})\end{array}$ & $\begin{array}{c}6-10 \mathrm{~cm} \\
\text { length }(\mathrm{cm})\end{array}$ & $\begin{array}{l}10-16 \mathrm{~cm} \\
\text { length }(\mathrm{cm})\end{array}$ & $\begin{array}{l}16-20 \mathrm{~cm} \\
\text { length }(\mathrm{cm})\end{array}$ & $\begin{array}{l}20-26 \mathrm{~cm} \\
\text { length }(\mathrm{cm})\end{array}$ & $\begin{array}{l}26-30 \mathrm{~cm} \\
\text { length }(\mathrm{cm})\end{array}$ \\
\hline $\begin{array}{l}\mathbf{R 1} \\
\text { mean value } \\
\text { std. Dev }\end{array}$ & $\begin{array}{r}17.50 \\
3.54\end{array}$ & $\begin{array}{l}1.75 \\
0.35\end{array}$ & $\begin{array}{l}2.50 \\
0.71\end{array}$ & $\begin{array}{l}1.75 \\
0.35\end{array}$ & $\begin{array}{l}0.40 \\
0.14\end{array}$ & \\
\hline $\begin{array}{l}\mathbf{R 2} \\
\text { mean value } \\
\text { std. Dev }\end{array}$ & $\begin{array}{r}17.50 \\
3.54\end{array}$ & $\begin{array}{l}0.90 \\
0.00\end{array}$ & $\begin{array}{l}0.90 \\
0.00\end{array}$ & $\begin{array}{l}0.90 \\
0.00\end{array}$ & $\begin{array}{l}0.95 \\
0.07\end{array}$ & $\begin{array}{l}1.75 \\
0.35\end{array}$ \\
\hline $\begin{array}{l}\text { R3 } \\
\text { mean value } \\
\text { std. Dov }\end{array}$ & $\begin{array}{l}5.83 \\
1.40\end{array}$ & $\begin{array}{l}0.65 \\
0.21\end{array}$ & $\begin{array}{l}0.57 \\
0.12\end{array}$ & $\begin{array}{l}2.23 \\
0.94\end{array}$ & $\begin{array}{l}2.20 \\
0.97\end{array}$ & $\begin{array}{l}0.87 \\
0.16\end{array}$ \\
\hline $\begin{array}{l}\text { overall mear } \\
\text { Mean Stdev }\end{array}$ & $\begin{array}{r}13.611 \\
2.82\end{array}$ & $\begin{array}{r}1.100 \\
0.19\end{array}$ & $\begin{array}{r}1.322 \\
0.28\end{array}$ & $\begin{array}{r}1.628 \\
0.43\end{array}$ & $\begin{array}{r}1.183 \\
0.39\end{array}$ & $\begin{array}{r}1.308 \\
0.26\end{array}$ \\
\hline $\begin{array}{l}\text { 4th order } \\
\text { depth }\end{array}$ & $\begin{array}{l}0-6 \mathrm{~cm} \\
\text { length }(\mathrm{cm})\end{array}$ & $\begin{array}{c}6-10 \mathrm{~cm} \\
\text { length }(\mathrm{cm})\end{array}$ & $\begin{array}{l}10-16 \mathrm{~cm} \\
\text { length }(\mathrm{cm})\end{array}$ & $\begin{array}{l}16-20 \mathrm{~cm} \\
\text { length }(\mathrm{cm})\end{array}$ & & \\
\hline $\begin{array}{l}\text { R1 } \\
\text { mean value } \\
\text { std. Dov }\end{array}$ & $\begin{array}{l}4.00 \\
1.41\end{array}$ & & & & & \\
\hline $\begin{array}{l}\text { R2 } \\
\text { mean value } \\
\text { std. Dov }\end{array}$ & $\begin{array}{l}4.00 \\
1.41\end{array}$ & & & & & \\
\hline $\begin{array}{l}\text { Rs } \\
\text { mean value } \\
\text { std. Dev }\end{array}$ & $\begin{array}{l}0.55 \\
0.12\end{array}$ & & & $\begin{array}{l}0.53 \\
0.08\end{array}$ & & \\
\hline $\begin{array}{l}\text { overall mear } \\
\text { Mean Stdev }\end{array}$ & $\begin{array}{r}2.850 \\
0.98\end{array}$ & & & $\begin{array}{r}0.533 \\
0.08\end{array}$ & & \\
\hline
\end{tabular}




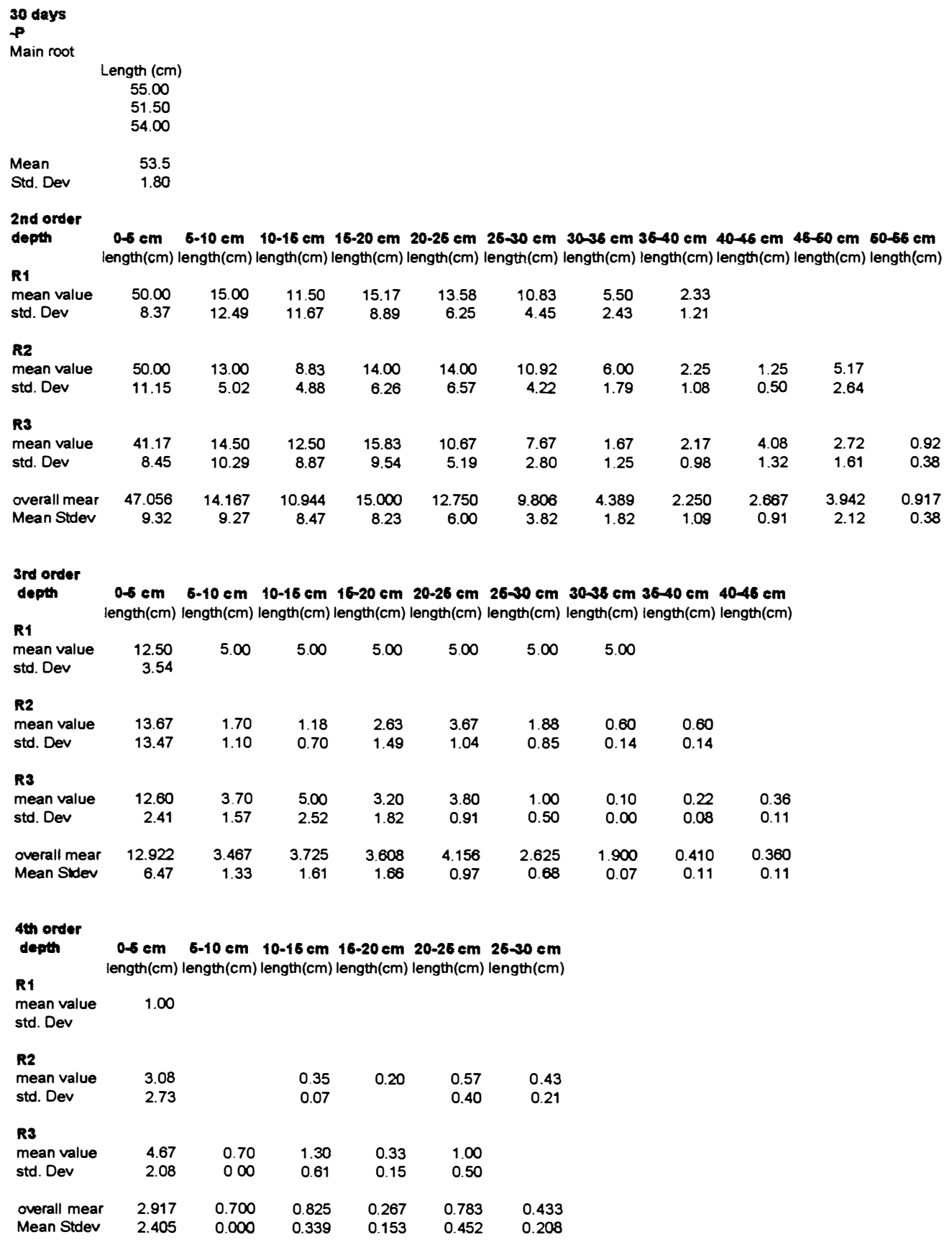




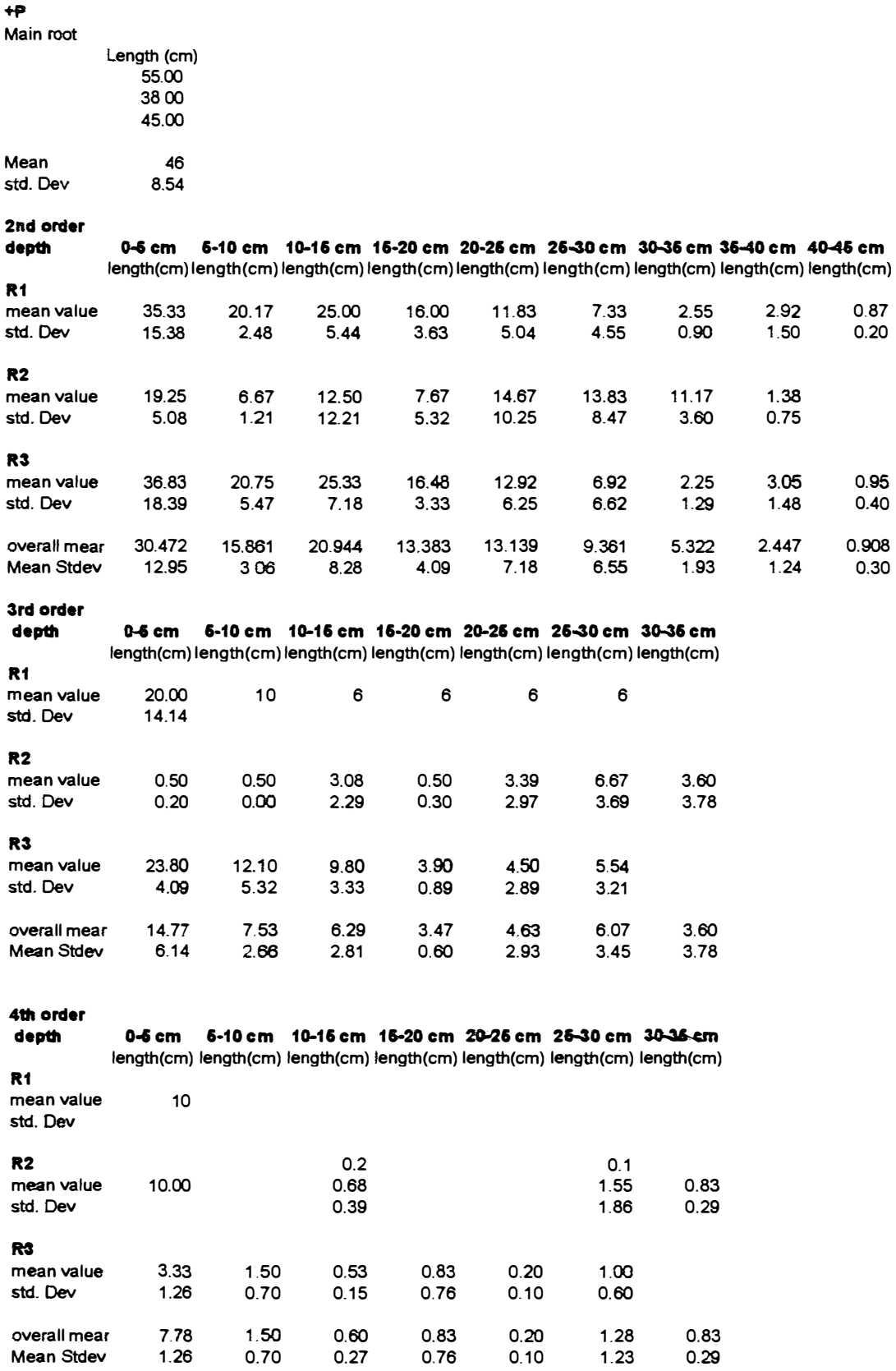




\section{ANEXO G - Rotinas computacionais do modelo de simulação}

Global k2()

Global k3()

Global Camada2\%()

Global Camada3\%()

Global TempoTotal\%

Global RamoAtual2\%

Global Idade

Global Cont2()

Global SoilDepth() 'Elongation rate computation

Global PlantAge 'Elongation rate computation

Global ElongationRate() 'Elongation rate computation

Global Av() As Double 'Elongation rate computation

Global $\mathrm{Bv}()$ As Double 'Elongation rate computation

Global $\mathrm{Cv}()$ As Double 'Elongation rate computation

Global ERgraphOrder 1() 'Elongation rate computation

Global ERgraphOrder2() 'Elongation rate computation

Global ERgraphOrder3() 'Elongation rate computation

Global ERgraphOrder4() 'Elongation rate computation

Global YOrigin() 'Elongation rate computation \& Branch distance computation

Global IndexPhosphorus 'Elongation rate computation \& Branch distance computation

Global BranchDistance() 'Branch distance computation

Global Adr() As Double 'Branch distance computation

Global Bdr() As Double 'Branch distance computation

Global $\mathrm{Cdr}()$ As Double 'Branch distance computation

Global Ddr() As Double 'Branch distance computation

Global BDgraphOrderl() 'Branch distance computation \& Form

Global BDgraphOrder2() 'Branch distance computation \& Form 
Global BDgraphOrder3() 'Branch distance computation \& Form

Global DepthGraphOrder 1() 'Branch distance computation \& Form

Global DepthGraphOrder2() 'Branch distance computation \& Form

Global DepthGraphOrder3() 'Branch distance computation \& Form

Global TwipsPerCM 'Branch distance computation \& Main routine \& Form

Global YCoordinate1 'Branch distance computation \& Main routine \& Form

Global XCoordinate1 'Main routine

Global Tempo 'Branch distance computation \& Elongation rate computation \& Main

routine \& Form

Global BNumber() 'Main routine \& Form

Global BNumber3() 'Main routine \& Form

Global BranchLength() As Double 'Main routine \& Form

Global pi As Double 'Main routine \& Form

Global Simulando As Integer 'Main routine \& Form

Global NumeroAtualDeRamos 'Main routine

Global MaxPlantAge 'Main routine \& Form

Global TimeStep As Single 'Main routine \& Form

Global Interromper As Integer 'Form

Global Pausa As Integer 'Form

Global Mensagem() As String 'Mensagens

Sub Mensagens()

ReDim Mensagem(4)

Mensagem(1) = "Teruel, Dourado-Neto \& Hopmans, 1999."

Mensagem(2) = "ROOT (v. 2.00) " + $\operatorname{Chr}(169)$

Mensagem(3) = "Soybean root growth simulation"

Mensagem(4) = "Os autores agradecem à FAPESP e ao Departamento de Produção

Vegetal."

End Sub 
Sub MainRoutine()

NumberOfLayers $=11$

ReDim SoilDepth(NumberOfLayers): 'cm

SoilDepth(1) $=5$

SoilDepth $(2)=10$

SoilDepth(3) $=15$

SoilDepth $(4)=20$

SoilDepth $(5)=25$

SoilDepth $(6)=30$

$\operatorname{SoilDepth}(7)=35$

SoilDepth $(8)=40$

SoilDepth $(9)=45$

SoilDepth $(10)=50$

SoilDepth $(11)=55$

PlantAge $=0$ : 'day

MaxPlantAge $=30$ : 'day

TempoTotal\% = Int(MaxPlantAge $/$ TimeStep)

MaxOrder $=4$

MaxBNumber $=250$

ReDim XOrigin(MaxOrder, MaxBNumber)

ReDim YOrigin(MaxOrder, MaxBNumber)

ReDim Camada2\%(MaxBNumber)

ReDim Camada3\%(MaxBNumber)

ReDim ElongationRate(MaxOrder, MaxBNumber)

ReDim ERgraphOrder1(TempoTotal\%)

ReDim ERgraphOrder2(TempoTotal\%, MaxBNumber)

ReDim ERgraphOrder3(TempoTotal\%, MaxBNumber)

ReDim Av(MaxOrder), Bv(MaxOrder), Cv(MaxOrder)

ReDim BranchDistance(MaxOrder, MaxBNumber)

ReDim Adr(MaxOrder - 1) 
ReDim Bdr(MaxOrder - 1)

ReDim Cdr(MaxOrder - 1)

ReDim Ddr(MaxOrder - 1)

ReDim BranchLength(MaxOrder, MaxBNumber)

ReDim BDgraphOrderl(MaxBNumber)

ReDim BDgraphOrder2(MaxBNumber)

ReDim BDgraphOrder3(MaxBNumber)

ReDim DepthGraphOrderl(MaxBNumber)

ReDim DepthGraphOrder2(MaxBNumber)

ReDim DepthGraphOrder3(MaxBNumber)

ReDim BNumber(MaxOrder)

BNumber $(1)=1$

BNumber $(2)=0$

BNumber $(3)=0$

BNumber(4) $=0$

ReDim DeflexionAngle(4)

DeflexionAngle $(1)=10 *(2 *$ pi $/ 360)$ : 'radianos

DeflexionAngle $(2)=15 *(2 *$ pi $/ 360)$ : 'radianos

DeflexionAngle $(3)=40 *(2 *$ pi $/ 360)$ : 'radianos

DeflexionAngle $(4)=10 *(2 *$ pi / 360): 'radianos

ReDim OrientationAngle(MaxOrder)

ReDim XCoordinate2(MaxBNumber) 'ORDER 2

ReDim YCoordinate2(MaxBNumber) 'ORDER 2

ReDim XCoordinate2ant(MaxBNumber) 'ORDER 2

ReDim YCoordinate2ant(MaxBNumber) 'ORDER 2

ReDim Cont2(MaxBNumber) 'ORDER 2

ReDim CoefAng(MaxBNumber)

Randomize

XCoordinate $1=$ RootDesign. Width $/ 2$

YCoordinatel $=0$ 
TwipsPerCM = (RootDesign. Height - 900) / SoilDepth(NumberOfLayers)

XOrigin $(1,1)=$ XCoordinate $1 /$ TwipsPerCM

YOrigin $(1,1)=$ YCoordinate $1 /$ TwipsPerCM

'Layer design

RootDesign.ForeColor $=\mathrm{QBColor}(6)$ : 'Yellow

RootDesign.Line $(0,0)$-(RootDesign.Width, 0$)$

RootDesign.Current $\mathrm{X}=0$

RootDesign.Current $Y=0$

RootDesign.Print " $0 \mathrm{~cm}$ "

For $\mathrm{X} \%=1$ To NumberOfLayers

RootDesign.Line $\quad(0, \quad$ SoilDepth $(\mathrm{X} \%) \quad * \quad$ TwipsPerCM)-(RootDesign.Width, SoilDepth $(\mathrm{X} \%) *$ TwipsPerCM)

RootDesign.Current $\mathrm{X}=0$

RootDesign.Current $\mathrm{Y}=$ SoilDepth $(\mathrm{X} \%) *$ TwipsPerCM

'RootDesign.Print Format(SoilDepth(X\%), "0") + " cm (" + Format(SoilDepth(X\%) *

TwipsPerCM, "0") + " twips)"

RootDesign.Print Format(SoilDepth(X\%), "0") + " cm"

Next X\%

MetNumVerticais $=\operatorname{Int}(($ RootDesign. Width $/$ TwipsPerCM $) / 5 / 2)-1$

RootDesign. ForeColor $=\mathrm{QBColor}(6)$

For $\mathrm{X} \%=0$ To MetNumVerticais

RootDesign.Line ((RootDesign.Width / 2) $+\mathrm{X} \% * 5 *$ TwipsPerCM, 0)(RootDesign.Width $/ 2+\mathrm{X} \% * 5 *$ TwipsPerCM, RootDesign.Height)

RootDesign.Current $\mathrm{Y}=$ RootDesign. Height -900

RootDesign.Print Format $(\mathrm{X} \%$ * 5, "0") + " cm"

Next X\%

For $\mathrm{X} \%=1$ To MetNumVerticais

RootDesign.Line ((RootDesign.Width / 2) $+\mathrm{X} \% *-5 *$ TwipsPerCM, 0)(RootDesign.Width $/ 2+\mathrm{X} \%$ * $-5 *$ TwipsPerCM, RootDesign.Height)

RootDesign.Current $\mathrm{Y}=$ RootDesign. Height -900 
RootDesign.Print Format $(\mathrm{X} \%$ * 5, "0") + " cm"

Next X\%

RootDesign.Current $\mathrm{X}=$ RootDesign. Width $/ 2$

RootDesign.Current $Y=0$

Tempo $=0$

NumeroAtualDeRamos $=1$

Output.Show

Output. Top $=$ RootDesign . Height - Output.Height -500

Output.Left $=$ RootDesign. Width - Output.Width -500

DoEvents

$\mathrm{cc}=1$

$\mathrm{nn}=5$

DistCrescidal $=0$

'Unit: rad

OrientationAngle $(1)=0+(-1)^{\wedge}(\operatorname{Int}(2 *$ Rnd +1$)) *$ Rnd * DeflexionAngle $(1)$

sinal $=(-1)^{\wedge}(\operatorname{Int}(2 * \operatorname{Rnd}+1))$

'Order 3

ReDim DistCrescida2(150)

ReDim BNumber3(150)

ReDim ProfAtualINIx2a3(150)

ReDim ProfAtualINIy2a3(150)

ReDim NumeroAtualDeRamos2(150)

ReDim XCoordinate3(150, 250)

ReDim YCoordinate3(150, 250)

ReDim CoefAng2 $(150,250)$

ReDim ProfAtualINIx3a4(250)

ReDim ProfAtualINIy3a4(250)

ReDim Cont3(250)

ReDim XCoordinate3ant $(150,250)$

ReDim YCoordinate3ant $(150,250)$ 
ReDim XOriginPos3(250)

ReDim YOriginPos3(250)

ReDim OrientationAngle2(250)

ReDim TempoDeAparecer2(150)

ReDim TempoDeAparecer3(150, 250)

ReDim k2(150)

ReDim k3(250)

Do

DoEvents

PlantAge $=$ PlantAge + TimeStep

Tempo $=$ Tempo +1

'Order 1

Idade $=$ Plant Age

ElongationRateComputation 1, 1 'Unit: $\mathrm{cm} /$ day

ProfAtualINIx $1 \mathrm{a} 2=$ XCoordinate 1

ProfAtualINIy $1 \mathrm{a} 2=$ YCoordinate 1

XCoordinatel $=$ XCoordinate $1+$ ElongationRate 1 ,

1) * TimeStep * Sin(OrientationAngle(1)) * TwipsPerCM 'Unit: Twips

YCoordinatel $=$ YCoordinatel + ElongationRate $(1,1) *$ TimeStep * Cos(OrientationAngle(1)) * TwipsPerCM 'Unit: Twips

'Order 2

BranchLength $(1,1)=\operatorname{BranchLength}(1,1)+$ ElongationRate $(1,1) *$ TimeStep 'Unit: $\mathrm{cm}$

BranchDistanceComputation 1, 1 'Unit: cm

DistCrescidal $=$ DistCrescida $1+$ ElongationRate $(1,1) *$ TimeStep

If DistCrescidal $>=$ BranchDistance $(1,1)$ Then

BNumber(2) $=$ BNumber(2) + CInt (DistCrescida $1 /$ BranchDistance $(1,1))$

DistCrescida $1=0$

If ProfAtualINIy $1 \mathrm{a} 2=0$ Then 
NumeroAtualDeRamos $=0$

BNumber(2) $=$ BNumber(2) -1

End If

For $\mathrm{X} \%=$ NumeroAtualDeRamos To BNumber(2)

If $X \%>0$ Then

$\mathrm{XOrigin}(2, \mathrm{X} \%)=$ ProfAtualINIxla2 / TwipsPerCM $+(\mathrm{X} \%=$ NumeroAtualDeRamos) * BranchDistance( 1,1$)$ * Sin(OrientationAngle(1)) 'Unit: cm YOrigin $(2, \mathrm{X} \%)=$ ProfAtualINIyla2 / TwipsPerCM $+(\mathrm{X} \%-$ NumeroAtualDeRamos) * BranchDistance $(1,1) * \operatorname{Cos}($ OrientationAngle(1)) 'Unit: cm

End If

Next X\%

OrientationAngle $(1)=0+(-1) \wedge(\operatorname{Int}(2 *$ Rnd +1$)) *$ Rnd * DeflexionAngle $(1)$

'Unit: rad

If ProfAtualINIy la2 $=0$ Then

NumeroAtualDeRamos $=1$

End If

End If

DoEvents

'Order 1

RootDesign. ForeColor $=$ QBColor $(0)$

RootDesign.Line -(XCoordinate1, YCoordinatel) 'Root design order 1

Output.LabelDAG.Caption = Format\$(PlantAge, "0.0") + " days"

Output.LabelProf(0).Caption $=$ Format $\$(Y$ Coordinatel $/$ TwipsPerCM, "0.0") + " cm"

Output.LabelProf(1).Caption = Format $\$($ BranchLength $(1,1), " 0.0 ")+" \mathrm{~cm} "$

Output.LabelBNumber. Caption = Format $(B N u m b e r(2), " 0 ")$

'Order 2

For $\mathrm{X} \%=$ NumeroAtualDeRamos To BNumber(2)

$\mathrm{XCoordinate} 2(\mathrm{X} \%)=\mathrm{XOrigin}(2, \mathrm{X} \%) *$ TwipsPerCM

YCoordinate $2(\mathrm{X} \%)=$ YOrigin $(2, \mathrm{X} \%) *$ TwipsPerCM

If $X \% \operatorname{Mod} 2=0$ Then 
$\operatorname{CoefAng}(\mathrm{X} \%)=$ sinal

Else

CoefAng $(X \%)=-1 *$ sinal

End If

If Rnd >0.7 Then

$k 2(X \%)=0.1666666$

Else

$\mathrm{k} 2(\mathrm{X} \%)=1$

End If

TempoDeAparecer2 $(\mathrm{X} \%)=1$

Next X\%

For $\mathrm{X} \%=1$ To BNumber(2)

Idade $=$ TempoDeAparecer2 $(\mathrm{X} \%) *$ TimeStep

TempoDeAparecer $2(\mathrm{X} \%)=$ TempoDeAparecer $2(\mathrm{X} \%)+1$

ElongationRateComputation 2, X\%

'Order 3

ProfAtualINIx2a3 $(\mathrm{X} \%)=\mathrm{XCoordinate} 2(\mathrm{X} \%)$

ProfAtualINIy2a3 $(X \%)=$ YCoordinate $2(X \%)$

Cont $2(\mathrm{X} \%)=\operatorname{Cont} 2(\mathrm{X} \%)+1$

XCoordinate2ant $(\mathrm{X} \%)=\mathrm{XCoordinate} 2(\mathrm{X} \%)$

YCoordinate2ant $(X \%)=$ YCoordinate $2(X \%)$

If Cont $2(\mathrm{X} \%)=1$ Then

OrientationAngle $2(\mathrm{X} \%)=\operatorname{CoefAng}(\mathrm{X} \%) *(\mathrm{pi} / 2)$

$\mathrm{XCoordinate} 2(\mathrm{X} \%)=\mathrm{XCoordinate} 2(\mathrm{X} \%)+$ ElongationRate $(2, \mathrm{X} \%) *$

TwipsPerCM * TimeStep * Sin(OrientationAngle2(X\%))

YCoordinate $2(\mathrm{X} \%)=$ YCoordinate $2(\mathrm{X} \%)+$ ElongationRate $(2, \mathrm{X} \%) *$ TwipsPerCM * TimeStep * Cos(OrientationAngle2(X\%))

ElseIf Abs(XCoordinate2(X\%) - RootDesign.Width / 2) $<1 *$ TwipsPerCM Then

OrientationAngle $2(X \%)=\operatorname{CoefAng}(X \%) *((-1) \wedge(\operatorname{Int}(2 * \mathrm{Rnd}+1)) *$ DeflexionAngle (2) + pi / 2) 
ElseIf Abs(XCoordinate2(X\%) - RootDesign.Width / 2) $<5 *$ TwipsPerCM Then

OrientationAngle $2(\mathrm{X} \%)=$ CoefAng $(\mathrm{X} \%) *((-1) \wedge(\operatorname{Int}(2 * \mathrm{Rnd}+1)) *$ DeflexionAngle $(2)+0.36 *$ pi)

ElseIf Abs(XCoordinate2(X\%) - RootDesign.Width / 2) $<10 *$ TwipsPerCM Then OrientationAngle $2(X \%)=\operatorname{CoefAng}(X \%) *((-1) \wedge(\operatorname{Int}(2 * \operatorname{Rnd}+1)) *$ DeflexionAngle $(2)+0.31 *$ pi)

ElseIf Abs(XCoordinate2(X\%) - RootDesign.Width / 2) $<15 *$ TwipsPerCM Then OrientationAngle $2(X \%)=\operatorname{CoefAng}(X \%) *((-1) \wedge(\operatorname{Int}(2 * \operatorname{Rnd}+1)) *$ DeflexionAngle $(2)+0.194 *$ pi)

ElseIf Abs(XCoordinate2(X\%) - RootDesign.Width / 2) $<20 *$ TwipsPerCM Then OrientationAngle $2(X \%)=\operatorname{CoefAng}(X \%) *((-1) \wedge(\operatorname{Int}(2 * \operatorname{Rnd}+1)) *$ DeflexionAngle $(2)+0.14 *$ pi)

ElseIf Abs(XCoordinate2(X\%) - RootDesign.Width / 2) $<25 *$ TwipsPerCM Then

OrientationAngle $2(\mathrm{X} \%)=\operatorname{CoefAng}(\mathrm{X} \%) *((-1) \wedge(\operatorname{Int}(2 * \operatorname{Rnd}+1)) *$ DeflexionAngle $(2)+0.083 *$ pi)

ElseIf Abs (XCoordinate2(X\%) - RootDesign. Width / 2) $<30 *$ TwipsPerCM Then

OrientationAngle $2(X \%)=\operatorname{CoefAng}(X \%) *((-1) \wedge(\operatorname{Int}(2 * \operatorname{Rnd}+1)) *$ DeflexionAngle $(2)+0.028 *$ pi)

Else

OrientationAngle $2(\mathrm{X} \%)=\operatorname{CoefAng}(\mathrm{X} \%) *((-1) \wedge(\operatorname{Int}(2 * \mathrm{Rnd}+1)) *$ DeflexionAngle $(2)+0)$

End If

$\mathrm{XCoordinate} 2(\mathrm{X} \%)=\mathrm{XCoordinate} 2(\mathrm{X} \%)+$ ElongationRate $(2, \mathrm{X} \%) *$ TimeStep * Sin(OrientationAngle2(X\%)) * TwipsPerCM

YCoordinate $2(X \%)=$ YCoordinate $2(X \%)+$ ElongationRate $(2, X \%) *$ TimeStep * $\operatorname{Cos}($ OrientationAngle2(X\%)) * TwipsPerCM

RootDesign.ForeColor $=\mathrm{QBColor}(2)$

RootDesign.Line (XCoordinate2ant $(X \%), \quad$ YCoordinate2ant $(X \%))-$ (XCoordinate2(X\%), YCoordinate2(X\%))

'Order 3 
BranchLength $(2, X \%)=\operatorname{BranchLength}(2, X \%)+\operatorname{ElongationRate}(2, X \%) *$ TimeStep

BranchDistanceComputation 2, X\%

DistCrescida2 $(\mathrm{X} \%)=$ DistCrescida2 $(\mathrm{X} \%)+$ ElongationRate $(2, \mathrm{X} \%){ }^{*}$ TimeStep If DistCrescida2 $(\mathrm{X} \%)>=$ BranchDistance $(2, \mathrm{X} \%)$ Then

BNumber3 $(\mathrm{X} \%)=\mathrm{BNumber} 3(\mathrm{X} \%)+\operatorname{CInt}($ DistCrescida2 $(\mathrm{X} \%) \quad /$

BranchDistance $(2, \mathrm{X} \%))$

DistCrescida2 $(\mathrm{X} \%)=0$

If ProfAtualiNIy $2 \mathrm{a} 3(\mathrm{X} \%)=0$ Then

NumeroAtualDeRamos $2(\mathrm{X} \%)=0$

BNumber $3(\mathrm{X} \%)=\mathrm{BNumber} 3(\mathrm{X} \%)-1$

End If

For $\mathrm{Y} \%=$ NumeroAtualDeRamos2(X\%) To BNumber3(X\%)

If $\mathrm{Y} \%>0$ Then

XOriginPos $3(\mathrm{Y} \%)=$ ProfAtualINIx2a3(X\%) / TwipsPerCM $+(\mathrm{Y} \%$ -

NumeroAtualDeRamos2(X\%)) * BranchDistance(2, $\quad \mathrm{X} \%) \quad$ *

Sin(OrientationAngle2(X\%)) 'Unit: cm

YOriginPos3 $(\mathrm{Y} \%)=$ ProfAtualINIy2a3 $(\mathrm{X} \%) /$ TwipsPerCM $+(\mathrm{Y} \%-$

NumeroAtualDeRamos2 $(\mathrm{X} \%)) \quad * \quad$ BranchDistance $(2, \quad X \%) \quad$ *

$\operatorname{Cos}($ OrientationAngle2(X\%)) 'Unit: $\mathrm{cm}$

$\mathrm{XOrigin}(3, \mathrm{Y} \%)=\mathrm{XOrigin}(2, \mathrm{X} \%)^{\prime} \mathrm{Unit}: \mathrm{cm}$

YOrigin(3, Y\%) = YOrigin(2, X\%) 'Unit: cm

End If

Next $Y \%$

End If

For $\mathrm{Y} \%=$ NumeroAtualDeRamos2 $(\mathrm{X} \%)$ To BNumber3(X\%)

$\mathrm{XCoordinate} 3(\mathrm{X} \%, \mathrm{Y} \%)=\mathrm{XOriginPos} 3(\mathrm{Y} \%) *$ TwipsPerCM

YCoordinate $3(\mathrm{X} \%, \mathrm{Y} \%)=$ YOriginPos3 $(\mathrm{Y} \%)$ * TwipsPerCM

If $\mathrm{Y} \% \operatorname{Mod} 2=0$ Then

CoefAng $2(\mathrm{X} \%, \mathrm{Y} \%)=$ OrientationAngle $2(\mathrm{X} \%)+\mathrm{pi} / 2$ 
Else

CoefAng2 $(\mathrm{X} \%, \mathrm{Y} \%)=$ OrientationAngle2(X\%) - pi / 2

End If

NumRandomico $=$ Rnd

If NumRandomico $>0.5$ Then

$\mathrm{k} 3(\mathrm{Y} \%)=1$

ElseIf NumRandomico $>0.3$ Then

$$
\mathrm{k} 3(\mathrm{Y} \%)=0.5
$$

Else

$$
\mathrm{k} 3(\mathrm{Y} \%)=0.1
$$

End If

TempoDeAparecer3(X\%, Y\%) = 1

Next Y\%

For $\mathrm{Y} \%=1$ To BNumber $3(\mathrm{X} \%)$

Idade $=$ TempoDeAparecer3 $(\mathrm{X} \%, \mathrm{Y} \%) *$ TimeStep

TempoDeAparecer3(X\%, Y\%) = TempoDeAparecer3(X\%, Y\%) + 1

ElongationRateComputation 3, Y\%

'Order 4

ProfAtualINIx3a4(Y\%) $=$ XCoordinate3(X\%, Y\%)

ProfAtualINIy3a4(Y\%) = YCoordinate3 $(\mathrm{X} \%, \mathrm{Y} \%)$

'Order 3

Cont3 $(\mathrm{Y} \%)=\operatorname{Cont} 3(\mathrm{Y} \%)+1$

OrientationAngle $(3)=$ CoefAng $2(X \%, Y \%)$

$\mathrm{XCoordinate} 3 \operatorname{ant}(\mathrm{X} \%, \mathrm{Y} \%)=\mathrm{XCoordinate} 3(\mathrm{X} \%, \mathrm{Y} \%)$

YCoordinate3ant $(\mathrm{X} \%, \mathrm{Y} \%)=\mathrm{YCoordinate} 3(\mathrm{X} \%, \mathrm{Y} \%)$

$\mathrm{v}=\mathrm{Rnd}$

$\mathrm{XCoordinate} 3(\mathrm{X} \%, \mathrm{Y} \%)=\mathrm{XCoordinate} 3(\mathrm{X} \%, \mathrm{Y} \%)+$ ElongationRate $(3, \mathrm{Y} \%)$

* TwipsPerCM * TimeStep * $\operatorname{Sin}($ OrientationAngle(3) $+(-1) \wedge(\operatorname{Int}(2 * v+1)) *$ DeflexionAngle(3)) 
YCoordinate $3(\mathrm{X} \%, \mathrm{Y} \%)=\mathrm{YCoordinate} 3(\mathrm{X} \%, \mathrm{Y} \%)+$ ElongationRate $(3, \mathrm{Y} \%)$

${ }^{*}$ TwipsPerCM * TimeStep * $\operatorname{Cos}($ OrientationAngle(3) $+(-1) \wedge(\operatorname{Int}(2 * \mathrm{v}+1)) *$ DeflexionAngle(3))

RootDesign.ForeColor $=\mathrm{QBColor}(4)$

RootDesign.Line (XCoordinate3ant(X\%, Y\%), YCoordinate3ant(X\%, Y\%))(XCoordinate3(X\%, Y\%), YCoordinate3(X\%, Y\%))

RootDesign.Current $\mathrm{X}=\mathrm{XCoordinate} 3(\mathrm{X} \%, \mathrm{Y} \%)$ : 'ORDER 3

RootDesign.Current $\mathrm{Y}=$ YCoordinate3(X\%, Y\%): 'ORDER 3

Next Y\%

RootDesign.CurrentX $=$ XCoordinate2(X\%): 'ORDER 2

RootDesign.Current $\mathrm{Y}=\mathrm{YCoordinate2}(\mathrm{X} \%)$ : 'ORDER 2

NumeroAtualDeRamos2(X\%) $=$ BNumber $3(\mathrm{X} \%)+1$

Next X\%

RootDesign.Current $\mathrm{X}=\mathrm{XCoordinate1}$ : 'ORDER 1

RootDesign.Current $Y=$ YCoordinatel: 'ORDER 1

NumeroAtualDeRamos $=$ BNumber $(2)+1$

Loop While PlantAge $<$ MaxPlantAge

RootDesign.. ause. Visible $=$ False

Simulando $=0$

Beep

End Sub

Sub ElongationRateComputation(Order, Ramo\%)

$'+P$

If IndexPhosphorus $=0$ Then

'...+P

If YOrigin(Order, Ramo\%) <= SoilDepth(1) Then

If Order $=2$ Then

Camada $2 \%($ Ramo\% $)=1$

Elself Order $=3$ Then 


\section{Camada3\%(Ramo\% $)=1$}

End If

$$
\begin{aligned}
& \operatorname{Av}(1)=42.28334172 \\
& \operatorname{Bv}(1)=5.276813226 \\
& \operatorname{Cv}(1)=-4.042976381 \\
& \operatorname{Av}(2)=37.30954177 \\
& \operatorname{Bv}(2)=11.21414505 \\
& \operatorname{Cv}(2)=-4.067729217 \\
& \operatorname{Av}(3)=16.2956 \\
& \operatorname{Bv}(3)=17.22042 \\
& \operatorname{Cv}(3)=-4.1935 \\
& \operatorname{Av}(4)=563.5077 \\
& \operatorname{Bv}(4)=67.6559 \\
& \operatorname{Cv}(4)=-5.25507 \\
& \ldots+P
\end{aligned}
$$

ElseIf YOrigin(Order, Ramo\%) $<=$ SoilDepth(2) Then

$$
\text { If Order }=2 \text { Then }
$$

$$
\text { Camada2\%(Ramo\%) }=2
$$

ElseIf Order $=3$ Then

$$
\text { Camada3\%(Ramo\% })=2
$$

End If

$$
\begin{aligned}
& \operatorname{Av}(1)=42.28334172 \\
& \operatorname{Bv}(1)=5.276813226 \\
& \operatorname{Cv}(1)=-4.042976381 \\
& \operatorname{Av}(2)=17.64709752 \\
& \operatorname{Bv}(2)=15.26119316 \\
& \operatorname{Cv}(2)=-2.60421744 \\
& \operatorname{Av}(3)=1913.16 \\
& \operatorname{Bv}(3)=156.6347 \\
& \operatorname{Cv}(3)=-3.36441
\end{aligned}
$$




$$
\begin{aligned}
& \operatorname{Av}(4)=563.5077 \\
& \operatorname{Bv}(4)=67.6559 \\
& \operatorname{Cv}(4)=-5.25507
\end{aligned}
$$

$1 . .+P$

ElseIf YOrigin(Order, Ramo\%) $<=$ SoilDepth(3) Then

If Order $=2$ Then

$$
\text { Camada2\%(Ramo\%) }=3
$$

ElseIf Order $=3$ Then

$$
\text { Camada3\%(Ramo\%) }=3
$$

End If

$$
\begin{aligned}
& \operatorname{Av}(1)=42.28334172 \\
& \operatorname{Bv}(1)=5.276813226 \\
& \operatorname{Cv}(1)=-4.042976381 \\
& \operatorname{Av}(2)=2558.140086 \\
& \operatorname{Bv}(2)=400.4745704 \\
& \operatorname{Cv}(2)=-1.859731608 \\
& \operatorname{Av}(3)=779.8251 \\
& \operatorname{Bv}(3)=123.7714 \\
& \operatorname{Cv}(3)=-3.40747 \\
& \operatorname{Av}(4)=563.5077 \\
& \operatorname{Bv}(4)=67.6559 \\
& \operatorname{Cv}(4)=-5.25507 \\
& \ldots+P
\end{aligned}
$$

ElseIf YOrigin(Order, Ramo\%) <= SoilDepth(4) Then

If Order $=2$ Then

$$
\text { Camada2\%(Ramo\%) }=4
$$

ElseIf Order $=3$ Then

$$
\text { Camada3\%(Ramo\% })=4
$$

End If

$$
\operatorname{Av}(1)=42.28334172
$$




$$
\begin{aligned}
& \operatorname{Bv}(1)=5.276813226 \\
& \operatorname{Cv}(1)=-4.042976381 \\
& \operatorname{Av}(2)=19.34402 \\
& \operatorname{Bv}(2)=22.43137 \\
& \operatorname{Cv}(2)=-4.01483 \\
& \operatorname{Av}(3)=526.7564 \\
& \operatorname{Bv}(3)=142.9383 \\
& \operatorname{Cv}(3)=-3.2283 \\
& \operatorname{Av}(4)=563.5077 \\
& \operatorname{Bv}(4)=67.6559 \\
& \operatorname{Cv}(4)=-5.25507 \\
& \ldots+P
\end{aligned}
$$

ElseIf YOrigin(Order, Ramo\%) <= SoilDepth(5) Then

If Order $=2$ Then

Camada2\%(Ramo\%) $=5$

ElseIf Order $=3$ Then

Camada3\%(Ramo\%) $=5$

End If

$$
\begin{aligned}
& \operatorname{Av}(1)=42.28334172 \\
& \operatorname{Bv}(1)=5.276813226 \\
& \operatorname{Cv}(1)=-4.042976381 \\
& \operatorname{Av}(2)=14.71497316 \\
& \operatorname{Bv}(2)=19.52456865 \\
& \operatorname{Cv}(2)=-5.822357969 \\
& \operatorname{Av}(3)=1717.011 \\
& \operatorname{Bv}(3)=140.5662 \\
& \operatorname{Cv}(3)=-3.86691 \\
& \operatorname{Av}(4)=563.5077 \\
& \operatorname{Bv}(4)=67.6559 \\
& \operatorname{Cv}(4)=-5.25507
\end{aligned}
$$


$\therefore+$ P $(25$ a $30 \mathrm{~cm})$

ElseIf YOrigin(Order, Ramo\%) <= SoilDepth(6) Then

If Order $=2$ Then

Camada $2 \%(\operatorname{Ramo} \%)=6$

ElseIf Order $=3$ Then

Camada $3 \%(\operatorname{Ramo} \%)=6$

End If

$\operatorname{Av}(1)=42.28334172$

$\mathrm{Bv}(1)=5.276813226$

$\operatorname{Cv}(1)=-4.042976381$

$\operatorname{Av}(2)=11.16851535$

$\operatorname{Bv}(2)=17.81968185$

$\operatorname{Cv}(2)=-11.94957928$

$\operatorname{Av}(3)=631.165$

$\operatorname{Bv}(3)=56.11897$

$\operatorname{Cv}(3)=-7.41044$

$\operatorname{Av}(4)=563.5077$

$\operatorname{Bv}(4)=67.6559$

$\operatorname{Cv}(4)=-5.25507$

$1 \ldots+\mathrm{P}$

ElseIf YOrigin(Order, Ramo\%) <= SoilDepth(7) Then

If Order $=2$ Then

Camada2\%(Ramo\%) $=7$

ElseIf Order $=3$ Then

Camada3\%(Ramo\%) $=7$

End If

$\operatorname{Av}(1)=42.28334172$

$\operatorname{Bv}(1)=5.276813226$

$\operatorname{Cv}(1)=-4.042976381$

$\operatorname{Av}(2)=6.383692336$ 


$$
\begin{aligned}
& \operatorname{Bv}(2)=17.30462467 \\
& \operatorname{Cv}(2)=-12.20258279 \\
& \operatorname{Av}(3)=374.332 \\
& \operatorname{Bv}(3)=56.11897 \\
& \operatorname{Cv}(3)=-7.41044 \\
& \operatorname{Av}(4)=563.5077 \\
& \operatorname{Bv}(4)=67.6559 \\
& \operatorname{Cv}(4)=-5.25507 \\
& \ldots+P
\end{aligned}
$$

ElseIf YOrigin(Order, Ramo\%) <= SoilDepth(8) Then

If Order $=2$ Then

$$
\text { Camada2\%(Ramo\%) }=8
$$

ElseIf Order $=3$ Then

$$
\text { Camada } 3 \%(\operatorname{Ramo} \%)=8
$$

End If

$$
\begin{aligned}
& \operatorname{Av}(1)=42.28334172 \\
& \operatorname{Bv}(1)=5.276813226 \\
& \operatorname{Cv}(1)=-4.042976381 \\
& \operatorname{Av}(2)=2.742286425 \\
& \operatorname{Bv}(2)=17.73254146 \\
& \operatorname{Cv}(2)=-9.718889915 \\
& \operatorname{Av}(3)=0 \\
& \operatorname{Bv}(3)=156.6347 \\
& \operatorname{Cv}(3)=-3.36441 \\
& \operatorname{Av}(4)=563.5077 \\
& \operatorname{Bv}(4)=67.6559 \\
& \operatorname{Cv}(4)=-5.25507 \\
& \ldots+P
\end{aligned}
$$

ElseIf YOrigin(Order, Ramo\%) $<=$ SoilDepth(9) Then If Order $=2$ Then 
Camada2\%(Ramo\%) = 9

ElseIf Order $=3$ Then

Camada3\%(Ramo\%) $=9$

End If

$\operatorname{Av}(1)=42.28334172$

$\mathrm{Bv}(1)=5.276813226$

$\operatorname{Cv}(1)=-4.042976381$

$\operatorname{Av}(2)=2.742286425$

$\operatorname{Bv}(2)=17.73254146$

$\operatorname{Cv}(2)=-9.718889915$

$\operatorname{Av}(3)=0$

$\operatorname{Bv}(3)=156.6347$

$\operatorname{Cv}(3)=-3.36441$

$\operatorname{Av}(4)=563.5077$

$\operatorname{Bv}(4)=67.6559$

$\operatorname{Cv}(4)=-5.25507$

'... + P

ElseIf YOrigin(Order, Ramo\%) $<=$ SoilDepth(10) Then

If Order $=2$ Then

Camada $2 \%(\operatorname{Ramo} \%)=10$

ElseIf Order $=3$ Then

$$
\text { Camada3\%(Ramo\% })=10
$$

End If

$$
\begin{aligned}
& \operatorname{Av}(1)=42.28334172 \\
& \operatorname{Bv}(1)=5.276813226 \\
& \operatorname{Cv}(1)=-4.042976381 \\
& \operatorname{Av}(2)=2.742286425 \\
& \operatorname{Bv}(2)=17.73254146 \\
& \operatorname{Cv}(2)=-9.718889915 \\
& \operatorname{Av}(3)=0
\end{aligned}
$$




$$
\begin{aligned}
& \operatorname{Bv}(3)=156.6347 \\
& \operatorname{Cv}(3)=-3.36441 \\
& \operatorname{Av}(4)=563.5077 \\
& \operatorname{Bv}(4)=67.6559 \\
& \operatorname{Cv}(4)=-5.25507 \\
& \ldots+P
\end{aligned}
$$

ElseIf YOrigin(Order, Ramo\%) <= SoilDepth(11) Then

$$
\text { If Order }=2 \text { Then }
$$

$$
\text { Camada } 2 \%(\operatorname{Ramo} \%)=11
$$

ElseIf Order $=3$ Then

$$
\text { Camada } 3 \%(\operatorname{Ramo} \%)=11
$$

End If

$$
\begin{aligned}
& \operatorname{Av}(1)=42.28334172 \\
& \operatorname{Bv}(1)=5.276813226 \\
& \operatorname{Cv}(1)=-4.042976381 \\
& \operatorname{Av}(2)=2.742286425 \\
& \operatorname{Bv}(2)=17.73254146 \\
& \operatorname{Cv}(2)=-9.718889915 \\
& \operatorname{Av}(3)=0 \\
& \operatorname{Bv}(3)=156.6347 \\
& \operatorname{Cv}(3)=-3.36441 \\
& \operatorname{Av}(4)=563.5077 \\
& \operatorname{Bv}(4)=67.6559 \\
& \operatorname{Cv}(4)=-5.25507
\end{aligned}
$$

End If

'-P

ElseIf IndexPhosphorus $=1$ Then '...-P

If YOrigin(Order, Ramo\%) <= SoilDepth(1) Then If Order $=2$ Then 
Camada $\%(\operatorname{Ramo} \%)=1$

ElseIf Order $=3$ Then

Camada3\%(Ramo\% $)=1$

End If

$\operatorname{Av}(1)=56.15491436$

$\operatorname{Bv}(1)=6.271603886$

$\operatorname{Cv}(1)=-1.426418693$

$\operatorname{Av}(2)=51.74642498$

$\operatorname{Bv}(2)=13.13549952$

$\operatorname{Cv}(2)=-2.433723514$

$\operatorname{Av}(3)=30.43403$

$\operatorname{Bv}(3)=35.00159$

$\operatorname{Cv}(3)=-2.24927$

$\operatorname{Av}(4)=8.192676$

$\operatorname{Bv}(4)=36.34126$

$\operatorname{Cv}(4)=-3.09559$

'...-P

ElseIf YOrigin(Order, Ramo\%) <= SoilDepth(2) Then

If Order $=2$ Then

Camada $2 \%(\operatorname{Ramo} \%)=2$

ElseIf Order $=3$ Then

Camada3\%(Ramo\%) $=2$

End If

$$
\begin{aligned}
& \operatorname{Av}(1)=56.15491436 \\
& \operatorname{Bv}(1)=6.271603886 \\
& \operatorname{Cv}(1)=-1.426418693 \\
& \operatorname{Av}(2)=18.95934632 \\
& \operatorname{Bv}(2)=11.51251246 \\
& \operatorname{Cv}(2)=-3.227120942
\end{aligned}
$$




$$
\begin{aligned}
& \operatorname{Av}(3)=3.567517 \\
& \operatorname{Bv}(3)=13.9552 \\
& \operatorname{Cv}(3)=-6.47178 \\
& \operatorname{Av}(4)=8.192676 \\
& \operatorname{Bv}(4)=36.34126 \\
& \operatorname{Cv}(4)=-3.09559 \\
& \ldots-P
\end{aligned}
$$

ElseIf YOrigin(Order, Ramo\%) <= SoilDepth(3) Then

If Order $=2$ Then

$$
\text { Camada } 2 \%(\operatorname{Ramo} \%)=3
$$

ElseIf Order $=3$ Then

$$
\text { Camada3\%(Ramo\%) }=3
$$

End If

$$
\begin{aligned}
& \operatorname{Av}(1)=56.15491436 \\
& \operatorname{Bv}(1)=6.271603886 \\
& \operatorname{Cv}(1)=-1.426418693 \\
& \operatorname{Av}(2)=13.12115572 \\
& \operatorname{Bv}(2)=11.81766929 \\
& \operatorname{Cv}(2)=-6.114421625 \\
& \operatorname{Av}(3)=7.783409 \\
& \operatorname{Bv}(3)=30.23816 \\
& \operatorname{Cv}(3)=-2.94459 \\
& \operatorname{Av}(4)=8.192676 \\
& \operatorname{Bv}(4)=36.34126 \\
& \operatorname{Cv}(4)=-3.09559 \\
& 1 . .-P
\end{aligned}
$$

ElseIf YOrigin(Order, Ramo\%) $<=$ SoilDepth(4) Then If Order $=2$ Then

$$
\text { Camada } 2 \%(\operatorname{Ramo} \%)=4
$$

ElseIf Order $=3$ Then 
Camada $3 \%(\operatorname{Ramo} \%)=4$

End If

$$
\begin{aligned}
& \operatorname{Av}(1)=56.15491436 \\
& \operatorname{Bv}(1)=6.271603886 \\
& \operatorname{Cv}(1)=-1.426418693 \\
& \operatorname{Av}(2)=16.86536 \\
& \operatorname{Bv}(2)=16.09504 \\
& \operatorname{Cv}(2)=-2.52582 \\
& \operatorname{Av}(3)=4.055108 \\
& \operatorname{Bv}(3)=18.9919 \\
& \operatorname{Cv}(3)=-7.2238 \\
& \operatorname{Av}(4)=8.192676 \\
& \operatorname{Bv}(4)=36.34126 \\
& \operatorname{Cv}(4)=-3.09559 \\
& \ldots-P
\end{aligned}
$$

Elself YOrigin(Order, Ramo\%) $<=$ SoilDepth(5) Then

If Order $=2$ Then

$$
\text { Camada } 2 \%(\operatorname{Ramo} \%)=5
$$

ElseIf Order $=3$ Then

$$
\text { Camada3\%(Ramo\%) }=5
$$

End If

$$
\begin{aligned}
& \operatorname{Av}(1)=56.15491436 \\
& \operatorname{Bv}(1)=6.271603886 \\
& \operatorname{Cv}(1)=-1.426418693 \\
& \operatorname{Av}(2)=14.27732391 \\
& \operatorname{Bv}(2)=14.49918685 \\
& \operatorname{Cv}(2)=-4.213904594 \\
& \operatorname{Av}(3)=1167.703 \\
& \operatorname{Bv}(3)=210.3321 \\
& \operatorname{Cv}(3)=-2.92097
\end{aligned}
$$




$$
\begin{aligned}
& \mathrm{Av}(4)=563.5077 \\
& \mathrm{Bv}(4)=67.6559 \\
& \mathrm{Cv}(4)=-5.25507 \\
& \text { E..P } \\
& \text { ElseIf YOrigin(Order, Ramo } \%) \\
& \text { If Order }=2 \text { Then } \\
& \mathrm{Camada} 2 \%(\text { Ramo\%) }=6 \\
& \mathrm{ElseIf} \text { Order }=3 \text { Then } \\
& \mathrm{Camada} 3 \%(\mathrm{Ramo} \%)=6 \\
& \mathrm{End} \text { If } \\
& \mathrm{Av}(1)=56.15491436 \\
& \mathrm{Bv}(1)=6.271603886 \\
& \mathrm{Cv}(1)=-1.426418693 \\
& \mathrm{Av}(2)=11.16851535 \\
& \mathrm{Bv}(2)=15.88430849 \\
& \mathrm{Cv}(2)=-5.261550001 \\
& \mathrm{Av}(3)=1.836319 \\
& \mathrm{Bv}(3)=14.92142 \\
& \mathrm{Cv}(3)=-12.4417 \\
& \mathrm{Av}(4)=563.5077 \\
& \mathrm{Bv}(4)=67.6559 \\
& \mathrm{Cv}(4)=-5.25507 \\
& \ldots-\mathrm{P}
\end{aligned}
$$

ElseIf YOrigin(Order, Ramo\%) <= SoilDepth(6) Then

ElseIf YOrigin(Order, Ramo\%) <= SoilDepth(7) Then

If Order $=2$ Then

$$
\text { Camada } 2 \%(\operatorname{Ramo} \%)=7
$$

ElseIf Order $=3$ Then

$$
\text { Camada3\%(Ramo\% })=7
$$

End If

$$
\operatorname{Av}(1)=56.15491436
$$




$$
\begin{aligned}
& \operatorname{Bv}(1)=6.271603886 \\
& \mathrm{Cv}(1)=-1.426418693 \\
& \mathrm{Av}(2)=5.097138478 \\
& \mathrm{Bv}(2)=15.53494507 \\
& \mathrm{Cv}(2)=-4.377920781 \\
& \mathrm{Av}(3)=61.58068 \\
& \mathrm{Bv}(3)=51.81944 \\
& \mathrm{Cv}(3)=-6.31087 \\
& \mathrm{Av}(4)=563.5077 \\
& \mathrm{Bv}(4)=67.6559 \\
& \mathrm{Cv}(4)=-5.25507 \\
& \ldots-\mathrm{P}
\end{aligned}
$$

ElseIf YOrigin(Order, Ramo\%) $<=$ SoilDepth(8) Then

If Order $=2$ Then

$$
\text { Camada } 2 \%(\operatorname{Ramo} \%)=8
$$

ElseIf Order $=3$ Then

$$
\text { Camada3\%(Ramo\%) }=8
$$

End If

$$
\begin{aligned}
& \operatorname{Av}(1)=56.15491436 \\
& \operatorname{Bv}(1)=6.271603886 \\
& \operatorname{Cv}(1)=-1.426418693 \\
& \operatorname{Av}(2)=2.950576123 \\
& \operatorname{Bv}(2)=16.80867341 \\
& \operatorname{Cv}(2)=-8.408922397 \\
& \operatorname{Av}(3)=0 \\
& \operatorname{Bv}(3)=13.9552 \\
& \operatorname{Cv}(3)=-6.47178 \\
& \operatorname{Av}(4)=563.5077 \\
& \operatorname{Bv}(4)=67.6559 \\
& \operatorname{Cv}(4)=-5.25507
\end{aligned}
$$


'...-P

ElseIf YOrigin(Order, Ramo\%) $<=$ SoilDepth(9) Then

If Order $=2$ Then

Camada2\%(Ramo\%) $=9$

ElseIf Order $=3$ Then

Camada3\%(Ramo\%) $=9$

End If

$\operatorname{Av}(1)=56.15491436$

$\operatorname{Bv}(1)=6.271603886$

$\operatorname{Cv}(1)=-1.426418693$

$\operatorname{Av}(2)=2.950576123$

$\operatorname{Bv}(2)=16.80867341$

$\operatorname{Cv}(2)=-8.408922397$

$\operatorname{Av}(3)=0$

$\operatorname{Bv}(3)=13.9552$

$\operatorname{Cv}(3)=-6.47178$

$\operatorname{Av}(4)=563.5077$

$\mathrm{Bv}(4)=67.6559$

$\operatorname{Cv}(4)=-5.25507$

'...-P

ElseIf YOrigin(Order, Ramo\%) <= SoilDepth(10) Then

If Order $=2$ Then

Camada2\%(Ramo\% $)=10$

ElseIf Order $=3$ Then

Camada3\% $($ Ramo\% $)=10$

End If

$\operatorname{Av}(1)=56.15491436$

$\operatorname{Bv}(1)=6.271603886$

$\operatorname{Cv}(1)=-1.426418693$

$\operatorname{Av}(2)=2.950576123$ 


$$
\begin{aligned}
& \operatorname{Bv}(2)=16.80867341 \\
& \operatorname{Cv}(2)=-8.408922397 \\
& \operatorname{Av}(3)=0 \\
& \operatorname{Bv}(3)=13.9552 \\
& \operatorname{Cv}(3)=-6.47178 \\
& \operatorname{Av}(4)=563.5077 \\
& \operatorname{Bv}(4)=67.6559 \\
& \operatorname{Cv}(4)=-5.25507
\end{aligned}
$$

'...-P

ElseIf YOrigin(Order, Ramo\%) <= SoilDepth(11) Then

If Order $=2$ Then

$$
\text { Camada } 2 \%(\text { Ramo\% })=11
$$

ElseIf Order $=3$ Then

$$
\text { Camada3\%(Ramo\% })=11
$$

End If

$$
\begin{aligned}
& \operatorname{Av}(1)=56.15491436 \\
& \operatorname{Bv}(1)=6.271603886 \\
& \operatorname{Cv}(1)=-1.426418693 \\
& \operatorname{Av}(2)=2.950576123 \\
& \operatorname{Bv}(2)=16.80867341 \\
& \operatorname{Cv}(2)=-8.408922397 \\
& \operatorname{Av}(3)=0 \\
& \operatorname{Bv}(3)=13.9552 \\
& \operatorname{Cv}(3)=-6.47178 \\
& \operatorname{Av}(4)=563.5077 \\
& \operatorname{Bv}(4)=67.6559 \\
& \operatorname{Cv}(4)=-5.25507
\end{aligned}
$$

End If

End If

'Elongation Rate, $\mathrm{cm} /$ day 
If Order $=1$ Then

ElongationRate $($ Order, Ramo\%) $=-\mathrm{Av}($ Order $) *(\mathrm{Cv}($ Order $) *((1 / \mathrm{Bv}($ Order $)) \wedge$ $\mathrm{Cv}($ Order $)) *($ PlantAge $\wedge(\mathrm{Cv}($ Order $)-1))) /\left(\left(1+(\text { PlantAge } / \mathrm{Bv}(\text { Order }))^{\wedge} \mathrm{Cv}(\right.\right.$ Order $\left.)\right)$ ^)

ElseIf Order $=2$ Then

ElongationRate $($ Order, Ramo\% $)=-\operatorname{Av}($ Order $) *(\mathrm{Cv}($ Order $) *((1 / \mathrm{Bv}($ Order $)) \wedge$ $\mathrm{Cv}($ Order $)) *($ PlantAge $\wedge(\mathrm{Cv}($ Order $)-1))) /\left(\left(1+(\text { PlantAge } / \mathrm{Bv}(\text { Order }))^{\wedge} \mathrm{Cv}(\right.\right.$ Order $\left.)\right)$ 2)

ElongationRate(Order, Ramo\%) = ElongationRate(Order, Ramo\%) * k2(Ramo\%)

ElseIf Order $=3$ Then

ElongationRate $($ Order, Ramo\%) $=-\mathrm{Av}($ Order $) *(\mathrm{Cv}($ Order $) *((1 / \mathrm{Bv}($ Order $)) \wedge$

$\mathrm{Cv}($ Order $)) *\left(\right.$ Idade $^{\wedge}(\mathrm{Cv}($ Order $\left.\left.)-1)\right)\right) /\left(\left(1+(\text { Idade } / \mathrm{Bv}(\text { Order }))^{\wedge} \mathrm{Cv}(\text { Order })\right)^{\wedge} 2\right)$

ElongationRate(Order, Ramo\%) = ElongationRate(Order, Ramo\%) *k3(Ramo\%)

End If

If Order $=1$ Then

ERgraphOrder 1 (Tempo) $=$ ElongationRate(Order, 1)

ElseIf Order $=2$ Then

ERgraphOrder2(Tempo, Ramo\%) = ElongationRate(Order, Ramo\%)

ElseIf Order $=3$ Then

ERgraphOrder3(Tempo, Ramo\%) = ElongationRate(Order, Ramo\%)

ElseIf Order $=4$ Then

ERgraphOrder4(Tempo) $=$ ElongationRate(Order, Ramo\%)

End If

End Sub

Sub BranchDistanceComputation(Order, Ramo\%)

$+P$

If IndexPhosphorus $=0$ Then

'order 1

$\operatorname{Adr}(1)=0.279958$ 


$$
\begin{aligned}
& \operatorname{Bdr}(1)=-7.1 * 10^{\wedge}(-5) \\
& \operatorname{Cdr}(1)=5.07 * 10^{\wedge}(-5) \\
& \operatorname{Ddr}(1)=6.42 * 10^{\wedge}(-21) \\
& \operatorname{order} 2 \\
& \operatorname{Adr}(2)=0.228161 \\
& \operatorname{Bdr}(2)=0.001405 \\
& \operatorname{Cdr}(2)=-0.00038 \\
& \operatorname{Ddr}(2)=1.06 * 10^{\wedge}(-15) \\
& \operatorname{Order} 3 \\
& \operatorname{Adr}(3)=0.200448 \\
& \operatorname{Bdr}(3)=0.01402 \\
& \operatorname{Cdr}(3)=-0.00376 \\
& \operatorname{Ddr}(3)=2.12 * 10^{\wedge}(-16) \\
& -\operatorname{P}
\end{aligned}
$$

ElseIf IndexPhosphorus $=1$ Then

'order 1

$\operatorname{Adr}(1)=0.312453$

$\operatorname{Bdr}(1)=-0.00065$

$\operatorname{Cdr}(1)=0.000227$

$\operatorname{Ddr}(1)=9.89 * 10^{\wedge}(-25)$

'order 2

$\operatorname{Adr}(2)=0.358571$

$\operatorname{Bdr}(2)=-0.00265$

$\operatorname{Cdr}(2)=0.0008$

$\operatorname{Ddr}(2)=6.22 * 10^{\wedge}(-20)$

'Order 3

$$
\begin{aligned}
& \operatorname{Adr}(3)=0.317503 \\
& \operatorname{Bdr}(3)=0.011573 \\
& \operatorname{Cdr}(3)=-0.0033 \\
& \operatorname{Ddr}(3)=1.28 * 10^{\wedge}(-13)
\end{aligned}
$$


End If

If Order $=1$ Then

DepthVar $=$ YCoordinatel $/$ TwipsPerCM 'cm=twips/(twips $/ \mathrm{cm})$

ElseIf Order $=2$ Or Order $=3$ Then

Depth Var $=$ YOrigin(Order, Ramo\% $\%)^{\prime} \mathrm{cm}=\mathrm{cm}$

End If

BranchDistance $($ Order, Ramo\%) $=\operatorname{Adr}($ Order $)+\operatorname{Bdr}($ Order $) *($ DepthVar $\wedge 2)+$ Cdr(Order) * (DepthVar^ $\left.{ }^{\wedge}\right) * \log ($ DepthVar $)+\operatorname{Ddr}($ Order $) * \operatorname{Exp}($ DepthVar $)$

If Order $=1$ Then

BDgraphOrder 1 (Tempo) $=$ BranchDistance $($ Order, Ramo\%)

DepthGraphOrder1(Tempo) = DepthVar 'average root lenght

ElseIf Order $=2$ Then

BDgraphOrder2 $($ Tempo $)=$ BranchDistance $($ Order, Ramo\%)

DepthGraphOrder2(Tempo $)=$ DepthVar

ElseIf Order $=3$ Then

BDgraphOrder3 $($ Tempo $)=$ BranchDistance $($ Order, Ramo\%)

DepthGraphOrder3 $($ Tempo $)=$ DepthVar

End If

End Sub 


\section{REFERÊNCIAS BIBLIOGRÁFICAS}

BÖHM, W. Methods of studying root systems. Berlin: Springer Verlag, 1979. 188 p. (Ecological Studies Vol. 33)

BONSER, A.M.; LYNCH, J.P.; SIEGLINDE, S. Effect of phosphorus deficiency on growth angle of basal roots in Phaseolus vulgaris. New Phytologist, v.132, p.28188, 1996.

CANNON, W.A. A tentative classification of root systems. Ecology, v.30, n.4, p.542-8, 1949.

CLAUSNITZER, V. \& HOPMANS, J. W. An algorithm for three dimensional, simultaneous modeling of root growth and transient soil water flow (version 1.0). Davis: LAWR/UCDAVIS, 1993. 108p.

CRESTANA, S.; GUIMARÃES, M.F.; JORGE, L.A.C.; RALISCH, R.; TOZZI, C.L.; TORRE, A.; VAZ, C.M.P. Avaliação da distribuição de raízes no solo auxiliada por processamento de imagens digitais. Revista Brasileira de Ciência do Solo, v. 18, p.365-371, 1994.

DIGGLE, A.J. ROOTMAP: a model in three-dimensional coordinates of the growth and structure of fibrous root systems. Plant and Soil, v. 105, p. 169-78, 1988.

DREW, M.C. Comparison of the effects of a localized supply of phosphate, nitrate, ammonium and potassium on the growth of the seminal root system, and the shoot, in barley. New Phytologist, v.75, p.479-90, 1975.

ESAU, K. Anatomia das plantas com sementes. Trad. De B.L. de Morretes. São Paulo: Editora Edgard Blücher, 1974. 293p. 
FITTER, A. H. Functional significance of root morphology and root system architecture. IN: FITTER, A. H. (ed.) Ecological interactions in soil. Oxford: Blackwell Scientific Publications, 1985. p. 87-106

FITTER, A. H. An architectural approach to the comparative ecology of plant root systems. New Phytologist, v.106 (supl.), p.61-77, 1987.

FITTER, A. H. The ecological significance of root system architecture: na economic approach. In: ATKINSON, D. (ed.) Plant root growth: an ecological perspective. Oxford: Blackwell Scientific Publications, 1991. p.229-243.

FITTER, A. H.; STICKLAND, T.R.; HATVEY, M.L.; WILSON, G.W. Architectural analysis of plant root systems. 1. Architectural correlates of exploitation efficiency. New Phytologist, v.118, p.375-82, 1991.

FITTER, A. H. Characteristics and funtions of root systems. In: WAISEL, Y.; ESHEL, A.; KAFKAFI, U. (ed.) Plant roots: the hidden half. $2^{\text {nd }}$ ed. New York: Marcel Dekker, 1996. p. 1-20.

GAUCH, H. G. Inorganic plant nutrition. Stroudsburg: Dowden, Hutchinson \& Ross Inc., 1972. 488p.

GERSANI, M.; SACHS, T. Development correlations between roots in heterogeneous environments. Plant, Cell and Environment, v. 15, p.463-69, 1992.

HACKETT, C. \& ROSE, D. A. A model of the extension and branching of a seminal root of barley, and its use in studying relations between root dimensions. 1. The model. Australian Journal of Biological Sciences, v. 25, p.669-79, 1972.

HARPER, J.L.; JONES, M.; SACKVILLE-HAMILTON, N.R. The evolution of roots and the problems of analysing their behaviour. In.: ATKINSON, D. (ed.) Plant root growth: an ecological perspective. Oxford: Blackwell Scientific Publications, 1991. p.3-22.

HEERAMAN, D.A.; HOPMANS, J.W.; CLAUSNITZER, V. Three dimensional imaging of plant roots in situ with x-ray computed tomography. Plant and Soil, v.189, p.167-79, 1997. 
LUNGLEY, D. R. The growth of root systems - a numerical computer simulation model. Plant and Soil, v.38, p.145-59, 1973.

LYNCH, J. Root architecture and plant productivity. Plant Physiology, v.109, p.7-13, 1995.

LYNCH, J. P.; BEEBE, S.E. Adaptation of beans (Phaseolus vulgaris L.) to low phosphorus availability. HortScience, v.30, n.6, p.1165-71, 1995.

LYNCH, J.P.; NIELSEN, K.L. Simulation of root system architecture. In: WAISEL, Y.; ESHEL, A.; KAFKAFI, U. (eds). Plant roots: the hidden half. $2^{\text {nd }}$ ed. New York: Marcel Dekker, 1996. p. 247-57.

LYNCH, J.P.; NIELSEN, K.L.; DAVIS, R.D.; JABLOKOW, A. G. SimRoot: Modelling and visualization of root systems. Plant and Soil, v.188, p.139-151, 1997.

MACKIE-DAWSON, L.A.; ATKINSON, D. In: ATKINSON, D. (ed.). Plant root growth: an ecological perspective. Oxford: Blackwell Scientific Publications, 1991. p.103-30.

McCULLY, M. How do real roots work? Some new views of root structure, Plant Physiology v.109, p.1-6, 1995.

MITCHELL, R.L.; RUSSELL, W.J. Root development and root patterns of soybean (Glycine max (L.) Merrill) evaluated under field conditions. Agronomy Journal, v.63, p.313-6, 1971.

NIELSEN, K.L.; LYNCH, J.; JABLOKOW, A.G.; CURTIS, P.S. Carbon cost of root systems: an architectural approach. Plant and Soil, v. 165, p.161-9, 1994.

PAGES, L.; JORDAN, M. O.; PICARD, D. A simulation model of the threedimensional architecture of the maize root system. Plant and Soil, v.119, p.147-54, 1989.

PASSIOURA, J.B. Accountability, philosophy and plant physiology. Search, v.10, n. 10, p.347-50, 1979. 
PEARSON, R.W. Significance of rooting pattern to crop production and some problems of root research. In: Carson, E.W. (ed.) The plant root and its environment. Charlottesville: University Press of Virginia. 1974. p.247-70.

PORTER, J. R.; KLEPPER, B.; BELFORD, R. K.; A model (WHTROOT) which synchronizes root growth and development with shoot development for winter wheat. Plant and Soil, v.92, p.133-45, 1986.

POSADAS, D.A.N.; TANNÚS, A.; PANEPUCCI, H.; CRESTANA, S. Magnetic ressonance imaging as a non-invasive technique for investigating 3-D preferential flow occurring within stratified soil samples. Computers and Electronics in Agriculture, v. 14, p.255-267, 1996

RENDIG, V.V.; TAYLOR, H.M. Principles of soil plant interrelationships. New York: McGraw-Hill, 1989. cap. 2, p.37-77: Root growth and distribution.

ROBINSON, D. Roots and resource fluxes in plants and communities. In: ATKINSON, D. (ed.) Plant root growth: an ecological perspective. Oxford: Blackwell Scientific Publications, 1991. p. 103-30.

ROBINSON, D. The responses of plants to non-uniform supplies of nutrients. New Phytologist, v. 127, p.635-74, 1994.

ROBINSON, D. Variation, co-ordination and compensation in root systems in relation to soil variability. Plant and Soil, v. 187, p.57-66, 1996a.

ROBINSON, D. Resource capture by localized root proliferation: why do plants bother? Annals of Botany, v.77, p. 179-85, 1996 b.

ROSE, D. A. The description of the growth of root systems. Plant and Soil, v.75, p.405$15,1983$.

SCHUURMAN, J. J. \& GOEDEWAAGEN, M. A. J. Methods for the examination of root systems and roots. Wageningen: Centre for agricultural publishing and documentation, $1971.86 \mathrm{p}$.

SMIT, A. L.; GROENWOLD, J.; VOS, J. The Wageningen Rhizolab - a facility to study soil-root-shoot-atmosphere interactions in crops. II- Methods of root observations. Plant and Soil, v.161, p.289-98, 1994. 
SOMMA, F.; HOPMANS, J.W.; CLAUSNITZER, V. Transient three-dimensional modeling of soil water and solute transport with simultaneous root growth, root water and nutrient uptake. Plant and Soil, v.202, p.281-93, 1998.

STONE, J.A.; TAYLOR, H.M. Temperature and the development of the taproot and lateral roots of four indeterminate soybean cultivars. Agronomy Journal, v.75, p.613-8, 1983.

TIFFNEY, B.H.; NIKLAS, K.J. Clonal growth in land plants: a palaeobotanical perspective. In: JACKSON, J.B.C.; BUSS, L.W.; COOK, R.E. (eds.) Population biology and evolution of clonal organisms. New Haven: Yale University Press, 1985. p.35-66.

UPCHURCH, D.R.; RITCHIE, J.T. Battery-operated color video camera for root observations in mini-rhizotrons. Agronomy Journal, v.76, p. 1015-7, 1984.

VAN DE GEIJN, S. C.; VOS, J.; GROENWOLD, J.; GOUDRIAAN, J.; LEFFELAAR, P. A. The Wageningen Rhizolab - a facility to study soil-root-shoot-atmosphere interactions in crops. I- Description of main functions. Plant and Soil, v. 161, p.27587, 1994

WADDINGTON, J. Observation of plant roots in situ. Canadian Journal of Botany, v.49, p. 850-2, 1971.

WAISEL, Y.; ESHEL, A.; KAFKAFI, U. (eds). Plant roots: the hidden half. $2^{\text {nd }}$ ed. New York: Marcel Dekker, 1996. 1002p.

WERNER, C.; SMART, J.S. Some new methods of topologic classification of channel networks. Geographical Analysis, v.5, p.271-95, 1973.

WULLSCHLEGER, S.D.; LYNCH, J.P.; BERNTSON, G.M. Modeling the belowground response of plants and soil biota to edaphic and climatic change What can we expect to gain? Plant and Soil, v. 165, p.149-60, 1994. 